\title{
Methanol Worked Examples for the TEA and LCA Guidelines for $\mathrm{CO}_{2}$ Utilization
}


This work is available under DOI 10.3998/2027.42/145723

and can be downloaded via http://hdl.handle.net/2027.42/145723

\section{Main Contributors}

The University of Sheffield

Stavros Michailos

Peter Sanderson

Ana Villa Zaragoza

Stephen McCord

Katy Armstrong

Peter Styring

\section{Further Contributions}

$\mathrm{CO}_{2}$ Sciences, Inc.

Fred Mason

Gerald Stokes

Ellen Williams

Technische Universität Berlin

Arno Zimmermann

Johannes Wunderlich

Georg Buchner

Reinhard Schomäcker

\section{RWTH Aachen University}

Leonard Müller

André Bardow

Institute for Advanced Sustainability Studies e.V.

\section{Potsdam}

Annika Marxen

Henriette Naims 


\section{Foreword from $\mathrm{CO}_{2}$ Sciences}

Climate change is one of the largest challenges of our time. One of the major causes of anthropogenic climate change, carbon dioxide, also leads to ocean acidification. Left unaddressed, these two challenges will alter ecosystems and fundamentally change life, as we know it. Under the auspices of the UN Framework Convention on Climate Change and through the Paris Agreement, there is a commitment to keep global temperature increase to well below two degrees Celsius. This will require a variety of strategies including increased renewable power generation and broad scale electrification, increased energy efficiency, and carbon-negative technologies.

We believe that Life Cycle Assessment (LCA) is necessary to prove that a technology could contribute to the mitigation of environmental impacts and that Techno-Economic Assessment (TEA) will show how the technology could be competitively delivered in the market. Together they are a valuable toolkit for promoting carbon capture and utilization (CCU) technology development.

The work presented here was made possible through the vision of the Chairman of $\mathrm{CO}_{2}$ Sciences Inc., Bernard David, and the expertise of the $\mathrm{CEO}$ of $\mathrm{CO}_{2}$ Sciences Inc., Issam Dairanieh.

The Global $\mathrm{CO}_{2}$ Initiative was launched during the 2016 meeting of the World Economic Forum with the goal of catalyzing innovative research in $\mathrm{CO}_{2}$ utilization. Starting July of 2018, the Initiative will continue its work as The Global $\mathrm{CO}_{2}$ Initiative at the University of Michigan.

Development of standardized $\mathrm{CO}_{2}$ Life Cycle and Techno-economic Assessment Guidelines was commissioned by $\mathrm{CO}_{2}$ Sciences, Inc., with the support of $3 \mathrm{M}$, EIT Climate- $\mathrm{KIC}, \mathrm{CO}_{2}$ Value Europe, Emissions Reduction Alberta, Grantham Foundation for the Protection of the Environment, R. K. Mellon Foundation, Cynthia and George Mitchell Foundation, National Institute of Clean and Low Carbon Energy, Praxair, Inc., XPrize and generous individuals who are committed to action to address climate change.

Global CO2 Initiative@UM, August 2018

\section{SUPPORTED BY}

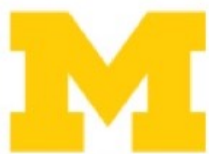

GLOBAL $\mathrm{CO}_{2}$

INITIATIVE

UNIVERSITY OF MICHIGAN
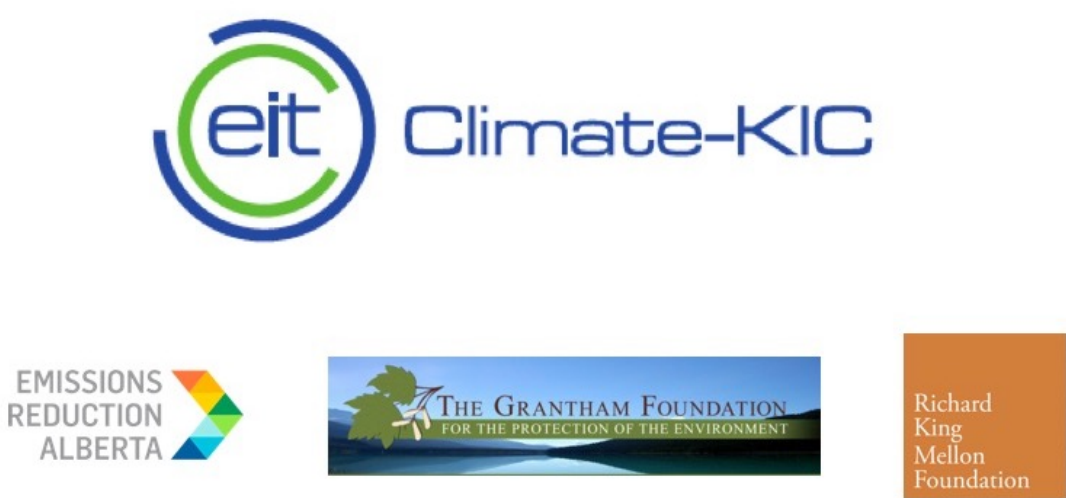


\section{List of abbreviations}

\begin{tabular}{|c|c|}
\hline ANOVA & Analysis of variance \\
\hline BFD & Block flow diagram \\
\hline CAPEX & Capital Cost \\
\hline CAPM & Capital asset pricing model \\
\hline CCS & Carbon capture and storage \\
\hline CCU & Carbon capture and utilization \\
\hline CEPCI & Chemical Engineering Plant Cost Index \\
\hline $\mathrm{CO}_{2}$ & Carbon dioxide \\
\hline COGM & Cost of goods manufactured \\
\hline COGS & Cost of goods sold \\
\hline ETS & Emission trading system \\
\hline EU & European Union \\
\hline $\mathbf{F C l}$ & Fixed capital investment \\
\hline FOAK & First of a kind \\
\hline GWP & Global warming potential \\
\hline $\mathrm{H}_{2}$ & Hydrogen \\
\hline IRR & Internal rate of return \\
\hline ISBL & Inside battery limits \\
\hline ISO & International standardization organization \\
\hline LCA & Life cycle assessment \\
\hline LCC & Life cycle costing \\
\hline LCl & Life cycle inventory \\
\hline LCOE & Levelized cost of electricity \\
\hline LHV & Lower heating value \\
\hline MADM & Multiple attribute decision making \\
\hline MCDA & Multicriteria decision analysis \\
\hline MODM & Multiple objective decision making \\
\hline NGO & Non-Governmental Organisation \\
\hline NOAK & Nth of a kind \\
\hline NOX & Nitrous Oxides \\
\hline NPV & Net present value \\
\hline OPEX & Operational Cost \\
\hline OSBL & Outside/off-site battery limits \\
\hline P\&ID & Piping and instrumentation diagram \\
\hline PEM & Proton exchange membrane \\
\hline PFD & Process flow diagram \\
\hline R\&D & Research and Development \\
\hline ROI & Return on investment \\
\hline SA & Sensitivity analysis \\
\hline SI-UNITS & International System of Units \\
\hline SMR & Steam methane reforming \\
\hline TCl & Total cost indicator \\
\hline TEA & Techno-economic assessment \\
\hline TRL & Technology readiness level \\
\hline UA & Uncertainty analysis \\
\hline US DOE & United States Department of Energy \\
\hline USD & United States Dollars \\
\hline WACC & Weighted average cost of capital \\
\hline
\end{tabular}


Authors Part A: $\quad$ Peter W Sanderson, Katy Armstrong, Stavros Michailos

\section{PART A Introduction}

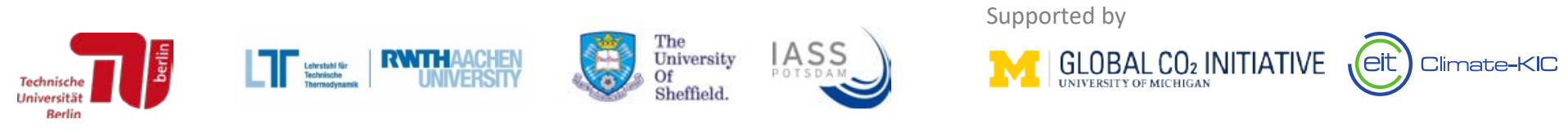




\section{A.1 Introduction}

This document contains worked examples of how to apply the accompanying "Guideline for TechnoEconomic Assessment of $\mathrm{CO}_{2}$ Utilization" and "Guideline for Life Cycle Assessment of $\mathrm{CO}_{2}$ Utilization", hereafter referred to as "the TEA and LCA guidelines".

These worked examples are not intended to be a definitive TEA or LCA report on the process described, but are provided as supporting material to show how the TEA and LCA methodologies described in the guidelines can be specifically applied to tackle the issues surrounding $\mathrm{CO}_{2}$ utilization.

The modelled examples were constructed using data collected from the literature and from the ecoinvent database v3.4. The aim of these worked example studies is not to prove whether the selected process is economically or environmentally viable or to make process alterations to make it so, but to clearly demonstrate how the proposed guidelines can be used to conduct a transparent TEA and LCA which can then be followed by others.

THE LCA WORKED EXAMPLE USES A MODEL PRODUCED SOLELY TO ASSIST IN THE USE AND INTERPRETATION OF THE ACCOMPANYING LCA GUIDELINES. THE FOLLOWING LCA WORKED EXAMPLE HAS THEREFORE NOT UNDERGONE AN EXTERNAL REVIEW IN ACCORDANCE WITH ISO 14040/14044 AND CONSEQUENTLY IT SHOULD NOT BE USED IN COMPARISONS OF OTHER LIFE CYCLE ASSESSMENTS OF CCU AND/OR METHANOL TECHNOLOGIES.

The TEA example is provided in Part A, followed by the LCA example in Part B. In Part C, the reader will find a short example of how a TEA and LCA can be integrated. This integration is not an exhaustive example. As many aspects can be analyzed to produce combined indicators and many approaches to multi-criteria decision making applied. However, it is included here to provide a starting point and initial example of how integration can be carried out.

\section{A.1.1 About the chosen CCU process}

These examples focus on the production of methanol from $\mathrm{CO}_{2}$ for the purpose of providing a carbon feedstock for the chemicals industry. Methanol production was chosen as it is a familiar $\mathrm{CO}_{2}$ utilization (CCU) route, which has been much studied, therefore it is hoped that the reader will be able to focus on the described methodology for conducting the assessment rather than understanding the specifics of the process route. For this reason, much of the Inventory data for the modelled process used for the LCA worked example has been placed into an appendix and only the critical data used for modelling the sections which are specific to CCU are provided within the main body of the report. This is done to help the reader focus upon applying the TEA and LCA guidelines and not the specifics of the data used. Having said that, the limitations of the data used is discussed in the examples, as this is likely to be an issue for many TEA and LCA reports of CCU technologies.

As methanol production via hydrogenation and PEM electrolysis of water to produce hydrogen are both at high technology readiness levels (TRL7+); a $\mathrm{CO}_{2}$ capture technology currently at a lower TRL (membrane separation at TRL3 or 4) was selected to demonstrate the differences that can be observed in the interpretation phase when working on TEA and LCA studies of processes with lower TRLs. It is acknowledged that there are many unknown variables with membrane capture, and it is not within the remit of this work to draw conclusions on their application. However, it is known that organizations wish to conduct TEA and LCA studies across a range of TRLS and therefore we hope to demonstrate here how this could affect the results. 
The intended application of these studies is as references on how to apply the guidelines for $\mathrm{CO}_{2}$ utilization to a comparative assessment between a CCU technology and a conventional (reference or benchmark) technology. These examples are for public use and are targeted at the TEA and LCA practitioner who wishes to assess a CCU process. Methanol is chosen as the process to assess due to its production demand and its feasibility as a $\mathrm{CO}_{2}$-based chemical.

\section{A.1.2 How to read the worked examples}

The subsequent TEA and LCA are written as worked examples, not in the format of a formal report for either academic, corporate or policy audiences. The examples are structured in this way to enable the reader to clearly understand how the guidelines have been applied by the authors, rather than focus on a specific style of reporting.

To enhance understanding the following explanations have been included:

- Light blue-coloured text boxes are used to refer the reader to specific sections of the guidelines:

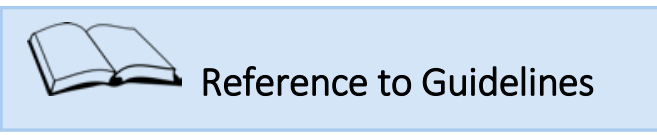

- Blue-coloured speech bubbles give an explanation of why certain decisions were taken or choices made:

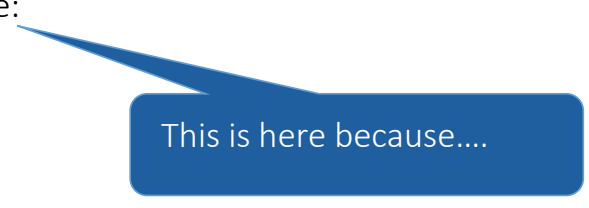

The studies contain example Executive and Technical Summaries for the reader's benefit. All 'shall' aspects of the guidelines are covered and 'should' and 'may' aspects and included as appropriate to each study.

The guidelines for conducting TEA and LCA of $\mathrm{CO}_{2}$ utilization processes, together with the accompanying worked examples, were commissioned by The Global $\mathrm{CO}_{2}$ Initiative $/ \mathrm{CO}_{2}$ Sciences. 
Authors Part B: $\quad$ Stavros Michailos, Stephen McCord, Katy Armstrong, Peter Styring

Reviewed by:

Arno Zimmermann, Johannes Wunderlich Georg Buchner, Annika Marxen, Henriette Naims

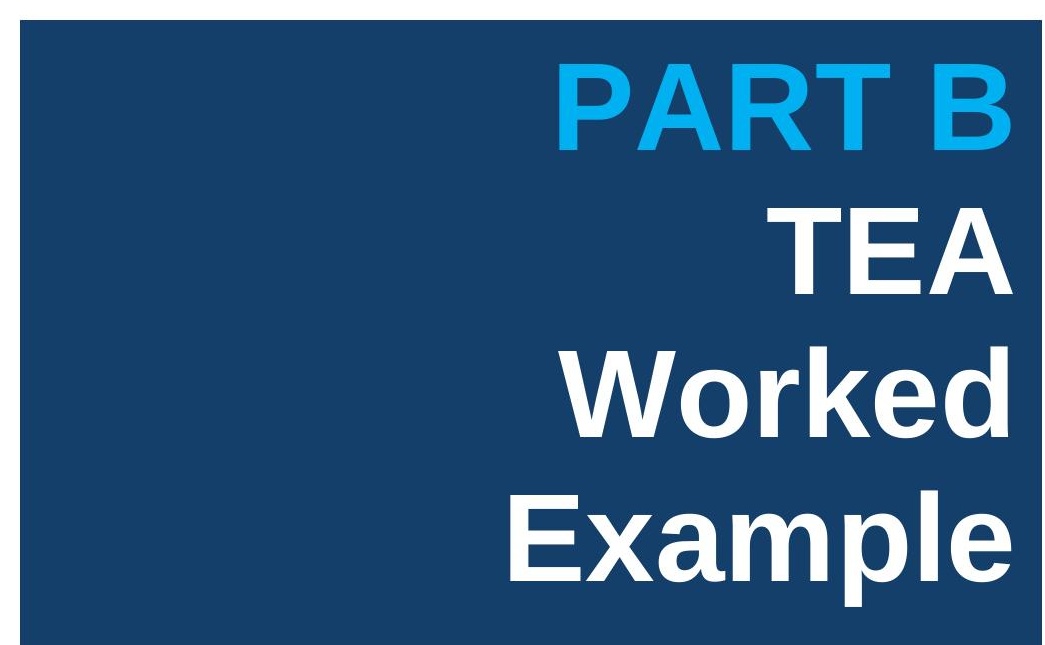

Supported by

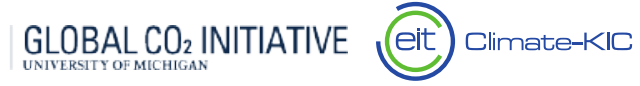




\section{Contents}

Contents

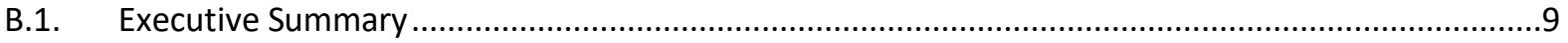

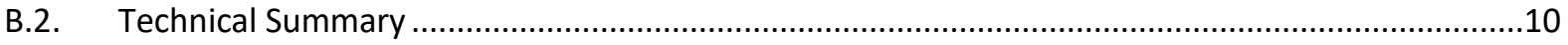

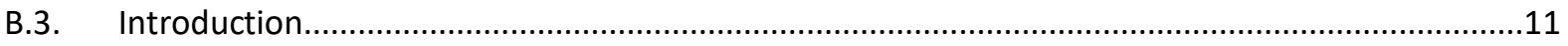

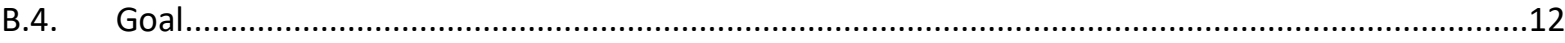

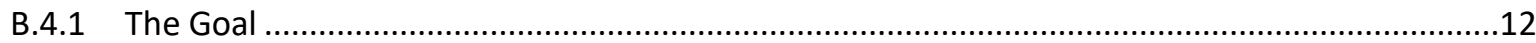

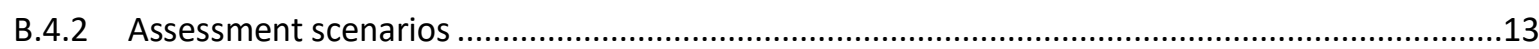

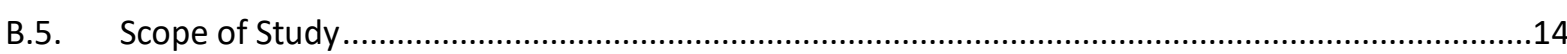

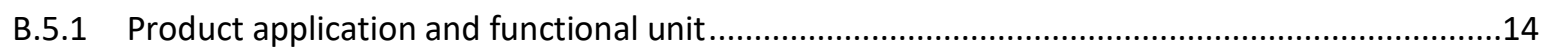

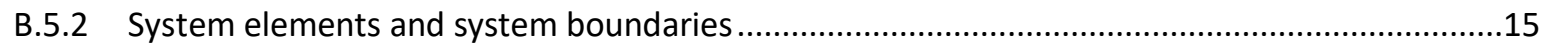

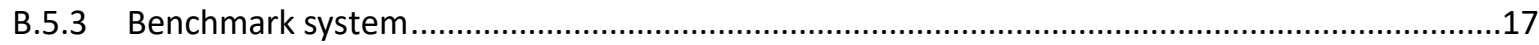

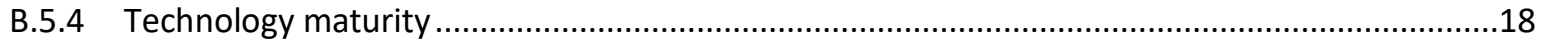

B.5.5 Assessment indicators, consistency and reproducibility ............................................18

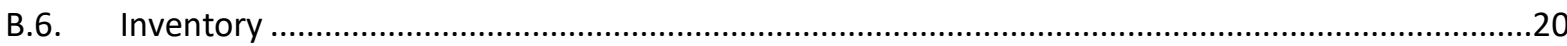

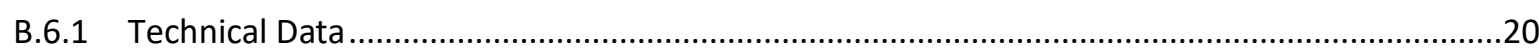

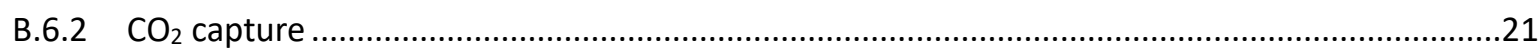

B.6.3 Renewable hydrogen production ...............................................................................23

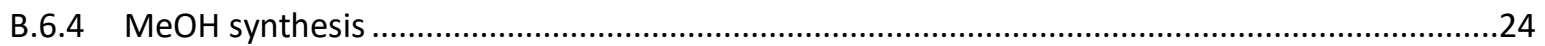

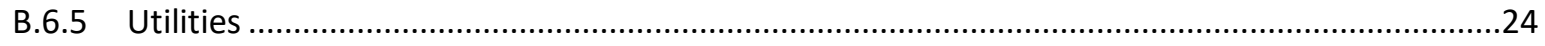

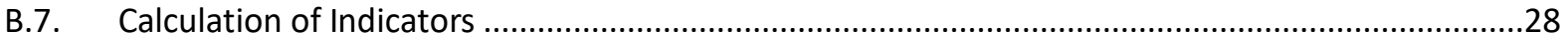

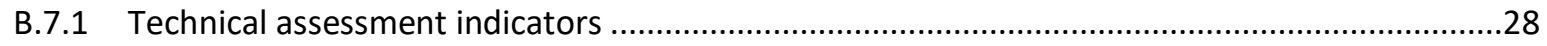

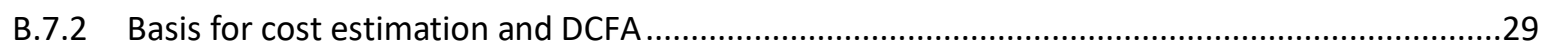

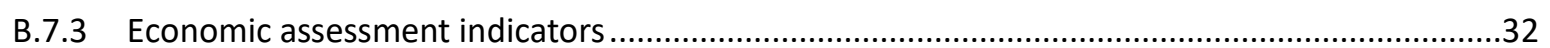

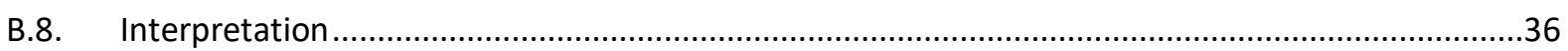

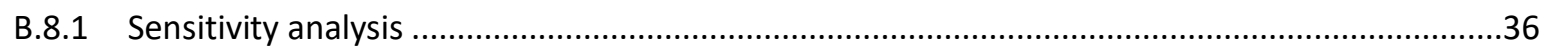

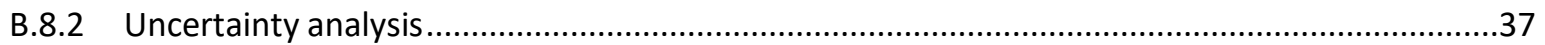

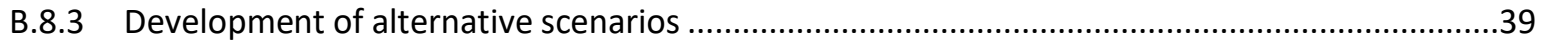

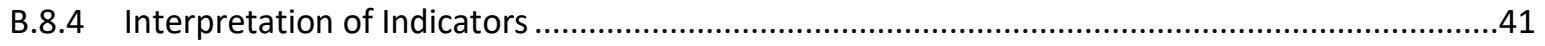

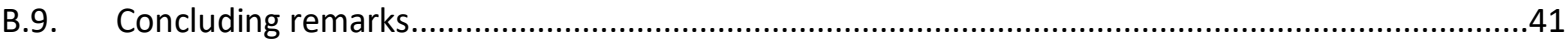

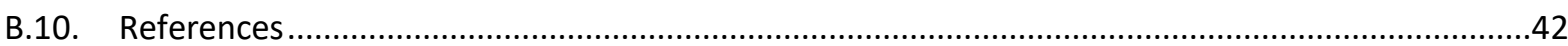

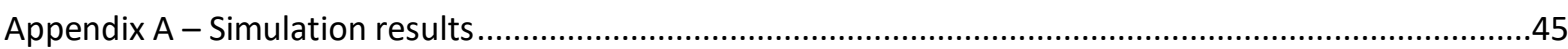

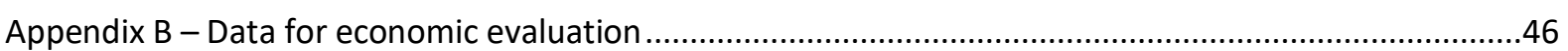

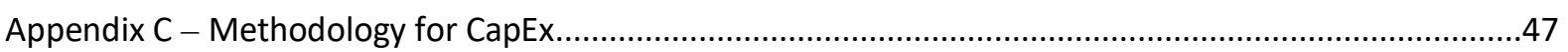




\section{B.1.Executive Summary}

Methanol has a huge global market as a commodity chemical acting as a feedstock for many chemical processes. It can be synthesized from $\mathrm{CO}_{2}$ instead of from natural gas, which means it becomes possible to indirectly substitute the fossil carbon currently used in a multitude of plastics, polymers and carbon containing chemicals with carbon from $\mathrm{CO}_{2}$. Doing so would release the chemicals industry from its current dependency upon fossil oil feedstock.

The goal of this study is to determine the economic performance and technical viability of Methanol $(\mathrm{MeOH})$ production via $\mathrm{CO}_{2}$ hydrogenation within a renewable power to liquid context. The study conducts a TEA from an R\&D perspective; the goal is to estimate total production costs and identify key cost drivers as well as gauge the market value of $\mathrm{MeOH}$ produced from $\mathrm{CO}_{2}$ hydrogenation. As such indicators such as CAPEX, OPEX, electricity consumption have been calculated. The proposed CCU project can contribute to the 'methanol economy' concept; $\mathrm{MeOH}$ is one of the most flexible chemicals and an important energy carrier. Within this study methanol is considered in its application as a chemical feedstock. This report is of public use and is targeted for the TEA practitioner that wishes to learn about assessment of CCU processes.

The study is based on a 1,000 metric tonnes per day (t/d) plant situated in Germany. $\mathrm{CO}_{2}$ is captured from flue gas by a membrane capture technology followed by a cryogenic unit (both at TRL 4), hydrogen is produced by PEM electrolyser using renewable energy (TRL 9) and then methanol is synthesised via $\mathrm{CO}_{2}$ hydrogenation (TRL 7). The studied system is compared with a conventional methanol plant using fossil feedstocks and producing methanol by steam reforming of methane. Data for the CCU plant design has been taken from literature and then modelled using simulations.

This study concluded that the estimated price of methanol produced from $\mathrm{CO}_{2}$ on a $1,000 \mathrm{t} / \mathrm{d}$ plant in Germany using membrane carbon capture and renewable hydrogen from water electrolysis was 3.5-fold greater than the current market price of conventional methanol. The factors that mostly affect the methanol price are associated with the electrolysis unit, i.e. electricity price and electrolyser efficiency. Changes in the renewable energy price cause wide fluctuations in the CCU methanol market price of $-67 \%$ to $+20 \%$.

There are several technology and market developments that can significantly improve the economics of the modelled processes. If energy independence and security are prioritised and societies begin to place a meaningful monetary burden on carbon-intensive technologies, these developments could accelerate the adoption of sustainable products such as the investigated $\mathrm{MeOH}$.

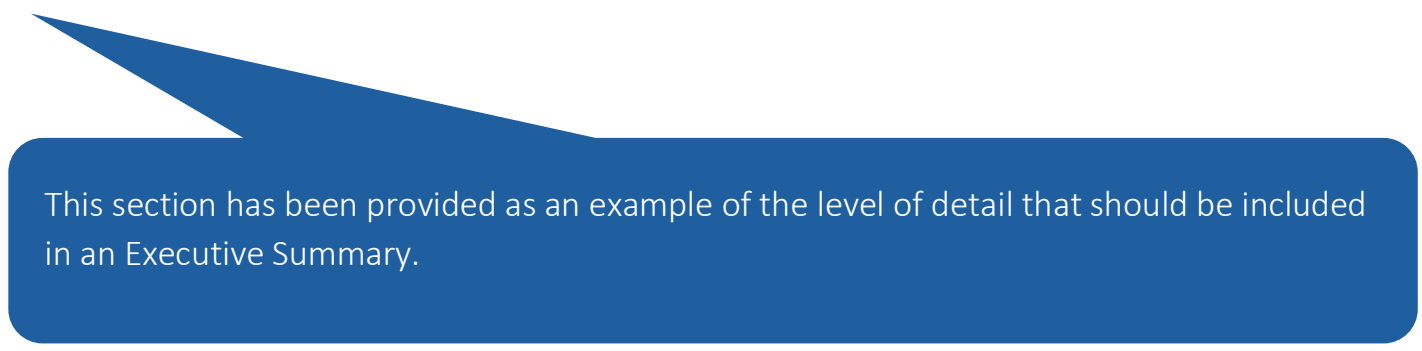




\section{B.2.Technical Summary}

\begin{tabular}{|c|c|c|c|}
\hline & CCU product & \multicolumn{2}{|c|}{ Methanol as a chemical feedstock } \\
\hline & $\begin{array}{l}\text { Intended application and } \\
\text { reasons for study }\end{array}$ & \multicolumn{2}{|c|}{$\begin{array}{l}\text { What is the economic performance of Methanol production via } \mathrm{CO}_{2} \\
\text { hydrogenation within a renewable power to liquid context? }\end{array}$} \\
\hline & Brief description & \multicolumn{2}{|c|}{$\begin{array}{l}\mathrm{CO}_{2} \text { is captured via membrane capture from a cement plant, } \mathrm{H}_{2} \text { is produced via } \\
\mathrm{PEM} \text { water electrolysis, subsequently methanol is produced via thermochemical } \\
\text { synthesis }\end{array}$} \\
\hline ن & Intended audience & \multicolumn{2}{|c|}{ TEA practitioners } \\
\hline & $\begin{array}{l}\text { Commissioners and } \\
\text { assessors }\end{array}$ & \\
\hline & Limitations of study & \multicolumn{2}{|c|}{$\begin{array}{l}\text { - } \quad \text { Based on literature data, deviations in real world process will occur } \\
\text { - } \quad \text { No infrastructure for } \mathrm{H} 2 \text { production included } \\
\text { - } \quad \text { Low TRL process for Carbon Capture }\end{array}$} \\
\hline & $\begin{array}{l}\text { System boundary } \\
\text { (e.g. cradle to gate) }\end{array}$ & \multicolumn{2}{|c|}{ Cradle to gate } \\
\hline & Benchmark system & \multicolumn{2}{|c|}{ Steam reforming of methane to produce methanol } \\
\hline & Plant size & \multicolumn{2}{|l|}{1,000 metric tonnes per day } \\
\hline 䒛 & Functional Unit & \multicolumn{2}{|c|}{ The production of 1 tonne of $\mathrm{MeOH}$ for use in chemical industry } \\
\hline ڤ & $\begin{array}{l}\text { System elements and } \\
\text { technology maturity }\end{array}$ & \multicolumn{2}{|c|}{$\begin{array}{l}\text { Carbon capture via membrane: TRL } 4 \\
\text { PEM water electrolysis: TRL } 9 \\
\text { Methanol Synthesis: TRL } 7\end{array}$} \\
\hline & Assessment indicators & \multicolumn{2}{|c|}{$\begin{array}{l}\text { Minimum MeOH Selling Price (MMSP), CapEx, OpEx, } \mathrm{CO}_{2} \text { conversion, energy } \\
\text { consumption }\end{array}$} \\
\hline \multirow{8}{*}{ 总 } & Data Source & $\begin{array}{l}\square \text { Primary sources } \\
\text { 囚Secondary sources } \\
\square \text { Stoichiometric data }\end{array}$ & $\begin{array}{l}\text { 囚Process modelling based data } \\
\square \text { Mixed sources } \\
\square \text { Other (please specify) }\end{array}$ \\
\hline & $\begin{array}{l}\text { Energy sources } \\
\text { (select all that apply) }\end{array}$ & $\begin{array}{l}\text { 凶Grid mix } \\
\text { \Power station with Carbon Capture } \\
\text { 冈Wind } \\
\square \text { Solar }\end{array}$ & $\begin{array}{l}\square \text { Nuclear } \\
\square \text { Hydro } \\
\square \text { Future (see timeframes) } \\
\square \text { Other (please specify) }\end{array}$ \\
\hline & Base year & \multicolumn{2}{|l|}{2016} \\
\hline & Currency & \multicolumn{2}{|l|}{ Euro } \\
\hline & Location & \multicolumn{2}{|l|}{ Germany } \\
\hline & Plant life time & \multicolumn{2}{|c|}{20 years } \\
\hline & $\begin{array}{l}\mathrm{CO}_{2} \text { sources and price } \\
\text { (if applicable) }\end{array}$ & \multicolumn{2}{|c|}{ Not applicable - capture included in boundary } \\
\hline & $\begin{array}{l}\mathrm{H}_{2} \text { sources and prices } \\
\text { (if applicable) }\end{array}$ & \multicolumn{2}{|c|}{ Not applicable $-\mathrm{H}_{2}$ production included in boundary } \\
\hline 읕 & $\begin{array}{l}\text { Energy consumption } \\
\text { per functional unit }\end{array}$ & \multicolumn{2}{|l|}{$10.84 \mathrm{MWh} / \mathrm{t}_{\mathrm{MeOH}}$} \\
\hline$\$$ & CAPEX per functional unit & \multicolumn{2}{|l|}{$336 € / \mathrm{t} \mathrm{MeOH}$} \\
\hline$\frac{\breve{u}}{4}$ & OPEX per functional unit & \multicolumn{2}{|l|}{$1101 € / \mathrm{t}_{\mathrm{MeOH}}$} \\
\hline & Price per functional unit & \multicolumn{2}{|l|}{$1402 € / \mathrm{t}_{\mathrm{MeOH}}$} \\
\hline & $\begin{array}{l}\text { Sensitivity analysis main } \\
\text { factors }\end{array}$ & \multicolumn{2}{|l|}{ Electricity price, electrolyser cost } \\
\hline & $\begin{array}{l}\text { Uncertainty manipulated } \\
\text { variables }\end{array}$ & \multicolumn{2}{|c|}{$\begin{array}{l}\text { Electricity price, electrolyser efficiency, electrolyser cost, tax rate and CapEx of } \\
\text { the } \mathrm{CO}_{2} \text { capture unit. }\end{array}$} \\
\hline 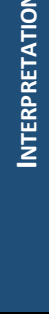 & Main Conclusions & \multicolumn{2}{|c|}{$\begin{array}{l}\text { - The deterministic MMSP is } 1402 € / t \text { and there is a confidence interval of } 95 \% \\
\text { that the MMSP is in the range of } 1,238 € / t \text { to } 1,448 € / t \text {. These figures are } 4.9 \text { - } \\
5.8 \text { fold greater than the fossil } \mathrm{MeOH} \text { price. } \\
\text { - Sensitivity analysis revealed that the process is OpEx intensive with the } \\
\text { electricity price to pose as the major cost component. In fact, the factors that } \\
\text { mostly affect the MMSP are associated with the electrolysis unit, i.e. electricity } \\
\text { price and electrolyser efficiency rather than with variables related to the } \\
\mathrm{CO}_{2} \text { conversion plant. }\end{array}$} \\
\hline
\end{tabular}




\section{B.3. Introduction}

Methanol can be used as a liquid fuel, either directly or after dehydration to dimethyl ether, but currently its main use is as a commodity chemical where it acts as a feedstock for many chemical processes. The market for methanol is large, with global demand reaching $70 \mathrm{Mt}$ in 2015, supplied by over 90 methanol plants worldwide [1]. Methanol can be synthesized from $\mathrm{CO}_{2}$ and is itself used as a chemical building block in the synthesis of many different compounds. By producing methanol using carbon capture and utilization (CCU) technologies from waste $\mathrm{CO}_{2}$, rather than from steam methane reformation as per the conventional route, it becomes possible to indirectly substitute fossil carbon with carbon derived from $\mathrm{CO}_{2}$ into a multitude of plastics, polymers and carbon containing chemicals. In this way, the dependency of the chemicals industry upon fossil oil feedstock is significantly reduced.

This report assesses the economic performance and technical viability of a CCU methanol plant capable of producing 1,000 MTPD.

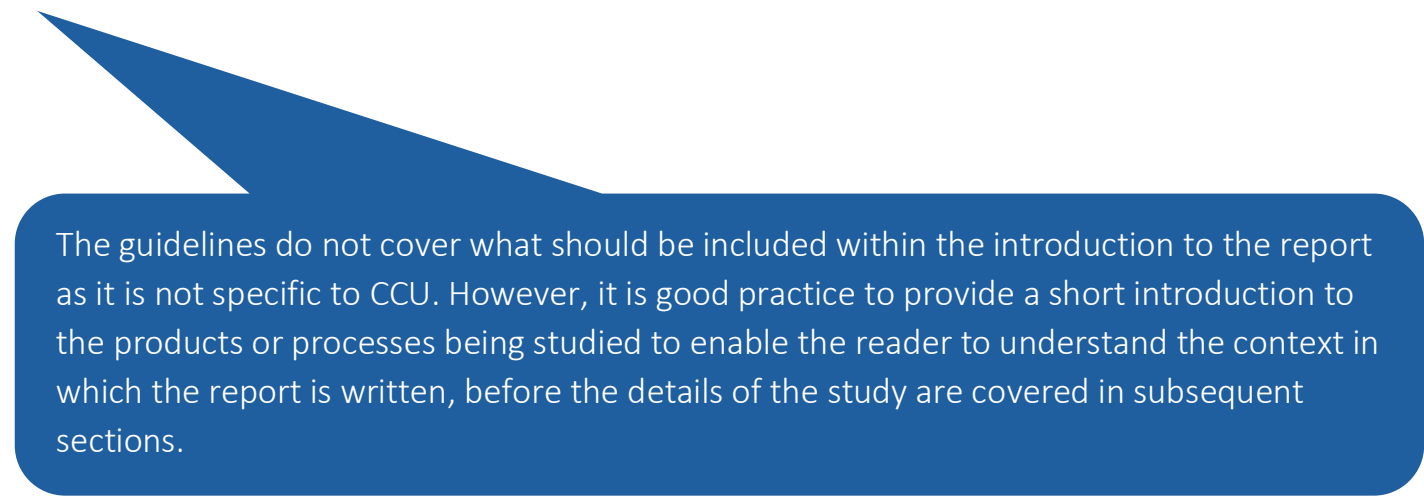




\section{B.4.Goal}

\section{Reference to TEA Guidelines}

A checklist of items to be included in each section of the report is included in Chapter B.8 Reporting of the guidelines, which for the goal is as follows:

\section{Goal of the study}

State goal - the intended application of the study and the reasons for the study

- State the target audience for the study

State commissioner and authors of the study

- State limitations in the usability from assumptions or methods

- State the base case with current conditions

\section{B.4.1 The Goal}

The goal of this study is to assess the economic performance and technical viability of methanol production via $\mathrm{CO}_{2}$ hydrogenation. The modelled 1000 tonnes per day plant incorporates carbon capture via membranes and cryogenics, PEM hydrogen production and methanol synthesis using renewable power. The plant model is located in Germany and based on 2016 costs.

The current study conducts a TEA from an R\&D perspective; the goal is to estimate total production costs and identify key cost drivers as well as assess the profitability of $\mathrm{MeOH}$ production from $\mathrm{CO}_{2}$ hydrogenation. The proposed CCU project can contribute to the 'methanol economy' concept; $\mathrm{MeOH}$ is one of the most flexible chemicals and an important energy carrier. Therefore, $\mathrm{MeOH}$ can play a significant role in the future at the crossroads of sustainable chemical production, energy generation and security $[1,2]$.

The report is of public use and by accompanying the guideline document serves as an example for the TEA practitioner that wishes to assess a CCU process or product. Cost and prices are reported in EUR 2016 and the plant is assumed to be located in Germany. The process design and economic parameter value choices, underlying this analysis, are based on public domain literature. For these reasons, the results are not indicative of potential performance, but are meant to represent the most likely performance given the assumptions (time and location) and the current state of public knowledge. This study was commissioned by The Global $\mathrm{CO}_{2}$ Initiative as part of the Guidelines project and was conducted by the University of Sheffield.

\section{Reference to TEA Guidelines}

This goal definition is described in Guideline B.1. The present report conducts a direct TEA from an $R \& D$ perspective. A feasibility assessment was carried that incorporates quantification of costs, profits and value for a power to $\mathrm{MeOH}$ plant via captured $\mathrm{CO}_{2}$ hydrogenation. The report serves to provide information and showcase good practices to a potential CCU practitioner. In order to raise awareness, the report is publicly available. As stated in Guideline B.1, data derives from up to date conditions, and assumptions and results are location and time dependent. 


\section{B.4.2 Assessment scenarios}

Scenario analysis is different from the high, medium, and low cases exploration. High, medium, and low scenarios look at different rates of progress along a path that is based on a single set of projections. Scenario analysis focuses on the areas of greatest uncertainty for a country or an operation, systematically develops several plausible alternative future environments in which the operation might be implemented, and determines how they would affect its success. Scenario analysis involves constructing or developing scenarios and integrating the content of scenarios into the decision making process. In the present study, after sensitivity and uncertainty analyses, hot spots will be identified. Scenarios for renewable electricity supply via onshore and offshore wind production will be assessed.

\section{Reference to TEA Guidelines}

Guideline B.2 presents possible ways to conduct scenario analysis. It is expected that, electricity price will be a significant costs component and therefore different scenarios of generating electricity will be investigated in the present study. 


\section{B.5.Scope of Study}

\section{Reference to TEA Guidelines}

A checklist of items to be included in each section of the report is included in Chapter B.8 Reporting of the guidelines, which for the goal is as follows:

\section{Scope of the study}

State product application(s) and functional unit, including consistency with goal and scope and reference flow

$\square$ State elements and boundaries of product system in a graphical scheme

- State the benchmark process

- State the selected indicator and methods, and including consistency with study goal and data availability associated with technology maturity

\section{B.5.1 Product application and functional unit}

$\mathrm{MeOH}$ can be used in the chemical industry as a solvent and as a $\mathrm{C}_{1}$ building block for producing intermediates and synthetic hydrocarbons, including polymers and single-cell proteins. Furthermore, $\mathrm{MeOH}$ can be mixed with conventional gasoline without requiring any technical modification in the vehicle fleet and it can be used as a convenient energy carrier for hydrogen storage and transportation, as an easily transportable fuel (see Figure 1). It may be produced both from (1) fossil fuels (natural gas, shale gas and coal) and (2) non-fossil fuel sources (residue/biomass/renewables $+\mathrm{CO}_{2}$ ). Consequently, $\mathrm{MeOH}$ is one of the most important and versatile platform chemicals for the chemical industry [3].

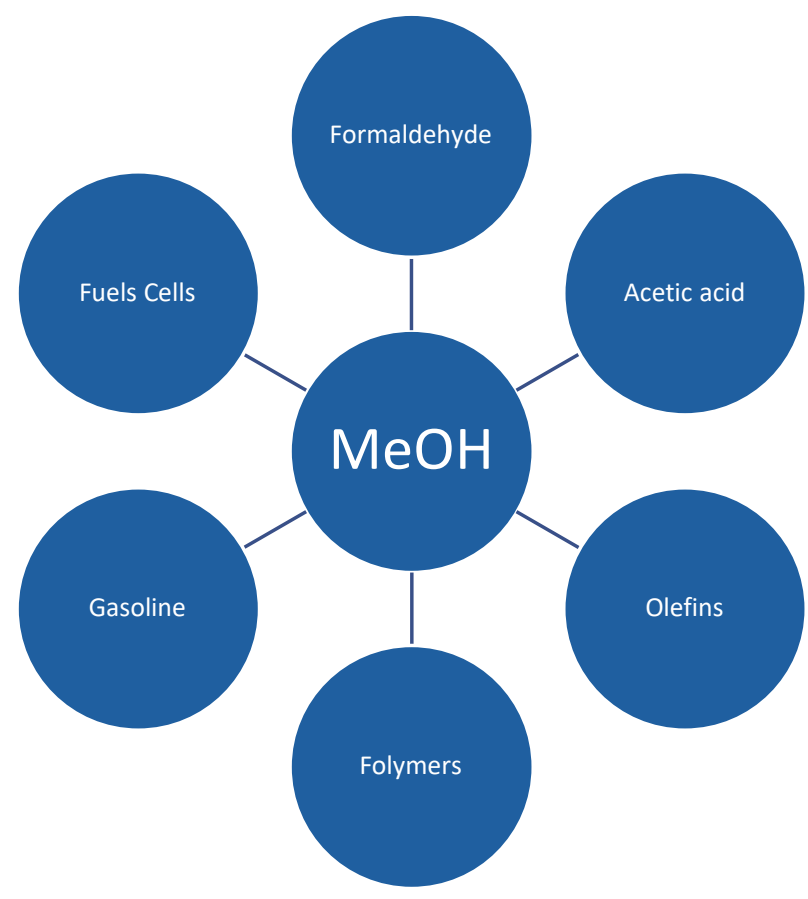

Figure 1. Different $\mathrm{MeOH}$ applications 
In the present study $\mathrm{MeOH}$ is considered as a building block chemical, i.e. as intermediate for the production of other chemicals (e.g. formaldehyde, acetic acid). The use of $\mathrm{MeOH}$ as feedstock, driven largely from the $\mathrm{MeOH}$ to olefins process, is projected to increase and consequently the role of emerging fossil sources (such as shale gas) will be developed. However, strong evidence already exists that the future development of such fossil sources has been overestimated [4]. For this reason, alternative sources such as $\mathrm{CO}_{2}$ can positively contribute to meet the increasing demand of $\mathrm{MeOH}$ in a sustainable manner. The functional unit of this study is 1 tonne of methanol considered as a chemical feedstock. The production output of the CCU methanol plant is 1000 tonne per day.

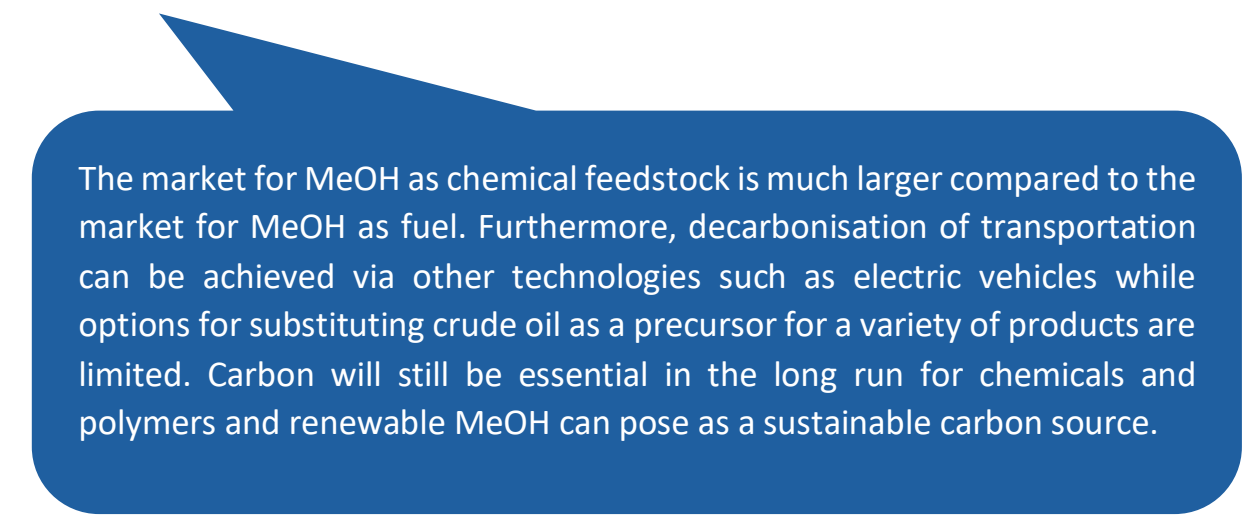

\section{Reference to TEA Guidelines}

As described in Guideline B.3, the product application must be included in the Scope of the study; here $\mathrm{MeOH}$ is treated as feedstock to produce chemicals. MeOH demand as chemical feedstock is projected to increase and the proposed CCU scenario can provide sustainable solutions. The functional unit definition is in accordance with Guideline B.3 for substitutes $\mathrm{CO}_{2}$-based chemicals and it is expressed on a mass basis; based on the scale of the plant metric tonnes of $\mathrm{MeOH}$ was selected as functional unit.

\section{B.5.2 System elements and system boundaries}

The examined power to liquid concept consists of an electrolyser, a $\mathrm{CO}_{2}$ capture unit and $\mathrm{MeOH}$ synthesis infrastructure. The inputs to the system are deionised water, green electricity and flue gas $\left(22 \% \mathrm{CO}_{2}\right)$ derived from a typical cement production unit. The system boundaries treat $\mathrm{H}_{2}$ and $\mathrm{CO}_{2}$ as intermediate products rather than as inputs to the system. In this way, lack of transparency caused by sourcing $\mathrm{CO}_{2}$ and $\mathrm{H}_{2}$ priced from third parties is eliminated and instead costs of onsite production are considered. For the study, it was assumed that both $\mathrm{CO}_{2}$ capture and hydrogen production occur onsite and hence long distance transportation costs (e.g. via pipelines) can be avoided. Boundaries are set as cradle to gate, therefore transportation or other costs after the factory gate are not considered.

The product system consists of four major elements:

1) $\mathrm{CO}_{2}$ membrane based capture from flue gas,

2) $\mathrm{H}_{2}$ production in a proton exchange membrane (PEM) electrolyser,

3) $\mathrm{MeOH}$ production via hydrogenation

4) utilities.

These elements constitute the inside battery limits (ISBL) plant; the outside battery limits (OSBL) plant consists of the balance of plant (BOP). The latter involves the required infrastructure for grid and water 
supply connections. MeOH production is subdivided to the compression, synthesis and recovery sections. The utilities section includes the CHP (combined heat and power) unit, the wastewater treatment plant and cooling towers. Figure 3 is a simplified visual representation of the system boundaries.
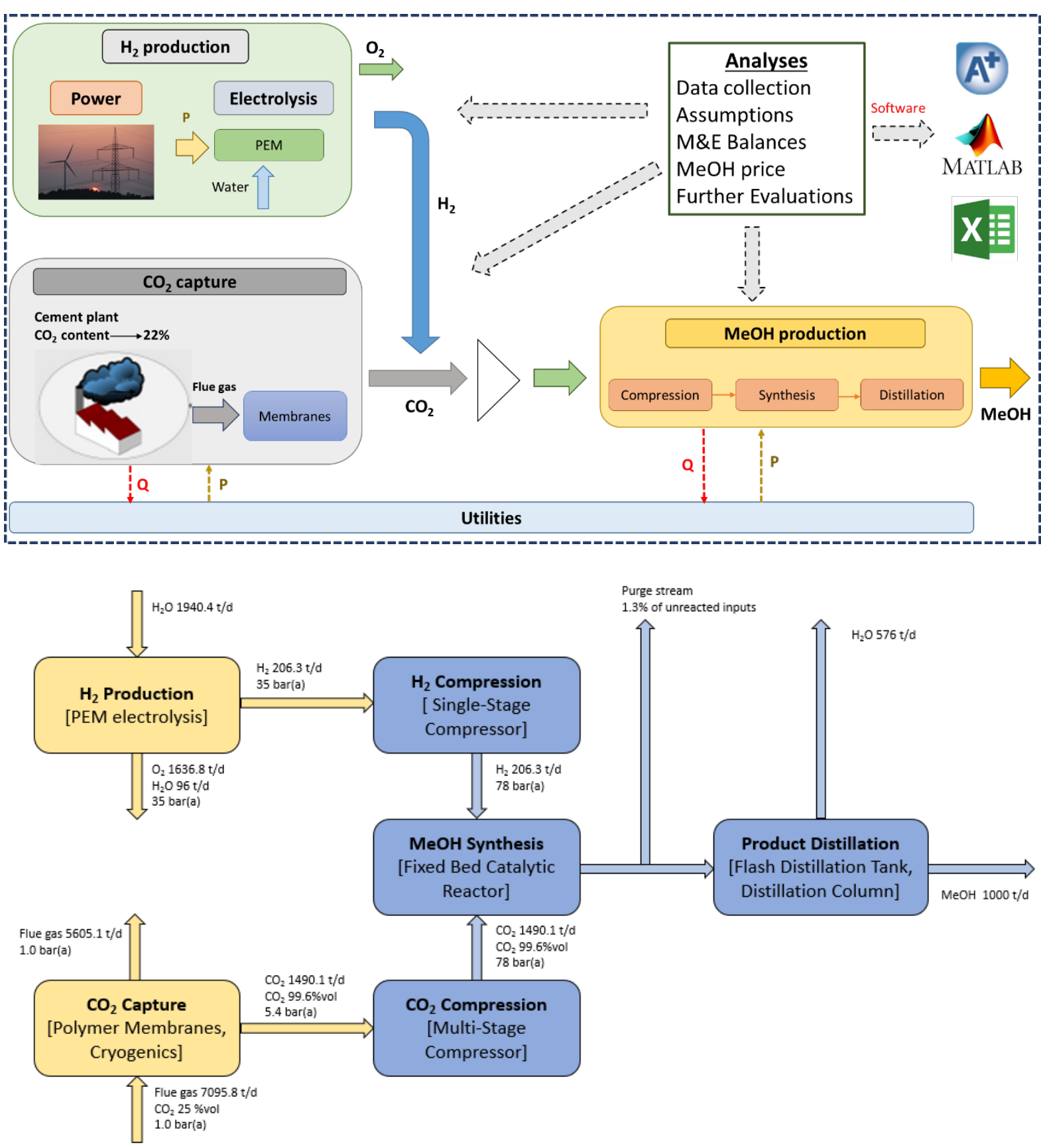

Figure 3. System elements and boundaries of the proposed $\mathrm{MeOH}$ plant

\section{Reference to TEA Guidelines}

In this section, both unit processes and system elements are presented as recommended in Guideline B.4. System boundaries are set to include capture of $\mathrm{CO}_{2}$ and production of $\mathrm{H}_{2}$ to ensure transparency in cost calculations. Figure 3 is a visual representation of the incorporated infrastructures and the basic material and energy flows. 


\section{B.5.3 Benchmark system}

The benchmark system for the proposed power to MeOH configuration is a conventional steam methane reforming $\mathrm{MeOH}$ plant utilising as natural gas as feedstock. The scale of the of a typical benchmark plant is 2,500-5,000 t/d. As CCU methanol plants would be likely to follow a distributed model based on feedstock availability, smaller plants are envisaged and therefore the CCU plant is scaled at 2.5-5 times smaller than a benchmark plant (CCU plant scaled at $1000 \mathrm{t} / \mathrm{d}$ ) [5]. As far as the price of commercial MeOH, Figure 2 reveals an average price of $248 € / t$ for 2016 [6]. The European contract price for the first quarter of 2018 has been initially settled at $380 € / t$ [6]. Significant volatilities that can be observed are mainly driven by changes in feedstock prices (natural gas, shale gas, coal) [7]. The Power to MeOH technology can, in theory, eliminate or limit the dependency on these volatilities in sourcing as feedstock prices depend mostly on local, technological and market factors.

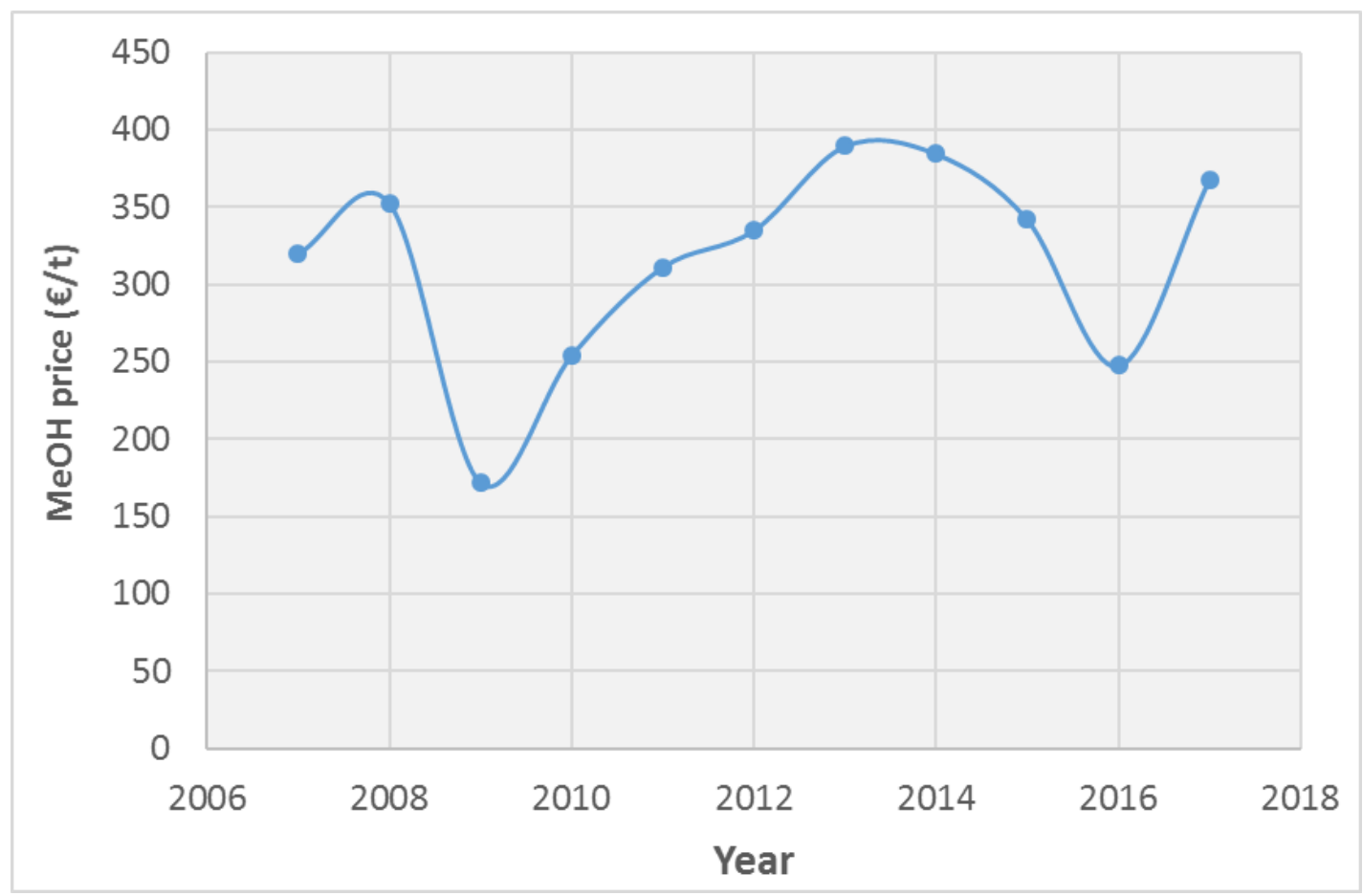

Figure 2. Historical yearly averaged MeOH prices, 2007 to 2017 [6]

\section{Reference to TEA Guidelines}

Consistent with Guideline B.5, the benchmark system was selected according to the product system function and targets similar group of users. $\mathrm{MeOH}$ from natural is the current best class system in the market that provides an identical product and targets similar group of users. As a futuristic scenario, someone may consider as benchmark bio-methanol produced by lignocellulosic wastes. 


\section{B.5.4 Technology maturity}

The TRL-concept from DoE was used to identify technology maturity of the individual process units. Table 1 provides the TRLS of the individual process units. Membranes are yet to achieve pilot or large scale applications for high purity $\mathrm{CO}_{2}$ recovery but since preliminary process design/simulation can be accomplished they are characterised as TRL 4. PEM electrolysers in the MW scale have recently become available, i.e. TRL 9 (Proton Onsite and Siemens) [8]. The TRL of the MeOH synthesis plant is based on the presence of a plant of the company CRI in Iceland that is operating since 2007; the capacity of the CRI Iceland plant is significantly lower than of a conventional $\mathrm{MeOH}$ plant, which is why a TRL 7 is attributed. For the $\mathrm{MeOH}$ process from $\mathrm{H}_{2}$ and $\mathrm{CO}_{2}$, Perez-Fortes and Tzimas estimate a TRL of 6-7 [9] and Buddenberg et al. a TRL of 8 [10].

Table 1. TRLs for each system elements of the process

\begin{tabular}{|l|c|}
\hline Process units & TRL \\
\hline PEM Electrolyser & 9 \\
\hline Membrane $\mathrm{CO}_{2}$ capture & 4 \\
\hline MeOH production & 7 \\
\hline Overall plant & 4 \\
\hline
\end{tabular}

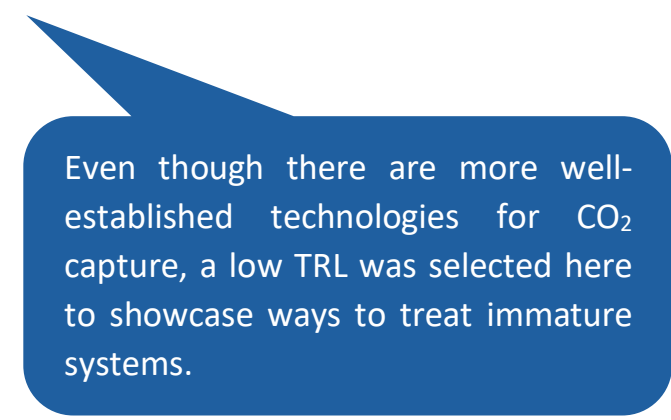

\section{Reference to TEA Guidelines}

The importance of identifying the technology maturity of the investigated configuration is highlighted in this section. The TRL-concept was adapted and as described in Guideline A.1, each system element was attributed a TRL. Subsequently, the overall product system TRL equals the lower TRL of the individual units.

\section{B.5.5 Assessment indicators, consistency and reproducibility}

Process design along with mass and energy balances are conducted here by means of simulations. Process intensification and heat integration were also carried out in order to enhance the performance of the system. Based on the simulations, a thorough cost breakdown of the produced $\mathrm{MeOH}$ is presented, in order to indicate the influence of the capital and operational expenditures on the final $\mathrm{MeOH}$ production cost and therefore to identify the most crucial techno-economic parameters that determine the $\mathrm{MeOH}$ price. The latter was estimated via a typical dynamic profitability calculation; consequently, a break-even analysis was utilised to calculate the minimum $\mathrm{MeOH}$ price at which revenues received equals the costs. It should be noted that break-even analysis is a supply-side analysis; it does not analyse how demand may respond at different price levels. Apart from cost breakdown and dynamic profitability calculation, sensitivity and probabilistic analyses (in Matlab environment) on the most significant parameters were carried out, investigating which conditions further influence the $\mathrm{MeOH}$ price, aiming to the optimisation of the scheme. For the sake of clarity and reproducibility simulation and financial methods are clearly stated throughout all chapters and/or Appendices. Data for the study came from peer-reviewed academic papers and textbooks and is therefore secondary data. 


\section{Reference to TEA Guidelines}

As stated in Guideline B.6, both economic and technical indicators were considered and calculated with the aim of providing robust answers to the assessment goal question. These comprise mass and energy efficiencies, CapEx, OpEx and $\mathrm{MeOH}$ selling price. Guideline B.7 acknowledges the importance of providing consistent and reproducible ways/methods. To this direction, process conditions and configurations (see Chapter B.4) as well as economic assumptions and data (see Chapter B.5) are clearly and thoroughly described. 


\section{B.6.Inventory}

\section{Reference to TEA Guidelines}

A checklist of items to be included in each section of the report is included in Chapter B.8 Reporting of the guidelines, which for the goal is as follows:

\section{Inventory of the study}

State types and sources of the data including the quality

$\square$ State the technical in SI units a technical parameter list

$\square$ State economic data in an economic parameter list

$\square$ State all economic decisions and assumption made

\section{B.6.1 Technical Data}

This section presents the process design and simulation of the showcase $\mathrm{MeOH}$ plant. For this purpose, Aspen Plus V8.4 simulator was employed to execute the necessary mass and energy balances. Economic evaluations were performed in Excel while probabilistic analysis was carried out in Matlab. A sequentialmodular approach was adapted in which the equations describing each process unit (module) were solved module-by-module in a stepwise manner. Iterative techniques were then used to solve the problems arising from the recycle of information. Four models have been employed to determine the thermodynamic properties: Redlich-Kwong-Soave with Huron-Vidal mixing rules for streams at high pressure ( $>10$ bar), and NRTL-RK for streams at low pressure ( $<10$ bar), electrolyte-NRTL for electrolysis reactions and typical steam tables for the CHP units.

For compressors and gas turbines mechanical and isentropic efficiencies are $95 \%$ and $90 \%$ respectively while for pumps overall efficiency is set equal to $70 \%$. For high pressure, intermediate pressure and low pressure steam turbines, isentropic efficiencies are 92\%, 94\% and $88 \%$ respectively [11]. Pressure drop in heat exchangers is typically dependent on phase. Usually liquid phase pressure drop is absolute and does not depend on relative pressure of the liquid. Liquid phase pressure drop for cold and hot side was set equal to 0.3 bar and gas phase pressure drop for cold and hot side 3\% [12]. In addition, a minimum temperature difference of $7^{\circ} \mathrm{C}$ was applied for heat transfer. If, during heating exchanging, phase change occurs, then at least three heat exchangers are used; two to account for the sensible heat above and below the temperature at which the phase change occurs and one for the latent heat. Open-recirculating cooling systems, that utilise the evaporation process to provide process or comfort cooling, were considered in the present study. A 5\% loss was assumed to count for drift, evaporation and blow down losses. The temperature range of cooling water is typically $15-25^{\circ} \mathrm{C}$. Furthermore, for a condensate return of $80 \%$ (of generated steam), the make-up rate of feed boiler water should be expected to be around $25 \%$ of the recirculated rate [13].

\section{Reference to TEA Guidelines}

The current subchapter provides typical process design configurations and assumption. Generic data derived from reliable process engineering literature (high quality) as described in Guideline B.8 was utilised. This level of detail serves to avoid CapEx and OpEx miscalculations and is in line with Guideline B.9. 


\section{B.6.2 $\mathrm{CO}_{2}$ capture}

Among the different carbon capture processes, membrane separation generates growing interest. Membrane separation can handle low to moderate dilute $\mathrm{CO}_{2}$ streams and achieve high purity of $\mathrm{CO}_{2}$ capture streams. However, based on the existing materials performances, the target purity $(>99.5 \%)$ cannot be attained by a single or multiple stages [14]. $\mathrm{CO}_{2}$ can be also separated from other gases by cooling and condensation. Cryogenic separation is widely used commercially for streams that already have high $\mathrm{CO}_{2}$ concentrations (typically $>90 \%$ ) but it is not used for more dilute $\mathrm{CO}_{2}$ streams. This suggests that a synergy between the two separations processes is possible and their combination could lead to a possible optimum with a minimal overall requirement. The study focuses on decarbonising heavy industries such as cement production, rather than power generation units as the latter are projected to shut down in the next few years while the market for the former is expected to grow over the foreseeable future.

There are two distinct sources of $\mathrm{CO}_{2}$ associated with a cement kiln. The first is the result of the direct combustion of fossil fuels for heat energy which produces a flue gas of 4-15 vol\% $\mathrm{CO}_{2}$ depending upon the source of fuel. The second is the by-product of calcining of limestone to produce the clinker material [15], where stoichiometric quantities of carbon dioxide are produced according to the reaction.

$$
\mathrm{CaCO}_{3} \rightarrow \mathrm{CaO}+\mathrm{CO}_{2}
$$

Both of these sources emit roughly equal amounts of $\mathrm{CO}_{2}$ per tonne of cement produced and therefore when combined generate a flue gas that is more concentrated in $\mathrm{CO}_{2}$ than in the power generation industry [16]. Typical total cement flue gas concentrations range from 22 to $28 \mathrm{~mol} \%$, with $900 \mathrm{~kg}$ of $\mathrm{CO}_{2}$ emitted during production of $1000 \mathrm{~kg}$ of cement [14].

A single-stage membrane unit cannot achieve a high $\mathrm{CO}_{2}$ capture ratio $(>80 \%)$ and $\mathrm{CO}_{2}$ purity $(>95 \%)$ simultaneously, as reported by He et al. [17], and energy efficiency could be improved using multiple-stage membrane systems to reduce the irreversibility of the whole process, as documented by Zhang et al. [18]. Based on the design of He et al. [19], a two-stage cascade membrane system was considered in the present study. The first stage membrane unit is used for pre-concentration of $\mathrm{CO}_{2}$ up to $50-70 \%$. The concentrated $\mathrm{CO}_{2}$ stream is then compressed to a certain pressure (e.g., 2-3 bar) and fed into the second stage membrane unit for ultimate $\mathrm{CO}_{2}$ purification to achieve high $\mathrm{CO}_{2}$ purity $(>95 \%)$. In order to document the process and economic feasibility of membrane systems, the following assumptions were made:

1) A membrane gas separation process based on MRT (Membrane Research and Technology) Polaris $^{\mathrm{TM}}$ membrane at a feed and permeate pressure of 2.5 bar and 250 mbar (optimal pressure reported in [17]) was employed,

2) a $\mathrm{CO}_{2} / \mathrm{N}_{2}$ and $\mathrm{CO}_{2} / \mathrm{O}_{2}$ selectivity of 50 and 20 were achieved [20]. Selectivity of $\mathrm{CO}_{2} / \mathrm{H}_{2} \mathrm{O}$ is assumed as unity and

3) pressure drop between retentate and feed streams in conjunction with temperature difference between feed and permeate sides due to the Joule-Thompson effect are assumed to be negligible.

For the assumptions made above, the governing equations for the membrane model are as follows.

$$
\begin{aligned}
& F_{f} y_{i, f}=F_{p} y_{i, p}+F_{r} y_{i, r},[i=1, \ldots, n] \\
& \sum_{i=1}^{n} y_{i, f}=1, \sum_{i=1}^{n} y_{i, p}=1, \sum_{i=1}^{n} y_{i, r}=1 \\
& F_{p} y_{i, p}=A_{m} Q_{i}\left(P_{f} y_{i, f}-P_{p} y_{i, p}\right)
\end{aligned}
$$

In the above equations, $F_{f}, F_{p}$ and $F_{r}$ are molar flow rates of feed, permeate and retentate streams, respectively; $y_{i, f}, y_{i, p}$ and $y_{i, r}$ are mole fractions of the $i^{\text {th }}$ component in the feed, permeate and retentate 
streams, respectively; $P_{f}$ and $P_{p}$ are feed-side and permeate-side pressures, respectively; $A_{m}$ is the membrane area and $Q_{i}$ is the permeance (= permeability/effective membrane thickness) of the $i^{\text {th }}$ component through the membrane. For a gas mixture of $n$ components, there are $2 n+3$ equations and $4 n$ +6 variables in the above model. Of these variables, $F_{f}, y_{1, f, \ldots} y_{n, f}, P_{f}$ are for the feed stream and are assumed to be given; $Q_{1}, \ldots, Q_{n}$ are related to membrane-specific variables to be found from the literature. Then, the remaining number of variables is $2 \mathrm{n}+4$ (namely, $F p, F r, y_{1, p}, \ldots y_{n, p}, y_{1, r}, \ldots y_{n, r}, P_{p}$ and $A_{m}$ ). As $\mathrm{y}_{1, f}, \ldots \mathrm{y}_{n, f}$ are known, mole fraction summation for feed in Eq. (3) becomes redundant. Now, there are $2 n+2$ equations in the model, and so the model has 2 degrees of freedom; for this, the user provides values of $A_{m}$ and $P_{p}$. The algebraic equations in the above model were solved in Matlab environment by utilising the nonlinear system solver fsolve. The output component flowrates were transferred to the Aspen plus file via Microsoft's COM technology for software interaction and using Excel as intermediate.

The Matlab solver is a variant of the Powell dogleg method. This algorithm, similar to the well-known Newton-Raphson method requires astute initial guesses. The latter were adopted from Aspen Plus.

Flue gas is assumed to be delivered free of $\mathrm{NO}_{x}$ and $\mathrm{SO}_{x}$ components. Initially, flue gas is cooled below dew point, water is then removed and subsequently compressed to 2.5 bars. Before each membrane, flue gas is conditioned so as to meet the pressure conditions (via vacuum pumps and compressors), monitor temperature at $35^{\circ} \mathrm{C}$ and where necessary remove condensed water. The permeate stream exiting the second membrane has a $95 \% \mathrm{CO}_{2}$ purity. Vent streams are collected and due to the high pressure of the mixed stream, electricity can be generated in an expander. Prior to this step, heat integration is realised with the aim of increasing the temperature (and consequently the enthalpy content) of the vent stream. For this purpose, three heat exchangers are added as depicted in Figure 4 (red circles) to recover heat from the gas streams exiting, Compr1, Compr2 and Compr3 as well as VPump2. The integrated design reduces the cooling duties by $27.2 \%$ and the electricity demand by 32.9\%. Furthermore, the total annual cost (TAC) - sum of annualised capital cost (ACC) Eq. (5) and operating expenditures - decreases by $31.6 \%$. Table 2 presents the comparison of the integrated with the initial scenario.

$$
A C C=\text { CapEx } \times \frac{i_{d} \times\left(1+i_{d}\right)^{n}}{-1+\left(1+i_{d}\right)^{n}}, i_{d} \text { is the discount rate and } n \text { is project lifetime in years }
$$

Table 2. Heat integration results for the $\mathrm{CO}_{2}$ capture plant

\begin{tabular}{|l|c|c|}
\hline & Initial design & Integrated design \\
\hline Cooling duties (MW) & 23.2 & 16.1 \\
\hline Electricity demand (MW) & 11.7 & 8.97 \\
\hline CapEx heat exchanger and expander(M€) & 3.06 & 3.6 \\
\hline OpEx electricity and cooling water (M€/y) & 8.07 & 6.19 \\
\hline TAC (M€/y) & 8.37 & 6.54 \\
\hline
\end{tabular}

The next step of the carbon capture system configuration involves the cryogenic treatment of the $\mathrm{CO}_{2}$ rich stream. According to Belaissaoui et al. [21], highly concentrated $\mathrm{CO}_{2}$ streams (>90\%), should be pressurised up to 11 bar before entering the economiser unit; a two stage compressor with intermediate cooling is utilised. Afterwards, the gas is cooled down by water and cooled down further 
in the economiser to $73^{\circ} \mathrm{C}$. The gas goes through a valve in order to reach the minimal necessary liquefaction pressure. The inlet pressure flash is set in order to have a $\mathrm{CO}_{2}$ partial pressure of $5.4 \mathrm{bar}$

\section{Reference to TEA Guidelines}

As stated in the Guidelines document, the reported range of $\mathrm{CO}_{2}$ price is very wide; in some cases it is considered free of charge or under an ETS scheme. To avoid such or similar misconceptions $\mathrm{CO}_{2}$ capture is within the system boundaries pricing is determined by capture costs. As recommended in Guideline B.10, a detailed design is presented including technical information of capture technology and $\mathrm{CO}_{2}$ source.

ensuring a proper liquefaction of $\mathrm{CO}_{2}$ and non-frosting conditions. After being heated in the economizer, the incondensable gases are mixed with the retentate streams and sent to an expander to generate electricity while the $\mathrm{CO}_{2}$ enters a flash unit to remove water and is sent to $\mathrm{MeOH}$ synthesis plant. Overall, a $\mathrm{CO}_{2}$ purity of $99.6 \%$ is achieved along with a capture ratio of approximately $87 \%$.

\section{B.6.3 Renewable hydrogen production}

Hydrogen is produced via electrolysis by passing electricity through two electrodes in water. The water molecule is split, generating oxygen at the anode and hydrogen at the cathode. A PEM electrolyser was selected over an alkaline process as it provides high efficiencies and also serves to separate the hydrogen and oxygen gases, as oxygen and hydrogen are produced on opposite sides of the membrane [22]. Additionally, PEM electrolysers operate very well under variable loads and further efficiency enhancements are anticipated in the coming decade [23]. The membrane allows the $\mathrm{H}^{+}$ion to transfer from the anode side of the membrane to the cathode side, where it forms hydrogen. An efficiency of $70 \%$ based on $\mathrm{H}_{2} \mathrm{LHV}$ [24] was considered and the required electricity is derived for the base case study from the grid. An additional $10 \%$ of electricity is supplied to cover the demand of the balance of the electrolysis (BOE) section [25]; the overall electrical consumption is $52.4 \mathrm{kWh} / \mathrm{kgH}_{2}$. The lifetime of the electrolyser is $80,000 \mathrm{~h} \mathrm{[26].}$ In order for the process to cause less environmental impacts renewable electricity is a prerequisite and therefore either renewable energy certificates and/or substantial penetration of renewable energy in the grid are required.

The PEM unit was modelled in Aspen Plus by employing two RSTOICH reactors both operating at temperature and pressure of $80^{\circ} \mathrm{C}$ and 35 bar respectively. The first represents the anode $\left(\mathrm{H}_{2} \mathrm{O} \rightarrow 1 / 2 \mathrm{O}_{2}+2 \mathrm{H}^{+}+2 \mathrm{e}^{-}\right)$and the second the cathode $\left(2 \mathrm{H}^{+}+2 \mathrm{e}^{-} \rightarrow \mathrm{H}_{2}\right)$. A 95\% water conversion is realised while the electricity demand was calculated by FORTRAN statements based on the necessary amount of hydrogen. Additionally, it should be noted deionised water is utilised. Oxygen is separated via a common separator (100\% efficiency was assumed), then cooling to $30^{\circ} \mathrm{C}$ is applied and subsequently condensed water is removed. Purified hydrogen is recovered and sent to the $\mathrm{MeOH}$ synthesis plant. It was assumed that electrolysis occurs on site and no transport is required. Additionally, for a constant electricity load, a constant $\mathrm{H}_{2}$ production can be assumed and as such no buffering is included for the study.

\section{Reference to TEA Guidelines}

Guideline 12 raises the issue of $\mathrm{H}_{2}$ pricing. In this study, hydrogen production is within the system boundaries and thereby cost of production include both associated CapEx and OpEx. Hydrogen is produced via PEM electrolysis; a realistic and environmental friendly scenario as suggested in Guideline B.11. 


\section{B.6.4 MeOH synthesis}

The process design for the $\mathrm{MeOH}$ plant is based on previous works conducted by Van-Dal and Bouallou [27], Perez-Fortes et al. [28] and Kiss et al. [29]. The plant produces $\mathrm{MeOH}$ at a rate of $42.78 \mathrm{t} / \mathrm{h}$ (1.02 $\mathrm{kt} /$ day). $\mathrm{CO}_{2}$ is delivered to the plant at a flowrate of $62.08 \mathrm{t} / \mathrm{h}$, pressure of 5.4 bar and temperature of $25^{\circ} \mathrm{C}$. The required $\mathrm{H}_{2}\left(3: 1 \mathrm{H}_{2}: \mathrm{CO}_{2}\right.$ molar ratio) produced from the PEM unit is supplied at a pressure of 35 bar and temperature of $25^{\circ} \mathrm{C}$. The first step of the process incorporates the conditioning of the reactant gases to the operating conditions of the synthesis reactor, i.e. 78 bar and $210^{\circ} \mathrm{C} . \mathrm{CO}_{2}$ is compressed via a multistage compressor consisting of two compressors with intermediate cooling. If the gas is cooled to the inlet or slightly higher temperature of the previous lower pressure compressor $\left(\sim 35^{\circ} \mathrm{C}\right)$, it can be shown that minimum specific work is consumed when the pressure ratios (3.8:1 in this case) of the compressors are equal [30]. A single stage compressor was utilised to raise $\mathrm{H}_{2}$ pressure up to 78 bar. The two gases are mixed and then re-mixed (for convergence purpose) with the recycle stream. The stream is then heated to $210^{\circ} \mathrm{C}$ and injected into the fixed bed adiabatic reactor. The adiabatic reactor is packed with a fixed bed of 44.5 tonnes of $\mathrm{Cu} / \mathrm{ZnO} / \mathrm{Al}_{2} \mathrm{O}_{3}$ commercial catalyst and it assumed that it is renewed once a year [28]. For this catalyst, the model proposed by Vanden Bussche and Froment [31] with readjusted parameters of Mignard and Pritchard [32] is able to describe with good precision the reactions of MeOH production, Eq. (6) and the RWGS reaction, Eq. (7).

$$
\begin{aligned}
& \mathrm{CO}_{2}+3 \mathrm{H}_{2} \rightarrow \mathrm{CH}_{3} \mathrm{OH}+\mathrm{H}_{2} \mathrm{O} \\
& \mathrm{CO}_{2}+\mathrm{H}_{2} \rightarrow \mathrm{CO}+\mathrm{H}_{2} \mathrm{O}
\end{aligned}
$$

The kinetic model is described with Langmuir-Hinshelwood kinetics and it can be found in [27]. The model was directly implemented in Aspen Plus and pressure drop was calculated by the Ergun equation, already nested in the simulator. For a pellet density of $1,775 \mathrm{~kg} / \mathrm{m}^{3}$ and a void fraction of 0.5 the volume of the reactor is approximately $50 \mathrm{~m}^{3}$. It was observed that steady state can be reached at lower volumes meaning that less amount of catalyst can result in same $\mathrm{MeOH}$ productivities, i.e. 35 tonnes. The gases leave the reactor at a temperature of $288^{\circ} \mathrm{C}$ and subsequently is divided into two streams: the first $(60 \%$ of initial stream) is used to heat the fresh feed, while the second is used in the reboiler and also to heat the feed of the distillation column. The two streams are re-mixed and cooled to $35^{\circ} \mathrm{C}$. Water and $\mathrm{MeOH}$, after being condensed, are separated from the non-reacted gases in a knock-out drum. Some of the non-reacted gases (1.3\%) are purged to minimise the accumulation of inerts and by-products in the reaction loop. The crude $\mathrm{MeOH}$ that leaves the reactor is a mixture of $\mathrm{MeOH}$, water and residual gases (i.e., $\mathrm{H}_{2}$ and $\mathrm{CO}$ and $\mathrm{CO}_{2}$ ). To remove the non-reacted gases, the stream is expanded to 1 bar using valves, and then separated in a flash tank. The remaining liquid is heated to $75^{\circ} \mathrm{C}$ and fed into the distillation column. The bottom product of the distillation column corresponds to water while the top product is mostly $\mathrm{MeOH}$ with some unreacted gases. The column was simulated with the rigorous model RadFrac. A rate-based calculation of the column is carried out, using the mass and heat transfer model from Billet and Schultes. The column has 50 stages and the reflux ratio is equal to 1.2. However, the column can be intensified by reducing the reflux ratio to 1; reboiler's heating duty is reduced to $16.5 \mathrm{MW}$ from 19.5 MW while $\mathrm{MeOH}$ recovery and purity remain unchanged. $\mathrm{MeOH}$ is then compressed to $1.2 \mathrm{bar}$ and cooled to $40^{\circ} \mathrm{C}$ proceeding to another flash that separates the gases (top outlet) from the $\mathrm{MeOH}$ product with $99 \% \mathrm{w} / \mathrm{w}$ in the bottom stream. Figure 5 provides the process flow diagram of the $\mathrm{MeOH}$ plant including the electrolysis unit.

\section{B.6.5 Utilities}

The streams containing unreacted gases are collected and sent to a gas turbine unit to generate electricity. The gas stream is compressed up to 6 bar and enters a gas turbine where it is burned with excess of pressurised air (15\%) to produce electricity at a temperature of $1200^{\circ} \mathrm{C}$. The required air is specified by a FORTRAN calculator according to the flows of carbon monoxide and hydrogen. The exhaust gas from the 
gas turbine is recovered from a heat recovery steam generation (HRSG) system, composed of three heat exchangers (namely economizer, evaporator and superheater) where superheated steam $\left(550^{\circ} \mathrm{C}, 100 \mathrm{bar}\right)$ is produced. According to the present design, the economiser is placed before HE1 to extract heat from the pressurised $\mathrm{CO}_{2}$. This way more steam can be produced as the exhaust gas provides heat only to the evaporator and the superheater. A series of high, intermediate and low pressure steam turbines are employed to generate electricity. Part of high pressure steam is utilised to provide heat to the deaerator. The combined Rankine-Brayton cycle generates $4 \mathrm{MW}$ of electricity. Furthermore, based on the design of Van-Dal and Bouallou [27], hot water at a temperature of $85^{\circ} \mathrm{C}$ that is raised from HE1, HE2, and H4 is mixed with the bottom stream of the distillation column and enters an Organic Rankine Cycle (ORC) unit. The working fluid is the R245fa and electricity of $1 \mathrm{MW}$ is generated. Finally, it should be noted that the wastewater unit and the cooling system were not simulated but considered in the economic evaluation.

A combined-cycle power plant uses both a gas and a steam turbine together to produce more electricity (typically up to $50 \%$ ) from the same fuel than a traditional simple-cycle plant. Even if capitals costs are higher, these are usually offset by the increased electricity generation for large scale applications (as the one here). 


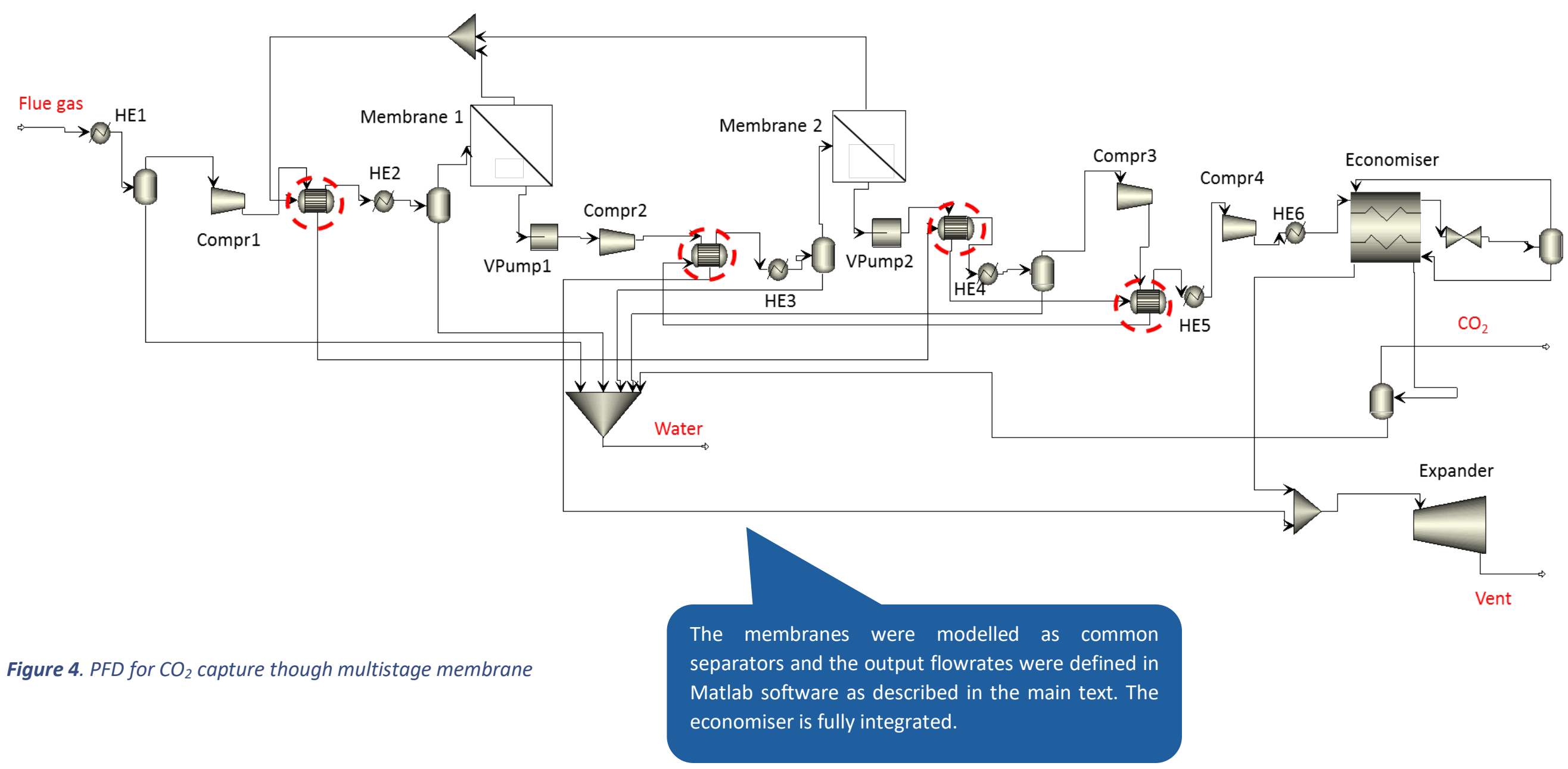




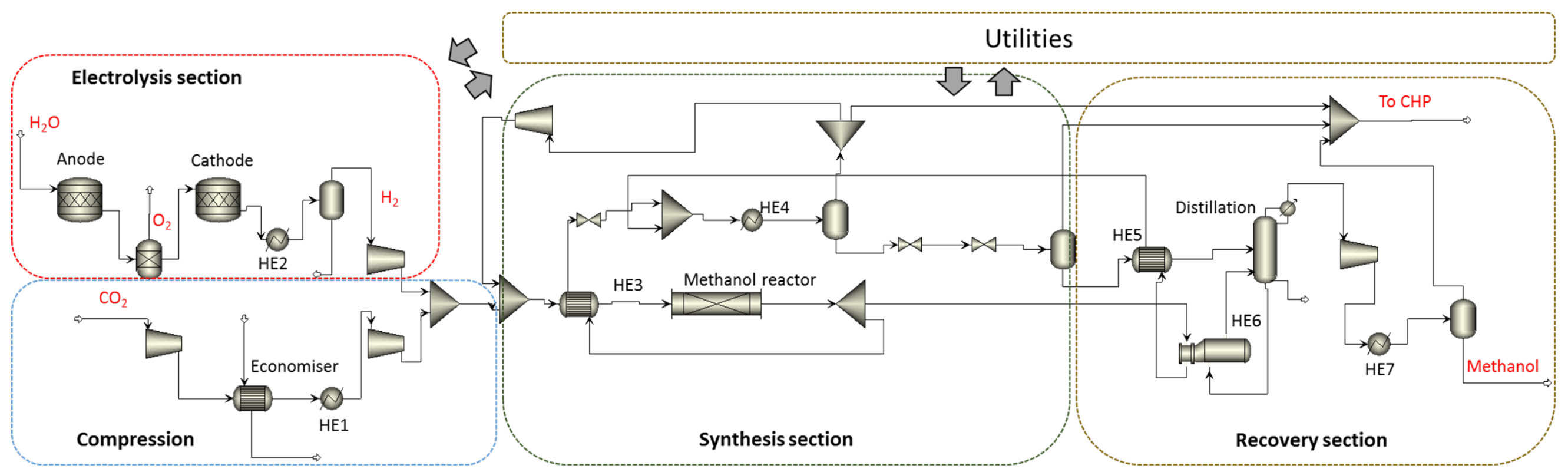

Figure 5. MeOH plant process flow diagram

\section{Reference to TEA Guidelines}

Generic data and sensible process design (see Guideline B.8) was employed to simulate the $\mathrm{MeOH}$ production and utilities system elements. Collection of high quality data (see Guideline B.9) enabled the intensification of the process. As recommended in Guideline B.12, technical parameters are documented in SI-Units in the Inventory section and throughout the manuscript. 


\section{B.7.Calculation of Indicators}

\section{Reference to TEA Guidelines}

A checklist of items to be included in each section of the report is included in Chapter $\mathbf{8}$ Reporting of the guidelines, which for the goal is as follows:

Inventory of the study

- State calculation procedures

Explain methodology of financial analysis

Include results of technical assessment

Include results of economic assessment

The previous chapter served to provide all the necessary data and assumptions for the assessment phase of the present study. Based on the simulations and the given process design material and energy streams were quantified and subsequently technical indices were calculated. As previously discussed, with the aim of determining the attractiveness of the investment a DCFA was carried out to estimate the $\mathrm{MeOH}$ price. Technical and economic indicators should go hand in hand. However, the economic indicators are those which support decision making; technical related results have the potential to identify hot spots and insights on why a project is profitable or not.

\section{B.7.1 Technical assessment indicators}

Given the process technologies modelled and integrated, mass and energy efficiencies were estimated for the proposed $\mathrm{MeOH}$ process configuration. The basic simulation outcomes can be found in Appendix A. As depicted in Table 3, some of the major indicators include specific energy consumptions, overall and per pass (around the $\mathrm{MeOH}$ reactor) $\mathrm{CO}_{2}$ conversion. The overall and the per pass $\mathrm{CO}_{2}$ conversions are defined as $\left(\mathrm{CO}_{2, \mathrm{in}}-\mathrm{CO}_{2, \text { out }}\right) / \mathrm{CO}_{2, \text { in }}$ around the $\mathrm{MeOH}$ plant and the reactor respectively. For a plant utilising $1,490 \mathrm{t} / \mathrm{d}$ of $\mathrm{CO}_{2}$, a MeOH yield of $1,000 \mathrm{t} / \mathrm{d}$ is realised.

Table 3. Technical indicators

\begin{tabular}{|l|c|c|}
\hline Indicator & Value & Unit \\
\hline Overall $\mathrm{CO}_{2}$ conversion & 94.65 & $\%$ \\
\hline Conversion factor & 1.45 & $\mathrm{tCO}_{2} / \mathrm{tMeOH}$ \\
\hline Per pass $\mathrm{CO}_{2}$ conversion & 24.8 & $\%$ \\
\hline $\begin{array}{l}\text { Specific energy consumption } \\
\text { for } \mathrm{CO}_{2} \text { capture }\end{array}$ & 0.145 & $\mathrm{MWh} / \mathrm{t} \mathrm{CO} 2 \mathrm{captured}$ \\
\hline $\begin{array}{l}\text { Specific energy consumption } \\
\text { for electrolysis }\end{array}$ & 0.21 & 52.4 \\
\hline $\begin{array}{l}\text { Specific energy consumption } \\
\text { for MeOH plant }\end{array}$ & 10.52 & $\begin{array}{c}\mathrm{MWh} / \mathrm{t} \mathrm{H} \\
\mathrm{MWh} / \mathrm{t} \mathrm{MeOH}\end{array}$ \\
\hline Overall energy consumption & 10.84 & $\mathrm{MWh} / \mathrm{t} \mathrm{MeOH}$ \\
\hline
\end{tabular}

Since methanol is treated as chemical, it is more sensible to report energy consumptions rather than energy efficiency. The latter considers the energy content of the final product in terms of heating value and as so it is a suitable metric for fuels production. However, for the sake of comparability the energy efficiency of the system on a LHV basis is $58.1 \%$. 


\section{Reference to TEA Guidelines}

As suggested in Guideline B.13, this section provides the necessary formulas for calculating indicators, uses common units and presents metrics for both the entire system and the individual system elements. Furthermore, simulation data (input/output) is stored and presented in Appendix A.

\section{B.7.2 Basis for cost estimation and DCFA}

The current section presents the utilised methodology for the estimation of capital and operating expenditures (CapEx and OpEx). In addition, all the required data and assumptions for the conduction of a typical DCFA are presented.

The location of the proposed plant is Germany; a location factor of 1.1 [33] was utilised to represent the difference in cost between building a plant in Germany versus building a plant in the US Midwest. The reference year of the study is 2016 and the currency is EUR. Where capital costs were reported at different currency than EUR the value was first converted to EUR by using exchange rates of the respective reported year and were subsequently brought up to date by utilising the Chemical Engineering Plant Cost Indices (CEPCI).

The scaling exponent method is utilised to estimate equipment costs. Eq. (8) represents the economies of scale because buying a piece of equipment with twice the size or capacity is less than twice as expensive (when the exponent is less than 1.0).

$$
\mathrm{C}=\mathrm{C}_{0}\left(\frac{\mathrm{S}}{\mathrm{S}_{0}}\right)^{\mathrm{f}}
$$

Where $C$ is the estimated actual cost of the unit, $C_{0}$ the base cost of the unit, $S$ the actual size or capacity of the unit (extracted from the simulations), $S_{0}$ the base or capacity and $f$ an empirical scaling exponent. The values of $C_{0}, S_{0}$ and $f$ can be found in Appendix B (Table B.1).

Then, the factorial method is employed to estimate CapEx. The latter includes ISBL, OSBL, indirect costs and working capital. As mentioned before, the OSBL counts only for the BOP and thereby a relatively lower cost value was attributed, i.e. $12 \%$ of the ISBL [34]. For the electrolysis unit a value of $1.5 \mathrm{M€} / \mathrm{MW}$ installed was utilised. This figure includes the balance of the electrolyser (BOE) and successively a factor of 1.524 [35] was employed for the fixed capital investment (both ISBL and OSBL). Based on confirmed information from sources in industry, the DoE reports a value between 0.6 and 0.7 for the cost exponent [36]; a value of 0.65 is considered here. The full methodology is provided in Appendix C (Table C.1).

The cost estimation described here incorporates what are known as " $n$th -plant" economics. The chief hypothesis involved in $\mathrm{n}^{\text {th }}$ of a kind (NOAK) economics is that the analysis does not designate a pioneer plant; as an alternative, several plants using same technologies have been already built and operating. It should be noted here that for the high TRL units of the plant (electrolysis and MeOH synthesis) NOAK costs were calculated directly while for the low $\mathrm{TRL}_{\mathrm{CO}}$ capture unit and indirect method was implemented. The indirect method involves the following three steps (1) estimate the equipment and installation cost, (2) find the FOAK total plant cost costs by adding appropriate engineering costs, process and project contingencies, and (3) find the NOAK total plant cost using learning curves [37,38]. The NOAK costs can be calculated from the FOAK using a single factor learning curve [39]:

$$
C_{N O A K}=C_{F O A K}\left(\frac{N_{N O A K}}{N_{F O A K}}\right)^{b}
$$


The learning rate coefficient $b$ is a parameter that is calculated from $L R=1-2^{b}$, where $L R$ is the learning rate. This single factor learning curve combines learning by doing, learning by searching (continued RD \& $D$ in the commercial stage of technology deployment), and scale factors. For MEA technology, a learning rate of 0.11 was proposed by Rubin [38]; since advances in membrane technologies are expected to be sharper than MEA, a higher LR was assumed, i.e. 0.15. N is the number of installed plants. According to Greig et al. [40] $N_{F O A K}$ is typically less than 10 (a nominal value of 5 was used in the present study), early movers range between ten and twenty, and $N_{\text {NOAK }}$ more than twenty ( 20 was selected).

In addition, an overall scaling factor (see Figure 6) was calculated by setting as design variable $\mathrm{MeOH}$ productivity in $\mathrm{t} / \mathrm{d}$. In this way, potential future designers can utilise the overall factor instead of individual factors. The limitation of this approach is that the technologies involved should be the same or at the very least similar. A scaling factor of 0.669 was calculated here which is in line with the figure reported by Couper [41], i.e. 0.7

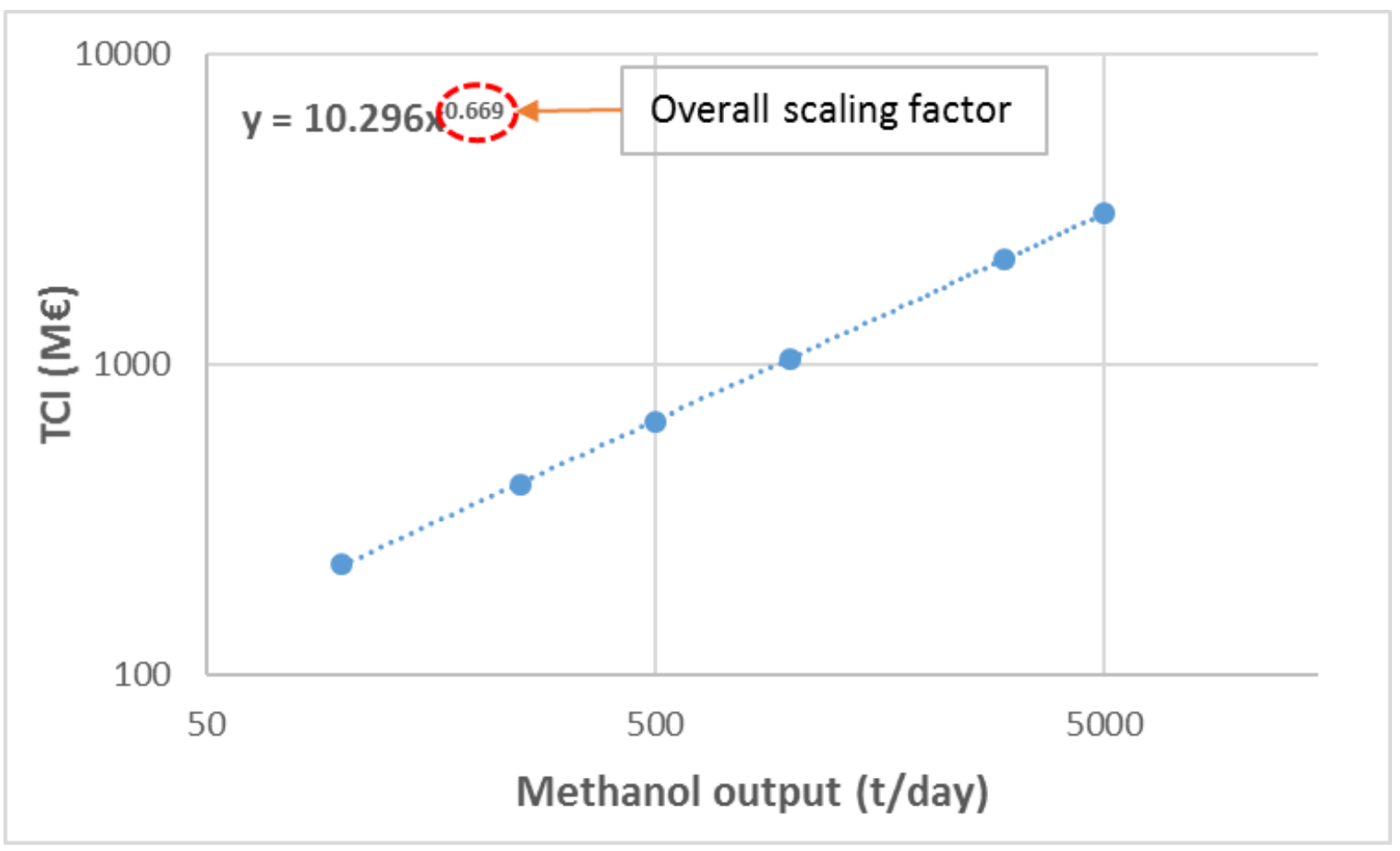

Figure 6. Economies of scale of the proposed power to MeOH plant (includes both ISBL and OSBL as defined in the present study)

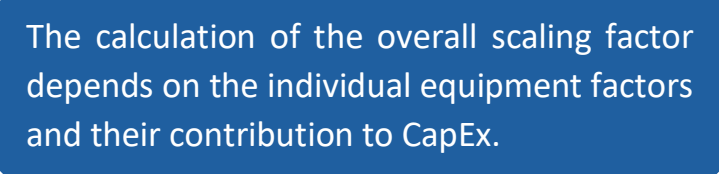

OpEx comprise variable costs and fixed costs. The former expenditures refer to raw materials price, catalyst costs, utilities and waste disposal (see Appendix B, Table B.2) while the latter comprise labour, supervision, direct salary overhead, maintenance, insurance and general plant overhead (see Appendix B, Table B.3). For the labour requirement, the following correlation was utilised (refers to fully automated processes) [42]:

$$
N_{O L}=(6.29+31.7 P+0.23 \mathrm{~N})^{0.5}
$$

Where $P$ the number of the solids handling steps and $N$ is the number of nonparticulate processing steps and includes compression, heating and cooling, mixing, and reaction. For each of the $N_{O L}$ operators per 8- 
hour shift, approximately 5 operators must be hired for a plant that runs 24 hours per day, to account for 3 shifts per day as well as regular and sick annual leaves. An average annual salary of $€ 85,000$ is considered [43].

The plant is financed with a 50-50 debt-equity split, considering an interest rate of $6 \%$ for the debt and assuming a cost of equity of $12 \%$. The weighted average cost of capital (WACC) is calculated as follows [44]:

$$
W A C C=D R \times i_{d}+\left[(1-D R) \times i_{e}\right]
$$

Where $D R$ is the debt ratio, $i_{d}$ interest rate due on debt and $i_{e}$ cost of equity. The WACC can serve as a good proxy for the discount rate and this approach was adopted here for budgeting the project and carrying out the DCFA. The capital investment is assumed to be spent over a 3 -year construction period, with $20 \%$ in the first year, followed by $50 \%$ and $30 \%$ for the second and third years respectively. Working capital is applied in the year before operation and recovered at the end of the plant life. A straight line depreciation was realised and assets are depreciated in ten years whereas the project life time is 20 years. Any salvage value was assumed to be fully offset by decommissioning expenses. The basic economic parameters and assumptions are presented in Table 4.

Table 4. Economic parameters and assumptions

\begin{tabular}{|c|c|c|}
\hline Parameter & Value & \\
\hline Location & Germany & \\
\hline Base year & 2016 & \\
\hline Project lifetime (y) & 20 & \\
\hline Construction period (y) & 3 & \\
\hline Plant availability $(h / y)$ & 8,000 & \\
\hline CHP capacity factor (\%) & 85 & \\
\hline Tax rate (\%) [45] & 29.72 & \\
\hline Equity/Debt (\% /\%) & $50 / 50$ & The capacity factor should not be \\
\hline Debt interest (\%) & 6 & capacity factor is the unitless ratio of \\
\hline Cost of Equity (\%) & 12 & units of electricity generated / units the \\
\hline WACC (\%) & 9 & plant can generate if in $100 \%$ operation. \\
\hline Depreciation & straight-line & So in our case the nameplate capacity is \\
\hline Depreciation period $(y)$ & 10 & \\
\hline Salvage value $(€)$ & 0 & \\
\hline
\end{tabular}

\section{Reference to TEA Guidelines}

This section along with Appendices B and C is aligned with Guidelines B.14 and B15. Consistent with Table 9 of the guidelines document, Table 4 presents all the necessary economic data. Furthermore, the full numerical methodology for estimating CapEx an OpEx is provided. For the low TRL section an indirect method for CapEx estimation was utilised while for the high TRL a direct one. Cost transformation was utilised for costing typical equipment (high quality data) and factorial methods for $\mathrm{FCl}$ and $\mathrm{TCl}$ (Appendix $\mathrm{B}$ and $\mathrm{C}$ respectively). Variable OpEx were estimated based on the quantification of material and energy streams while fixed OpEx follow a factored estimation. 


\section{B.7.3 Economic assessment indicators}

The goal is to calculate CapEx and OpEx for each segment of the proposed plant, total production costs and the minimum selling price of $\mathrm{MeOH}$. Results are presented in Table 5 and Table 6 depicts comparisons with the benchmark process. On the basis of the fixed capital investment cost and the cash flows at each successive year, the NPV of the project is calculated. Revenues are generated from $\mathrm{MeOH}$ and $\mathrm{O}_{2}$. The two widely used measures for evaluating an investment are based on calculating NPV and the internal rate of return (IRR). The NPV and IRR are calculated by using the following equations:

$$
\begin{gathered}
N P V=-T C I+\sum_{n=1}^{20} \frac{C F}{(1+\text { discount rate })^{t}} \\
\sum_{n=1}^{20} \frac{C F}{(1+I R R)^{n}}=0 \\
C F=P(1-t)+D t
\end{gathered}
$$

Where the $C F$ values are the after tax cash flow for each year, $P$ are gross profits, $t$ is the tax rate and $D$ the depreciation. The $\mathrm{MeOH}$ price is calculated for $\mathrm{NPV}=0$ or equally IRR=discount rate. This value is also referred as minimum $\mathrm{MeOH}$ selling price (MMSP) and accounts for the price that can cover the full costs of the investment. The DCFA resulted in a MMSP of 1,402 $€ / t$. Furthermore, Figures 7 and 8 provide detailed breakdown of purchased equipment costs and total operating costs respectively. Figure 9 is the breakdown

\begin{tabular}{|c|c|c|c|c|c|}
\hline & $\begin{array}{l}\mathrm{CO}_{2} \text { capture } \\
\text { plant }\end{array}$ & Electrolysis & MeOH synthesis & Utilities & Total \\
\hline CapEx (M€) & 258.06 & 140.90 & 403.12 & 247.21 & $1,049.28$ \\
\hline OpEx (M€/y) & 18.08 & 328.89 & 20.67 & 9.23 & 376.87 \\
\hline $\begin{array}{l}\text { CapEx per tonne of } \\
\mathrm{MeOH}(€ / t)\end{array}$ & 82.60 & 45.10 & 129.03 & 79.13 & 335.86 \\
\hline $\begin{array}{l}\text { OpEx per tonne of } \\
\mathrm{MeOH}(€ / t)\end{array}$ & 52.82 & 961.00 & 60.39 & 26.97 & $1,101.17$ \\
\hline Production cost & 135.42 & 1006.10 & 189.43 & 106.09 & $1,437.04$ \\
\hline $\begin{array}{l}\text { Revenues from } \mathrm{O}_{2}(€ / \mathrm{t} \\
\mathrm{MeOH})\end{array}$ & - & - & - & & 86.41 \\
\hline $\begin{array}{l}\text { Production cost }(€ / t \\
\text { MeOH) }\end{array}$ & - & - & - & & $1,350.63$ \\
\hline $\begin{array}{l}\text { Minimum selling price } \\
(€ / \mathrm{t} \mathrm{MeOH})\end{array}$ & - & - & - & & 1,402 \\
\hline
\end{tabular}
of the major OPEX contributor, i.e. electricity, across the three unit blocks.

Table 5. Economic indicator results of the plant

Table 6. Comparison of technical and techno-economic indicators of the proposed plant with weightedaverage conventional synthesis plant in Western Europe [9]

\begin{tabular}{|l|c|c|}
\hline Indicator & Proposed plant & Conventional plant \\
\hline Electricity needs $(\mathrm{MWh} / \mathrm{tMeOH})$ & 10.84 & 0.147 \\
\hline Cooling water needs $(\mathrm{tH} \mathbf{2 O} / \mathrm{tMeOH})$ & 128 & 90 \\
\hline CapEx per tonne of $\mathrm{MeOH}(€ / \mathrm{t} / \mathrm{y})$ & 3,066 & 862 \\
\hline OpEx per tonne of $\mathrm{MeOH}(\boldsymbol{€} / \mathrm{t})$ & 1,101 & 407 \\
\hline
\end{tabular}




\section{Reference to TEA Guidelines}

As suggested in Guideline B.3, economic results are presented on a functional unit basis, i.e. metric tonnes of $\mathrm{MeOH}$. For $\mathrm{CO}_{2}$ capture (low TRL) energy consumption and subsequently OpEx can give better insights on the performance of the process. The full methodology, equations and assumptions to conduct an NPV analysis is presented here as recommended in Guideline B.16.

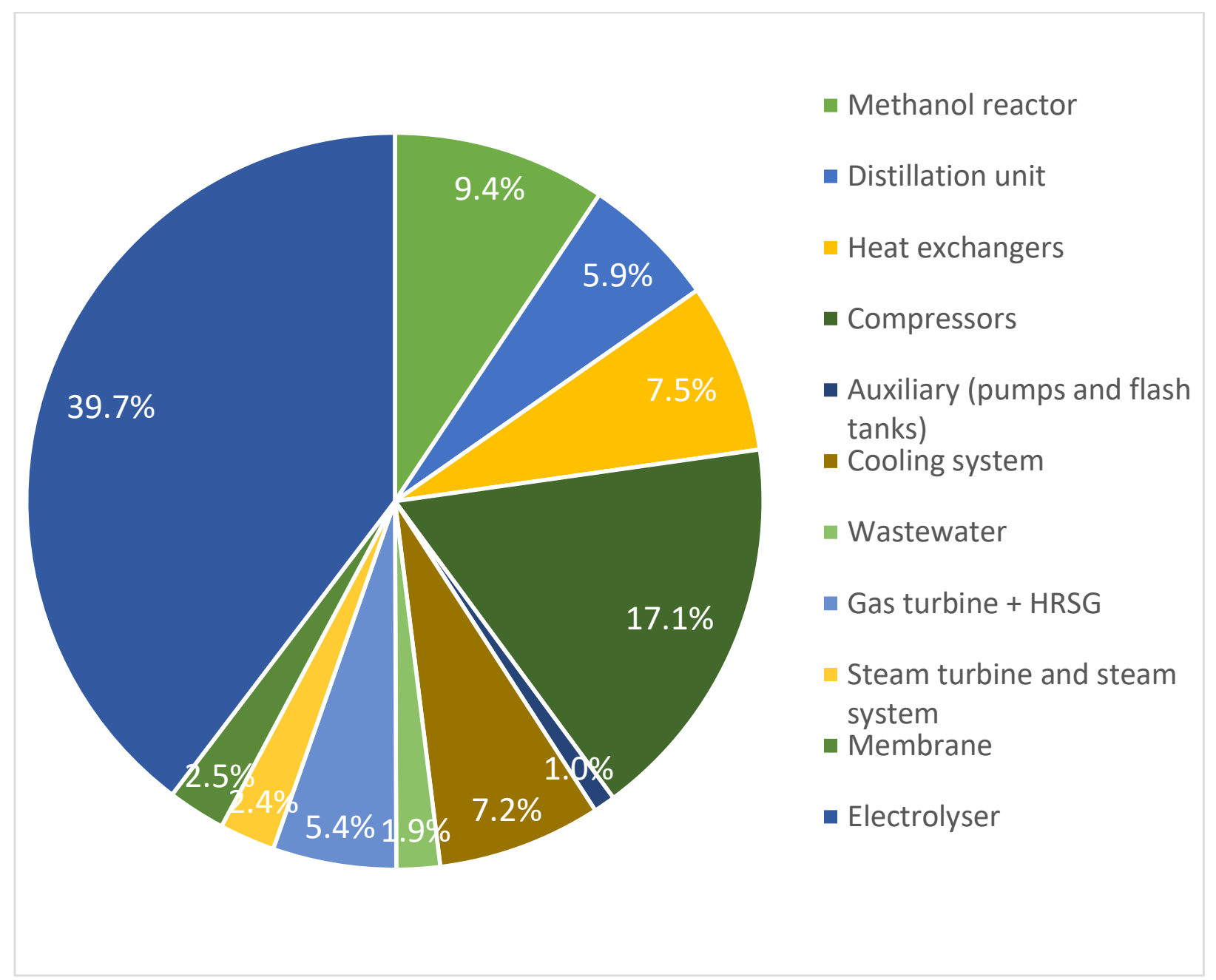

Figure 7. Purchased equipment cost breakdown 


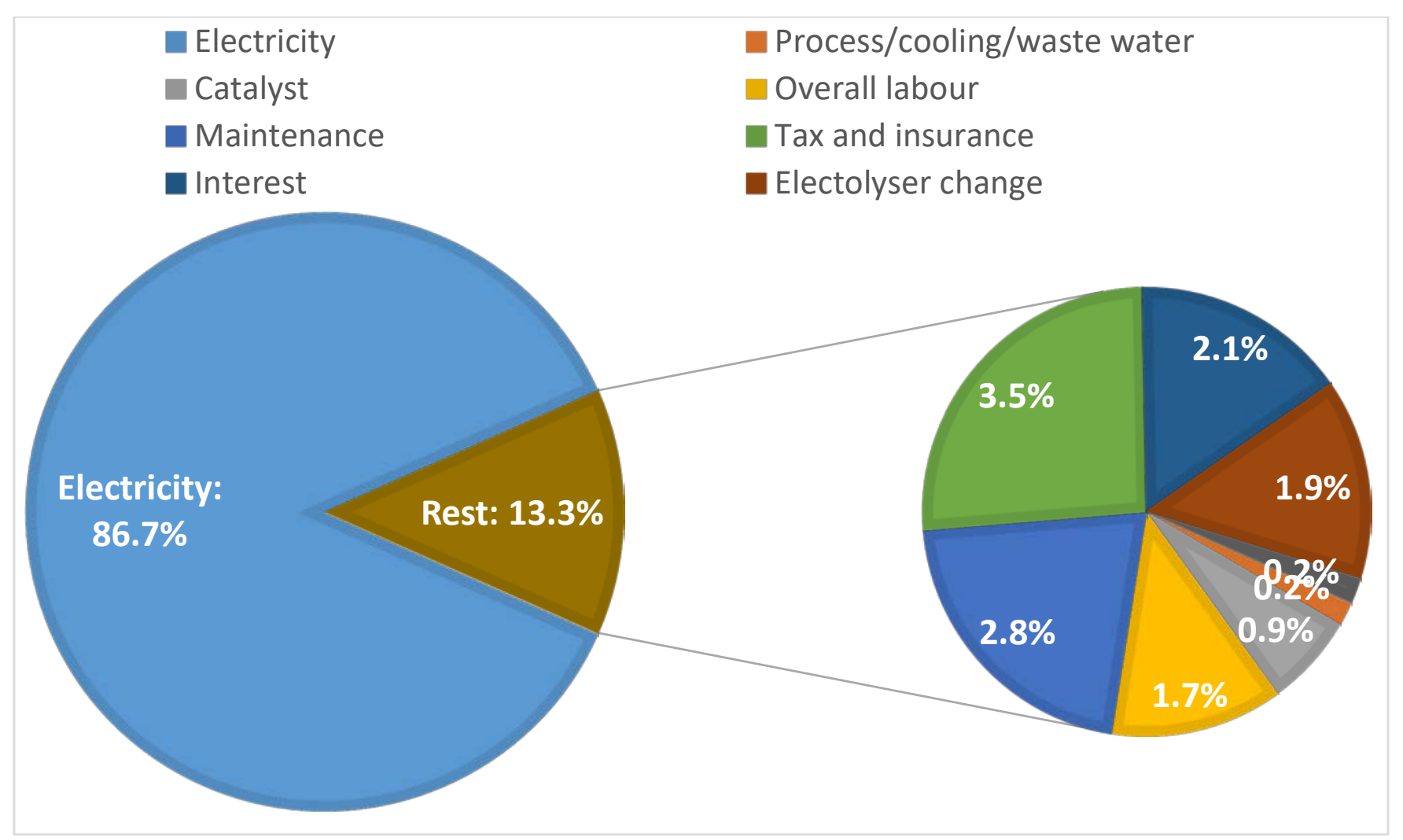

Figure 8. OPEX breakdown

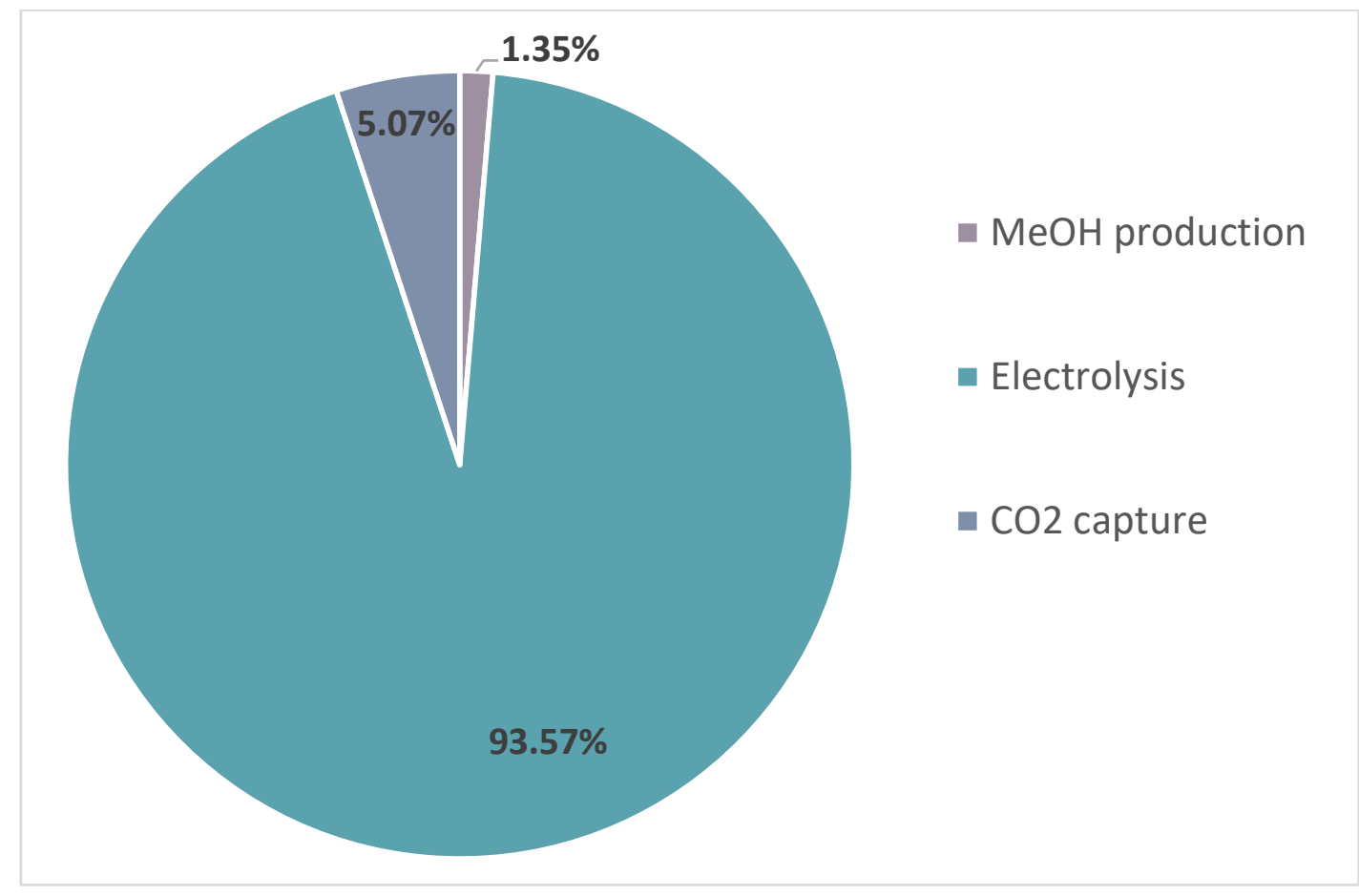

Figure 9. Electricity cost breakdown 
The electrolyser is the main contributor to CapEx accounting for $40 \%$ followed by gas pressure change equipment. The cost of compressors is relatively high because of the high pressure ratios (up to 10) in the $\mathrm{CO}_{2}$ capture unit. In addition, electricity costs dominate OpEx and it can be concluded that the major cost drivers are associated with the electrolysis unit.

\section{Reference to TEA Guidelines}

A checklist of items to be included in each section of the report is included in Chapter $\mathbf{8}$ Reporting of the guidelines, which for the goal is as follows:

\section{Interpretation of the study}

Include and describe the results

Include and describe uncertainty and sensitivity analysis

- State assumptions and limitation associated with the assumptions, methods and interpretation of results

Include conclusions

Include recommendations, if any 


\section{B.8.Interpretation}

\section{B.8.1 Sensitivity analysis}

A local sensitivity analysis was carried out for the proposed plant configuration to identify and rank the plant parameters that most influence the $\mathrm{MeOH}$ minimum selling price. The parametric analysis is carried out by changing one input variable to its low or high value while keeping all other variables at their nominal values. The low and high values were selected based on nominal variations or where possible, estimates and projects. Table 7 illustrates the independent parameters along with their respective lower and upper bounds. A highly optimistic scenario was included for electricity price whereby electricity is supplied for free (e.g. to avoid renewable energy curtailments) and for oxygen price a $\pm 30 \%$ fluctuation can reflect market uncertainties. Electrolyser cost is expected to drop in the near future $[8,22]$ down to $0.5 \mathrm{M} € / \mathrm{MW}$ and technological advances can increase the efficiency up to 85\% [46]. In addition, as electrolyser is the hot spot of the process, the capital cost exponent factor of the electrolyser was fluctuated. Due to insufficient relevant data, the electricity demand for the BOE is also included. According to the AACE International classification, the present $\mathrm{CO}_{2}$ capture plant is of "Class 5 estimate" and an accuracy in the range of $-30 \%$ to $+50 \%$ should be anticipated where the $\mathrm{MeOH}$ and utilities plants can be categorised as "Class 4 estimate" with an accuracy level of $-20 \%$ to $+30 \%$ [47]. Significantly, increased accuracy can only be achieved through acquiring capital cost data from a commercial plant which was not possible. Furthermore, the effect of typical economic parameters, such as tax and interest rates, was investigated.

Table 7. Selected parameters for sensitivity analysis and their bounds

\begin{tabular}{|l|c|c|c|c|}
\hline Parameter & Low value & Nominal & High value & Unit \\
\hline Electricity price & 0 & 87.7 & 114 & $€ / \mathrm{MWh}$ \\
\hline Electrolyser efficiency & 60 & 70 & 85 & $\%$ \\
\hline Electrolyser scaling factor & 0.55 & 0.65 & 0.8 & - \\
\hline BOP electricity demand & 5 & 10 & 20 & \% \\
\hline Oxygen price & 37.94 & 54.2 & 70.46 & M T \\
\hline CAPEX Electrolysis & 0.5 & 1.5 & 2 & $\mathrm{M}$ \\
\hline CAPEX MeOH & 322.5 & 403.12 & 524.06 & $\mathrm{M}$ \\
\hline CAPEX CO 2 capture & 180.64 & 258.05 & 387.08 & $\mathrm{M}$ \\
\hline CAPEX Utilities & 197.76 & 247 & 321.37 & $\%$ \\
\hline Interest rate & 5 & 6 & 8 & $\%$ \\
\hline Tax rate & 0 & 29.72 & 40 & \\
\hline
\end{tabular}

As depicted in Figure 10, three levels of uncertainty can be observed, i.e. high, intermediate and low. Electricity price and electrolyser efficiency raises a significant level of uncertainty while overall capital investment along with the electricity demand for the BOE and the tax rate have a medium effect on the MMSP. Interest rate as well as oxygen price have negligible effect on the MMSP. Overall, it is shown that the most crucial block is the electrolysis unit; in fact, changes in electricity price cause a wide variation to $\mathrm{MeOH}$ price of $-68.1 \%$ to $+20.3 \%$ and electrolyser efficiency causes the price to range between $-11.5 \%$ to $+15.6 \%$ from the nominal value. If excess of electricity can be generated by renewable sources such as wind turbines and that excess is provided free of charge, then the MMSP reduces drastically (447€/t); however still 1.8 times higher than the fossil MeOH price. On top of this, this scenario will raise competition with other technologies and should not be taken for granted. 


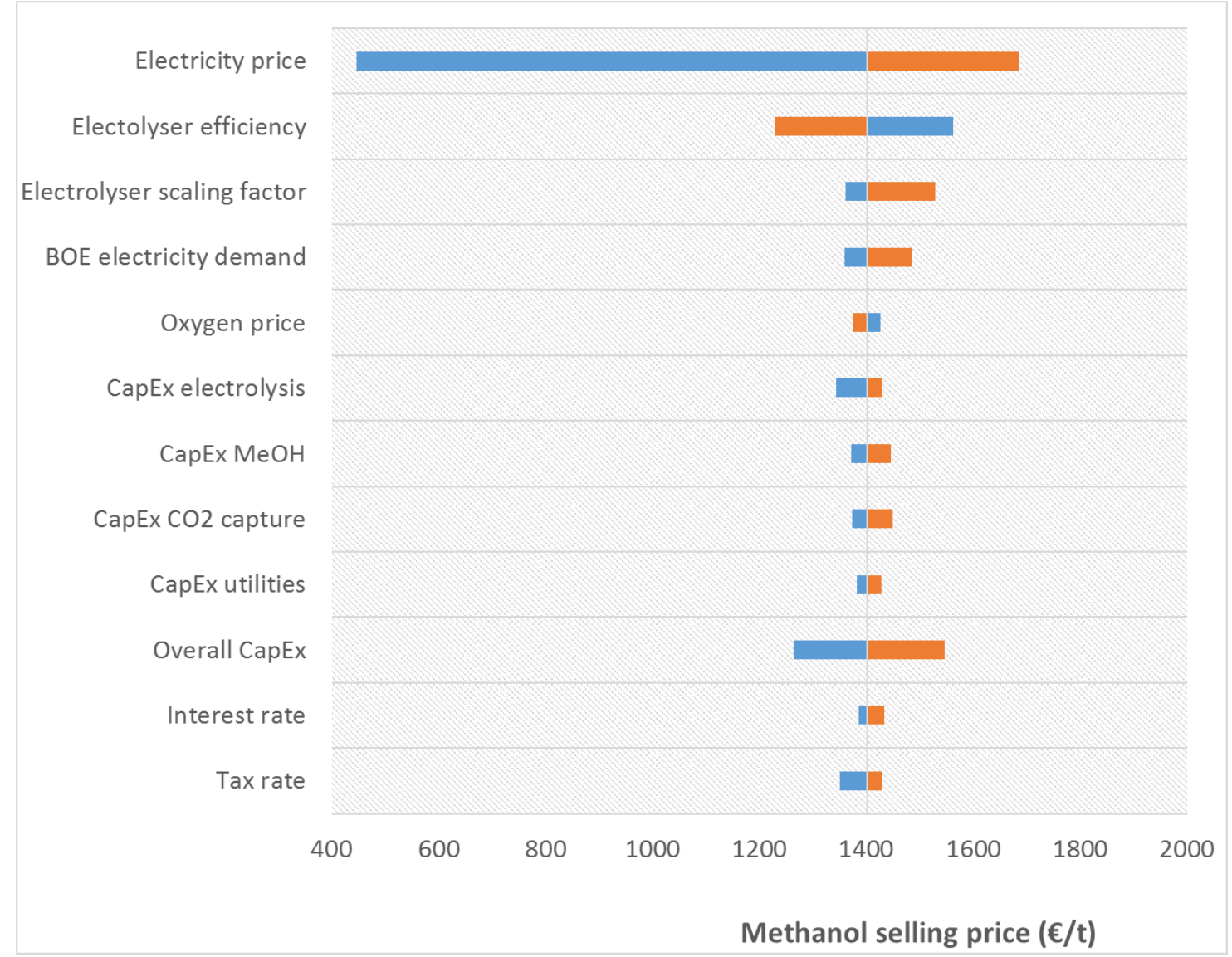

Figure 10. Sensitivities on $\mathrm{MeOH}$ price. When blue bar is on the left a positive correlation is depicted and vice versa

Rather than providing symmetric bounds

to the investigated parameters, ranges

were selected so as to provide realistic

reflections of techno-economic estimates

and/or projections

\section{B.8.2 Uncertainty analysis}

A limitation of local sensitivity analysis (LSA) is that uncertain variables typically are examined one at a time with all other parameters held constant. Thus, interactions among several uncertain parameters may be overlooked. In some cases, several parameter values may be changed simultaneously, for example, as a bounding analysis with parameters set to their maximum or minimum values. However, this provides no information on the likelihood of such extreme outcomes. A complementary approach to LSA is a probabilistic analysis in which distribution functions are assigned to multiple independent variables. The distributions are sampled repeatedly using Monte Carlo (or related) methods to yield a distribution function showing the probability of a specified outcome or result. After identifying the dominant parameters, a Monte Carlo simulation was applied to characterize the effect of uncertainty or variability of these parameters on $\mathrm{MeOH}$ price. The investigated parameters are those mentioned above with the greater/medium effect on $\mathrm{MeOH}$ price. In order to avoid probable correlations, CapEx for electrolysis and $\mathrm{MeOH}$ plant were excluded from the analysis in conjunction with BOE electricity demand; the latter was expressed as a portion of the electrolysis demand and as so it is correlated with the electrolyser efficiency. 
Therefore, the manipulated variables are electricity price, electrolyser efficiency, tax rate and CapEx. Regarding CapEx, the electrolyser cost was included in the analysis in terms of its scaling factor and the $\mathrm{CO}_{2}$ capital costs as it carries higher uncertainty due to low TRL. Based on the practitioner's understanding of the variables in question, the shape for the probability distribution can be selected. Uniform distribution suggests that all values have an equal chance of occurring, and the user simply defines the minimum and maximum; in the present study parameters related to manufacturing costs were assign uniform distributions. Another option is the triangular distribution where the user defines the minimum, most likely, and maximum values. Values around the most likely are more likely to occur and the results of such distributions tend toward the normal or log-normal distributions (preferred by purists). Electricity price, electrolyser efficiency and tax rates were assigned triangular distributions as the deterministic values are the most probable as well.

Figure 11 depicts the cumulative probability functions for two cases; Case 1 reflects the assumed distributions for parameters such as the electricity price which is non-symmetric relative to the nominal deterministic value and is skewed to the left (lower prices) while Case 2 assumes symmetric bounds. The MMSP for Case 1 has mean value of 1,356 $€ / t$ and a $95 \%$ confidence interval of approximately $1,238 € / t$ to $1,448 € / t$. The mean value of Case 2 is closer to the deterministic value, i.e. $1400 € / t$ and the range of a $95 \%$ confidence interval is narrower, 1,343 to $1,458 € / t$. The steepness of the Case 1 curve suggests a smaller value of variance compared to Case 2 . As a result, the probability that the MMSP is lower than the deterministic estimate is much higher for Case 1 than Case 2, i.e. 77\% and 51\% respectively.

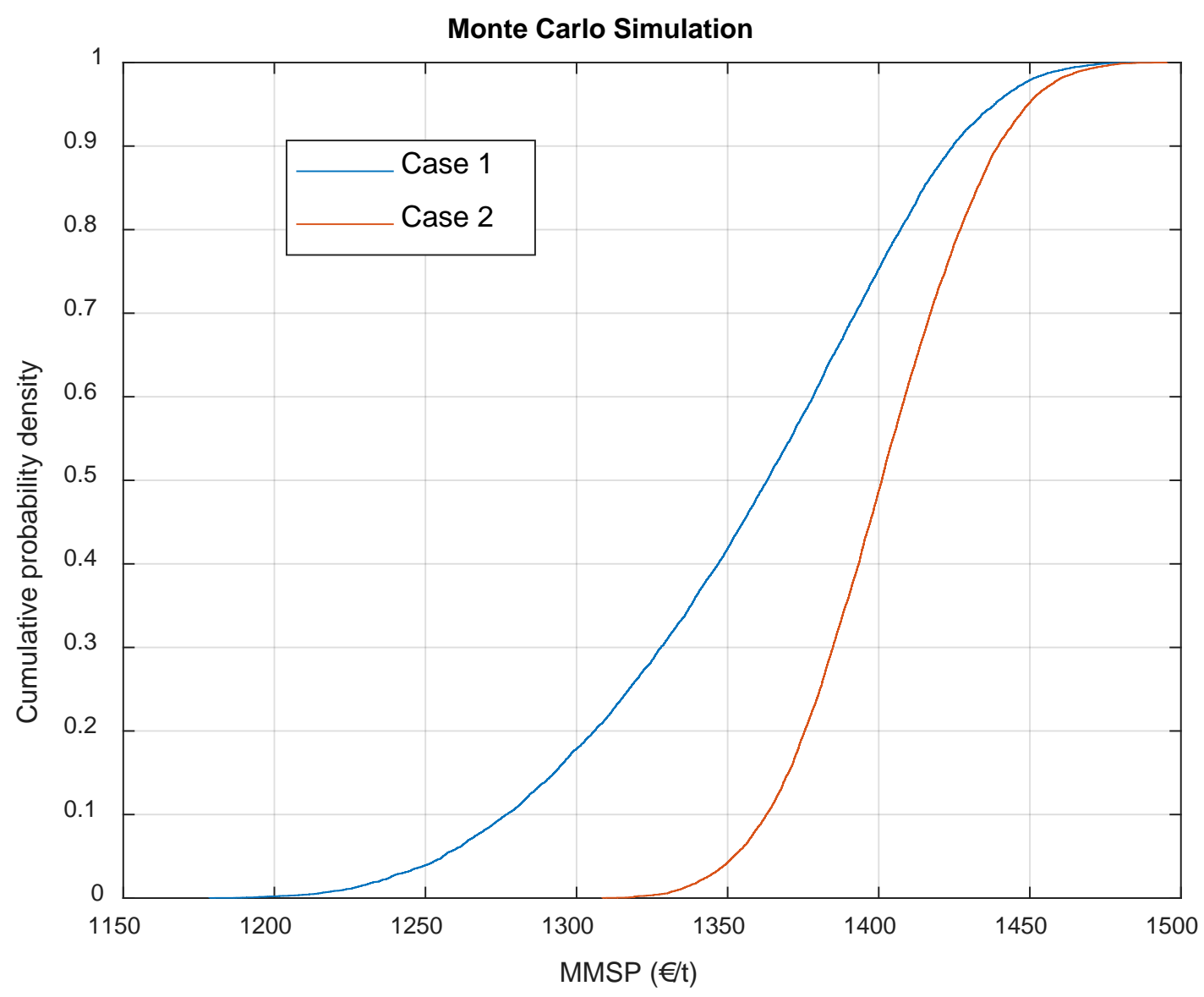

Figure 11. Monte Carlo simulation on MMSP 


\section{Reference to TEA Guidelines}

As suggested in Guideline B.18, quantitative local sensitivity analysis was conducted in conjunction with uncertainty analysis (Monte Carlo simulations). The purpose of the former was to identify key variables and those were subsequently utilised in the UA. As design variable the MMSP was set and confidence intervals were identified.

\section{B.8.3 Development of alternative scenarios}

The base case scenario of the proposed Power to $\mathrm{MeOH}$ assumed a green electricity load from the grid equal to approximately $464 \mathrm{MW}$. Furthermore, sensitivity analysis revealed that electricity price is the chief cost contributor. Renewable energy in Germany is mainly based on wind and solar. As for 2016, the total installed nameplate capacity of wind energy in Germany was 49,600 MW while the respective number for solar power was 40,720 MW [48]. These figures imply that at the current status the proposed plant would have to consume approximately $2.4 \%$ of the wind energy or roughly $3.8 \%$ of the solar; assuming a capacity factor of $40 \%$ for wind turbines and $30 \%$ for photovoltaics [49]. Even if these values can be considered relatively low and can be covered by the existing renewable energy infrastructure, in order to avoid distortion of the current applications and competition with other markets, scenario analysis was performed by expanding the system boundaries. Therefore, two alternative scenarios were developed considering the production of renewable energy within the system boundaries. Renewable electricity is supplied in both cases from wind energy either from an onshore (Scenario 1) or an offshore (Scenario 2) farm. It should be highlighted that the turbines provide power only to electrolysis section $(=450 \mathrm{MW})$ in order to avoid dynamic operation of the $\mathrm{MeOH}$ and $\mathrm{CO}_{2}$ capture units. According to Table 8 (calculation basis can be found in [49]), the installed capacity for the onshore capacity should be 1,128 MW and for the offshore 1,095 MW. Furthermore, the electrolyser was resized in order to exploit the power generated at the maximum achieved capacity factor. A challenge for any Power to X system is the temporary storage of hydrogen necessitated by the fluctuating power supply and consequent intermittent operation of the electrolyser. According to Gahleitner [50], hydrogen in high pressure gas cylinders is the current and future method of choice. The storage unit was not designed or simulated but was attributed a cost. Rough cost estimations for storage tanks can be found in [8] and suggest that for steady state operation of the hydrogen utilisation plant, storage expenditures can be as high as $28 \%$ of the electrolyser cost.

Table 8. Summary of the Land-Based and Offshore wind farms. Costs were brought up to date considering an inflation rate of $2.5 \%$

\begin{tabular}{|l|c|c|}
\hline & Onshore & Offshore \\
\hline Turbine capital cost (€/MW) & $1,140,335$ & $1,382,739$ \\
\hline Balance of system (€/MW) & 311,258 & $2,043,925$ \\
\hline Financial costs (€/MW) & 142,424 & 927,171 \\
\hline Normalised CapEx (€/MW) & $1,594,016$ & $4,353,834$ \\
\hline CapEx (€) & $1,797,762,914$ & $4,766,971,839$ \\
\hline Net capacity factor (\%) & 39.9 & 41.1 \\
\hline Maximum capacity factor (\%) & 95 & 95 \\
\hline Normalised OpEx (€/MW/y) & 48,103 & 183,475 \\
\hline OPEX (€/y) & $54,252,017$ & $200,885,036$ \\
\hline
\end{tabular}


The data of Table 8 was integrated in the economic model of the base case scenario. As depicted in Figure 12, a trade-off between CapEx and OpEx can be observed between the base case study and the alternative scenarios. The MMSP for the Scenario 1 is marginally lower than the case study, i.e. $1380 € / \mathrm{t}$ and $1402 € / \mathrm{t}$ respectively, showcasing benefits associated with minimizing electricity costs; however, the high initial investment can be unattractive for decision makers and/or potential investors. The offshore wind energy scenario come at very high costs mainly due to immature technologies and development constraints. It should be noted that a crucial factor, that has not been taken into consideration here, for the penetration of wind energy is land availability.

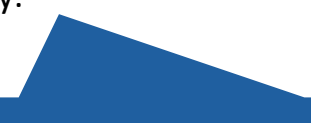

This section serves to demonstrate the effect of expanding the system boundaries rather than provide a realistic scenario. In particular for Germany, a Power to X plant is more probable to be installed in the northern area as the existing power infrastructure might be unable to transport the energy and exploit offshore wind energy.

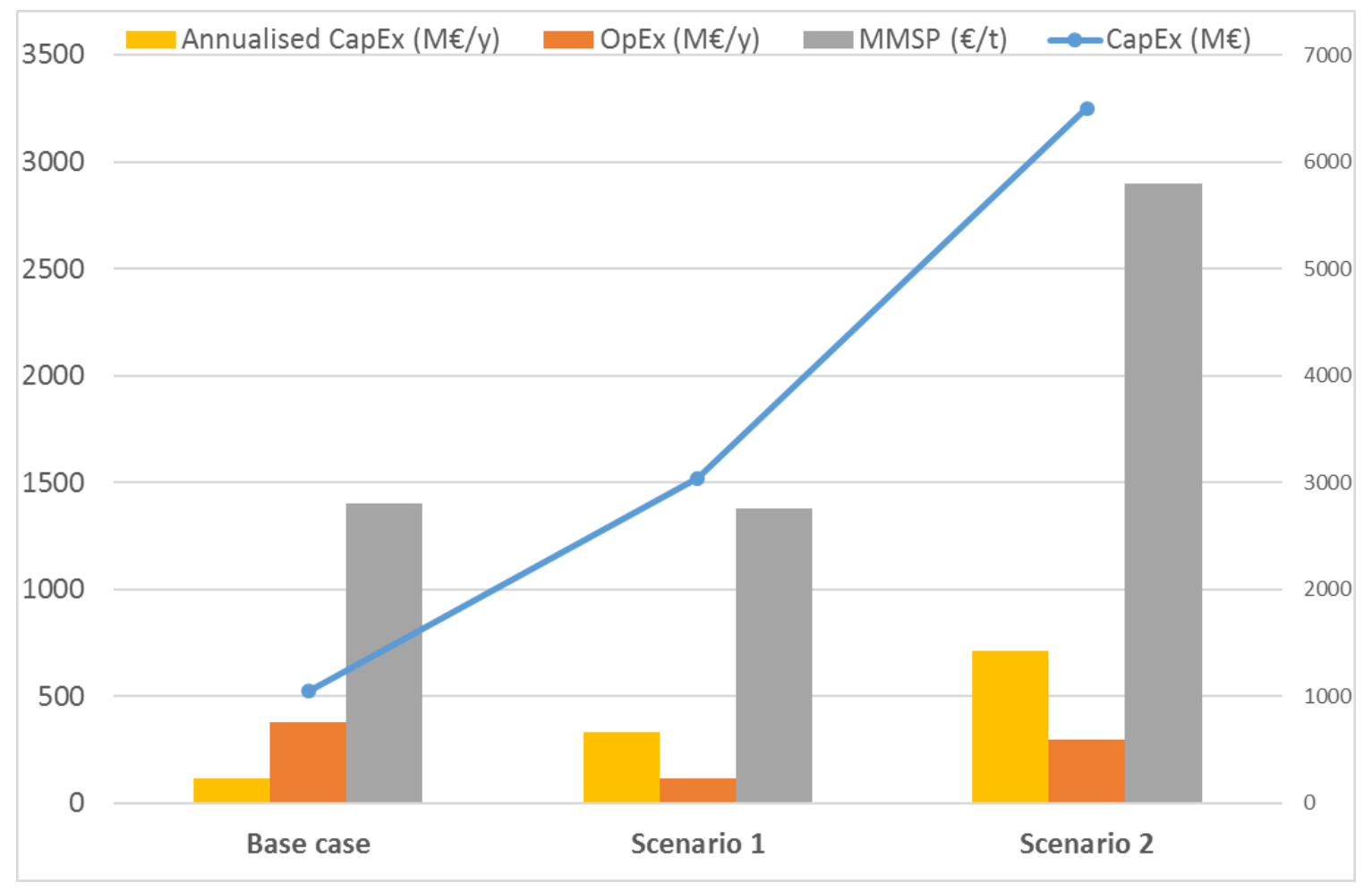

Figure 12. CapEx (right axis), Annualised CapEx OpEx and MMSP for the investigated scenarios

\section{Reference to TEA Guidelines}

As suggested in Guideline B.2, scenario analysis was conducted based on hot spot identification. Electricity price poses as the major cost driver and consequently alternative scenarios investigating different electricity supplies were developed. 


\section{B.8.4 Interpretation of Indicators}

The designed plant in the present situation does not produce any profit. The revenue obtained from selling $\mathrm{MeOH}$ and $\mathrm{O}_{2}$ does not cover the cost of the electricity needed for generating the required $\mathrm{H}_{2}$. The proposed CCUS MeOH plant is not an attractive investment with a discount rate of $9 \%$. The following sensitivity analyses verify the effect of changes in electricity price, electrolyser efficiency and overall CapEx on the financial aspect of the proposed plant. Comparing the bars in Figure 10 it can be concluded, that the electricity price has the greatest impact on the NPV. In order to have a NPV $=0$ the market price of MeOH should increase approximately more than 5 times. The high electricity consumption indicates that efforts should be focused on improving the efficiency of the electrolyser unit. Solid oxide electrolysers, could be a more efficient way of obtaining the necessary $\mathrm{H}_{2}$ as they consume less energy; however they are still at development stage.

\section{Reference to TEA Guidelines}

In accordance with Guideline B.19, scenario analysis was conducted based on hot spot identification. Electricity price poses as the major cost driver and consequently alternative scenarios investigating different electricity supplies were developed.

\section{B.9.Concluding remarks}

This report assessed the economic viability of a Power to $\mathrm{MeOH}$ concept through $\mathrm{CO}_{2}$ hydrogenation. A generic modelling platform was successfully established in Aspen Plus using coherent data to establish mass and energy balances for a subsequent economic assessment. The deterministic MMSP is $1402 € / t$ and there is a confidence interval of $95 \%$ that the MMSP is in the range of $1,238 € / t$ to $1,448 € / t$. These figures are 4.9-5.8 fold greater than the fossil $\mathrm{MeOH}$ price. Sensitivity analysis revealed that the process is OpEx intensive with electricity price to pose as the major cost component. In fact, the factors that mostly affect the MMSP are associated with the electrolysis unit, i.e. electricity price and electrolyser efficiency rather than with variables related to the $\mathrm{CO}_{2}$ conversion plant. A free of charge electricity supply will result in a competitive $\mathrm{MeOH}$ price; however, this will probably be unrealistic due to competition with other technological options of Power to X and beyond (e.g. exporting energy). Generation of positive NPV is not possible under the current technological and market status. Nevertheless, several technology and market developments can significantly improve the economics of the modelled processes. If energy independence and security are prioritised and societies begin to place a meaningful monetary burden on carbon-intensive technologies, these developments could accelerate the adoption of sustainable products such as the investigated $\mathrm{MeOH}$.

\section{Reference to TEA Guidelines}

Following Guideline B.21, the report states and analyses the entire spectrum of elements of the checklist. Overall, the present study highlights the importance of a standardised approach for conducting TEA for CCU technologies in a transparent and reproducible manner, enabling direct comparisons of the broad range of technologies that can result the same product. The study is a worked example that demonstrates how these guidelines can be followed. 


\section{B.10. References}

1. Bertau M, Effenberger FX, Keim W, Menges G, Offermanns H. MeOH Needs More Attention as a Fuel and Raw Material for the Future. Chem-Ing-Tech. 2010;82(12):2055-8.

2. Bertau M, Offermanns H, Plass L, Schmidt F, Wernicke HJ. MeOH: The Basic Chemical and Energy Feedstock of the Future: Asinger's Vision Today: Springer Berlin Heidelberg; 2014.

3. Chapter $1-\mathrm{MeOH}$ Production and Applications: An Overview

4. Chapter 22 - MeOH Economy: Environment, Demand, and Marketing With a Focus on the Wasteto-MeOH Process

5. Sheldon D. MeOH Production \&\#8208; A Technical History. Johnson Matthey Technology Review. 2017;61(3):172-82.

6. Methanex. Methanex posts regional contract MeOH prices for North America, Europe and Asia. Retrieved in March 2018 from: https://www.methanex.com/our-business/pricing

7. Shamsul NS, Kamarudin SK, Rahman NA, Kofli NT. An overview on the production of bio-MeOH as potential renewable energy. Renewable and Sustainable Energy Reviews. 2014;33:578-88.

8. Götz M, Lefebvre J, Mörs F, McDaniel Koch A, Graf F, Bajohr S, et al. Renewable Power-to-Gas: A technological and economic review. Renewable Energy. 2016;85:1371-90

9. Pérez-Fortes M, Tzimas E. JRC Science for Policy Report - Techno-economic and environmental evaluation of $\mathrm{CO} 2$ utilisation for fuel production (Synthesis of $\mathrm{MeOH}$ and formic acid), in: European Commission - JRC Science for Policy Report, 2016, pp. tt.

10. Buddenberg T, Bergins C, Schmidt S. Power to fuel as a sustainable business model for crosssectorial energy storage in industry and power plants, in: $5^{\text {th }}$ Conference on Carbon Dioxide as Feedstock for Fuels, Chemistry and Polymers, Cologne, Germany, 2016.

11. CArbon-free Electricity by SEWGS: Advanced materials, Reactor-, and process design. European best practice guidelines for assessment of CO2 capture technologies, 2011.

12. Walas SM. Chemical Process Equipment: Selection and Design: Butterworth-Heinemann; 1988.

13. Brian B. Guidelines for Estimating Unmetered Industrial Water Use. Pacific Northwest National Laboratory, 2011.

14. Vatopoulos K, Tzimas E. Assessment of CO2 capture technologies in cement manufacturing process. Journal of Cleaner Production. 2012;32:251-61.

15. Hassan SMN, Douglas PL, Croiset E. Techno-Economic Study of CO2 Capture from an Existing Cement Plant Using MEA Scrubbing. International Journal of Green Energy. 2007;4(2):197-220.

16. Scholes CA, Ho MT, Aguiar AA, Wiley DE, Stevens GW, Kentish SE. Membrane gas separation processes for $\mathrm{CO} 2$ capture from cement kiln flue gas. International Journal of Greenhouse Gas Control. 2014;24:78-86.

17. He X, Hägg M-B. Energy Efficient Process for CO2 Capture from Flue gas with Novel Fixedsite-carrier Membranes. Energy Procedia. 2014;63:174-85.

18. Zhang X, He X, Gundersen T. Post-combustion Carbon Capture with a Gas Separation Membrane: Parametric Study, Capture Cost, and Exergy Analysis. Energy \& Fuels. 2013;27(8):4137 19. He X, Fu C, Hägg M-B. Membrane system design and process feasibility analysis for $\mathrm{CO} 2$ capture from flue gas with a fixed-site-carrier membrane. Chemical Engineering Journal. 2015;268:1 20. Pascu A, Badea A, Dinca C, Stoica L. Simulation of polymeric membrane in Aspen Plus for CO 2 post-combustion capture. 4th International Conference on Engineering Optimization Volume: Engineering Optmization, 2014.

21. Belaissaoui B, Le Moullec Y, Willson D, Favre E. Hybrid membrane cryogenic process for postcombustion CO2 capture. Journal of Membrane Science. 2012;415-416:424-34.

22. Carmo M, Fritz DL, Mergel J, Stolten D. A comprehensive review on PEM water electrolysis. International Journal of Hydrogen Energy. 2013;38(12):4901-34.

23. Hank C, Gelpke S, Schnabl A, White RJ, Full J, Wiebe N, et al. Economics \& Carbon Dioxide Avoidance Cost of $\mathrm{MeOH}$ Production based on Renewable Hydrogen and recycled Carbon Dioxide Power-to-MeOH. Sustainable Energy \& Fuels. 2018. 
24. Teichmann D, Stark K, Muller K, Zottl G, Wasserscheid P, Arlt W. Energy storage in residential and commercial buildings via Liquid Organic Hydrogen Carriers (LOHC). Energy \& Environmental Science. 2012;5(10):9044-54.

25. Atsonios K, Panopoulos KD, Kakaras E. Investigation of technical and economic aspects for $\mathrm{MeOH}$ production through CO2 hydrogenation. International Journal of Hydrogen Energy. 2016;41(4):2202-14.

26. SILYZER 200 High-pressure efficiency in the megawatt range. Retrieved in March 2018 from: https://www.industry.siemens.com/topics/global/en/pem-electrolyzer/silyzer/Documents/2017-04Silyzer200-boschure-en.pdf.

27. Van-Dal ÉS, Bouallou C. Design and simulation of a MeOH production plant from $\mathrm{CO} 2$ hydrogenation. Journal of Cleaner Production. 2013;57:38-45.

28. Pérez-Fortes M, Schöneberger JC, Boulamanti A, Tzimas E. MeOH synthesis using captured CO2 as raw material: Techno-economic and environmental assessment. Applied Energy. 2016;161:718-32.

29. Kiss AA, Pragt JJ, Vos HJ, Bargeman G, de Groot MT. Novel efficient process for MeOH synthesis by CO2 hydrogenation. Chemical Engineering Journal. 2016;284:260-9.

30. Nag PK. Engineering Thermodynamics, 5e: McGraw Hill Education.

31. Vanden Bussche KM, Froment GF. A steady-state kinetic model for MeOH synthesis and the water gas shift reaction on a commercial Cu/ZnO/Al2O3 catalyst. Journal of Catalysis. 1996;161(1):1-10.

32. Mignard D, Sahibzada M, Duthie JM, Whittington HW. MeOH synthesis from flue-gas $\mathrm{CO} 2$ and renewable electricity: a feasibility study. International Journal of Hydrogen Energy. 2003;28(4):455-64.

33. Cost Data On Line Inc., 2008. Richardson International Construction Factors Manual [Internet]. Pahrump, NV; Available from: http://www.icoste.org/BookReviews/CFM-Info.pdf.

34. M. Swanson R, Platon A, Satrio J, Brown R, D. Hsu D. Techno-Economic Analysis of Biofuels Production Based on Gasification2010.

35. Colella WG, James BD, Moton JM, Saur G, Todd Ramsden T. Techno-economic Analysis of PEM Electrolysis for Hydrogen Production. Electrolytic Hydrogen Production Workshop NREL, Golden, Colorado.

36. Ruth Mark, Ramsden Todd. Current (2009) state-of-the-art hydrogen production cost estimate using water electrolysis. Independent Review Published for the U.S. Department of Energy Hydrogen Program. NREL/BK-6A1e46676. September 2009.

37. Rubin ES. Evaluating the Cost of Emerging Technologies. Presentation to the Climit workshop on emerging CO2 capture technologies. Oslo: Climit; 2016.

38. Rubin ES. Seven Simple Steps to Improve Cost Estimates for Advanced Carbon Capture Technologies. Presentation to the DOE transformational carbon capture technology workshop. Pittsburgh, Pa: DOE NETL; 2014.

39. van der Spek M, Ramirez A, Faaij A. Challenges and uncertainties of ex ante techno-economic analysis of low TRL CO2 capture technology: Lessons from a case study of an NGCC with exhaust gas recycle and electric swing adsorption. Applied Energy. 2017;208:920-34.

40. Greig C, Garnett A, Oesch J, Smart S. Guidelines for Scoping and Estimating Early Mover CCS Projects, Brisbane, 2014.

41. Couper J. R., Process Engineering Economics New York, Basel: Marcek Dekker, Inc., 2003.

42. Turton R, Bailie RC, Whiting WB, Shaeiwitz JA. Analysis, Synthesis and Design of Chemical Processes: Pearson Education; 2008.

43. Bureau of Labor Statistics - Netherlands. International Labor Comparisons. Retrieved in Feb 2018 from: https://www.bls.gov/fls/country/netherlands.htm

44. Towler G, Sinnott R. Chapter 9-Economic Evaluation of Projects. Chemical Engineering Design (Second Edition). Boston: Butterworth-Heinemann; 2013. p. 307-54.

45. KPMG Corporate tax rates table. Retrieved in Feb 2018 from:

https://home.kpmg.com/xx/en/home/services/tax/tax-tools-and-resources/tax-rates-online/corporatetax-rates-table.html

46. Saba SM, Müller M, Robinius M, Stolten D. The investment costs of electrolysis - A comparison of cost studies from the past 30 years. International Journal of Hydrogen Energy. 2018;43(3):1209-23.

47. P. Christensen, L. R. Dysert, J. Bates, D. Burton, R. C. Creese, J. Hollmann, Cost Estimate Classification system-as applied in engineering, procurement, and construction for the process industries 
48. Net installed electricity generation capacity in Germany. Retrieved in March 2018 from: https://www.energy-charts.de/power inst.htm

49. US Energy Information Administration. Retrieved in March 2018 from: https://www.eia.gov/electricity/monthly/current month/epm.pdf

50. Mone C, Hand M, Bolinger M, Rand J, Heimiller D, Ho J. 2015 Cost of Wind Energy Review, Technical Report NREL/TP-6A20-66861.

51. Gahleitner G. Hydrogen from renewable electricity: An international review of power-to-gas pilot plants for stationary applications. International Journal of Hydrogen Energy. 2013;38(5):2039-61.

52. Kourkoumpas DS, Papadimou E, Atsonios K, Karellas S, Grammelis P, Kakaras E. Implementation of the Power to $\mathrm{MeOH}$ concept by using $\mathrm{CO} 2$ from lignite power plants: Techno-economic investigation. International Journal of Hydrogen Energy. 2016;41(38):16674-87.

53. Eric D. Larson HJ, Fuat E. Celik. Gasification-Based Fuels and Electricity Production from Biomass, without and with Carbon Capture and Storage. 2005

54. Kreutz T, Larson E, Liu G, Williams R. Fischer-Tropsch fuels from coal and biomass. New Jersey: Princeton Environmental Institute, Princeton University; 2008

55. DOE-NETL. Cost and performance baselines for fossil energy plants, Volume 1. DOE; 2007

56. Atsonios K, Koumanakos A, Panopoulos KD, Doukelis A, Kakaras E. Techno-economic comparison of $\mathrm{CO} 2$ capture technologies employed with natural gas derived GTCC. 2013

57. Chen C. A Technical and Economic Assessment of CO2 Capture Technology for IGCC Power Plants. Carnegie Mellon University 2005

58. Sadhukhan J, Ng KS, Hernandez EM. Economic Analysis. Biorefineries and Chemical Processes: John Wiley \& Sons, Ltd; 2014. p. 43-61.

59. McGivney W, Kawamura S. Cost Estimating Manual for Water Treatment Facilities: John Wiley \& Sons; 2008.

60. Bellotti D, Rivarolo M, Magistri L, Massardo AF. Feasibility study of MeOH production plant from hydrogen and captured carbon dioxide. Journal of CO2 Utilization. 2017;21:132-8.

61. Turi DM, Ho M, Ferrari MC, Chiesa P, Wiley DE, Romano MC. CO2 capture from natural gas combined cycles by $\mathrm{CO} 2$ selective membranes. International Journal of Greenhouse Gas Control. 2017;61:168-83.

62. Towler G, Sinnott R. Chapter 8 - Estimating Revenues and Production Costs. Chemical Engineering Design (Second Edition). Boston: Butterworth-Heinemann; 2013. p. 355-87.

63. Eurostat File:Electricity prices. Retrieved in Feb 2018 from:

http://ec.europa.eu/eurostat/statistics-

explained/index.php/File:Electricity prices, first half of year, 2015-2017.png

64. Okeke, I. J. and S. Mani (2017). "Techno-economic assessment of biogas to liquid fuels conversion technology via Fischer-Tropsch synthesis." Biofuels, Bioproducts and Biorefining 11(3): 472-487.

65. Peters M, Timmerhaus K, West R (2003) Plant Design and Economics for Chemical Engineers. McGraw-Hill Education

66. Towler G, Sinnott R. Chapter 7 - Capital Cost Estimating. Chemical Engineering Design (Second Edition). Boston: Butterworth-Heinemann; 2013. p. 307-54.

67. Perry RH, Green DW. Perry's chemical engineers' handbook. 8th ed. New York: McGraw-Hill; 2008 


\section{Appendix A - Simulation results}

Table A.1. Data extracted from simulations

\begin{tabular}{|c|c|c|}
\hline Parameter & Value & Unit \\
\hline \multicolumn{3}{|l|}{ Electrolysis } \\
\hline Deionised water & 80.85 & $\mathrm{t} / \mathrm{h}$ \\
\hline Oxygen & 68.2 & $\mathrm{t} / \mathrm{h}$ \\
\hline $\mathrm{H}_{2}$ & 8.594 & $\mathrm{t} / \mathrm{h}$ \\
\hline Electricity for electrolysis & 450.12 & $\mathrm{MW}$ \\
\hline Cooling duties & 2.81 & $\mathrm{MW}$ \\
\hline Cooling water (circulated) & 248 & $\mathrm{t} / \mathrm{h}$ \\
\hline Cooling water (make up) & 12 & $\mathrm{t} / \mathrm{h}$ \\
\hline Waste water & 4 & $\mathrm{t} / \mathrm{h}$ \\
\hline \multicolumn{3}{|l|}{ MeOH plant } \\
\hline $\mathrm{CO}_{2}$ input & 62.09 & $t / h$ \\
\hline $\mathrm{CO}_{2}$ output & 3.32 & $t / h$ \\
\hline MeOH output & 42.78 & $\mathrm{t} / \mathrm{h}$ \\
\hline Cooling duties & 43.13 & $\mathrm{MW}$ \\
\hline Heating duties* & 31.3 & $\mathrm{MW}$ \\
\hline Electricity consumption & 9.73 & $\mathrm{MW}$ \\
\hline Electricity generation & 5 & $\mathrm{MW}$ \\
\hline Net electricity demand & 4.73 & $\mathrm{MW}$ \\
\hline Cooling water (circulated) & 3806 & $t / h$ \\
\hline Cooling water (make up) & 190.3 & $\mathrm{t} / \mathrm{h}$ \\
\hline Boiler water (circulated) & 6.4 & $\mathrm{t} / \mathrm{h}$ \\
\hline Boiler water (make up) & 1.6 & $\mathrm{t} / \mathrm{h}$ \\
\hline Air & 20 & $\mathrm{t} / \mathrm{h}$ \\
\hline Catalyst loading & 35 & $\mathrm{t} / \mathrm{y}$ \\
\hline Waste water & 24 & $\mathrm{t} / \mathrm{h}$ \\
\hline \multicolumn{3}{|l|}{$\mathrm{CO}_{2}$ Capture } \\
\hline Flue gas & 224.27 & $\mathrm{t} / \mathrm{h}$ \\
\hline $\mathrm{CO}_{2}$ input & 71.39 & $t / h$ \\
\hline $\mathrm{CO}_{2}$ capture & 86.979 & $\%$ \\
\hline Electricity consumption & 16.86 & MW \\
\hline Electricity generation & 7.89 & $\mathrm{MW}$ \\
\hline Net electricity demand & 8.97 & $\mathrm{MW}$ \\
\hline Cooling duty & 16.1 & $\mathrm{MW}$ \\
\hline Cooling water (circulated) & 1421 & $\mathrm{t} / \mathrm{h}$ \\
\hline Cooling water (make up) & 71.05 & $\mathrm{t} / \mathrm{h}$ \\
\hline Waste water & 9 & $\mathrm{t} / \mathrm{h}$ \\
\hline *Fully integrated & & \\
\hline
\end{tabular}




\section{Appendix B - Data for economic evaluation}

Table B.1. Equipment cost data

\begin{tabular}{|c|c|c|c|c|c|c|c|}
\hline Process unit section & Reference cost (M€) & Design variable & Unit & Reference size & Scaling factor & Reference year & Reference \\
\hline $\mathrm{MeOH}$ reactor & 7.69 & Feed gas & $t / h$ & 87.5 & 0.6 & 2006 & 52 \\
\hline Heat exchangers & 39.26 & Heat duty & MWth & 355 & 1 & 2007 & 53 \\
\hline Distillation unit & 16.58 & MeOH flow rate & $t / h$ & 87.5 & 0.7 & 2006 & 52 \\
\hline Compressors & 12.08 & Power & MWe & 10 & 0.67 & 2006 & 54 \\
\hline Cooling system & 49.6 & $Q$ rejected & MWth & 470 & 0.67 & 2007 & 55 \\
\hline Pump & 14.77 & Power & MWe & 47.61 & 0.67 & 2011 & 56 \\
\hline Flash tank & 0.983 & Gas feed & $t / s$ & 1 & 0.8 & 2000 & 57 \\
\hline Gas turbine & 20.98 & Power & MWe & 16.1 & 0.8 & 2001 & 58 \\
\hline Steam turbine & 4.44 & Power & MWe & 4.1 & 0.8 & 2001 & 58 \\
\hline Wastewater & 7.15 & Flowrate & Millions gallons & 1 & 0.6174 & 2007 & 59 \\
\hline Electrolyser & 1.5 & Power installed & MW & 1 & 0.65 & 2015 & 36,60 \\
\hline Membrane Housing & 0.189 & Area & $\mathrm{m}^{2}$ & 2000 & 0.7 & 2015 & 61 \\
\hline Membrane cost & $37.75 € / \mathrm{m}^{2}$ & & & & & & 61 \\
\hline
\end{tabular}

Table B.2. Prices for variable costs

\begin{tabular}{llll}
\hline Parameter & Price & Unit & Reference \\
\hline Cooling water & 0.025 & $€ / \mathrm{t}$ & 62 \\
Process water & 1 & $€ / \mathrm{t}$ & 62 \\
Catalyst & 95.2 & $€ / \mathrm{kg}$ & 9 \\
Electricity & 87.7 & $€ / \mathrm{MWh}$ & 63 \\
Oxygen & 54.2 & $€ / \mathrm{t}$ & 9 \\
Waste water disposal & 0.4 & $€ / \mathrm{t}$ & 64 \\
\hline
\end{tabular}

Table B.3. Methodology for fixed costs $[62,65]$

\begin{tabular}{ll}
\hline Parameter & Price \\
\hline Supervision & $0.25 \times$ Labour \\
Direct overhead & $0.5 \times($ Labour + supervision $)$ \\
General overhead & $0.65 \times($ Labour + supervision + direct $)$ \\
Maintenance materials & $0.03 \times \mathrm{ISBL}$ \\
Interest & Debt interest $\times \mathrm{WC}$ \\
Insurance and tax & $0.015 \times \mathrm{FCl}$ \\
\hline
\end{tabular}

Insurance and tax $\quad 0.015 \times \mathrm{FC}$ 


\section{Appendix C - Methodology for CapEx}

Table C.1. Total Capital Investment (TCI) estimation methodology [65,66,67]

\begin{tabular}{l|l}
\hline Cost component & Lang factor \\
\hline Purchased Equipment Cost (PEC) & 1 \\
Purchased Equipment Installation & 0.39 \\
Instrumentation and controls & 0.26 \\
Piping & 0.31 \\
Electrical Systems & 0.1 \\
Buildings (including services) & 0.29 \\
Yard Improvements & 0.12 \\
\hline ISBL & $2.47 \times \mathrm{PEC}$ \\
\hline OSBL & $0.12 \times \mathrm{ISBL}$ \\
\hline Engineering and Supervision & $0.32-0.5 \times(\mathrm{ISBL}+\mathrm{OSBL})$ \\
Construction Expenses & 0.34 (ISBL+OSBL) \\
Legal Expenses & $0.04 \times(\mathrm{ISBL}+\mathrm{OSBL})$ \\
\hline Contractor's Fee & $0.19 \times(\mathrm{ISBL}+\mathrm{OSBL})$ \\
\hline Indirect costs (IC) & $\mathbf{0 . 8 9 - 1 . 0 7 \times ( I S B L + O S B L )}$ \\
\hline Project Contingency & $0.15-0.4 \times(\mathrm{ISBL}+\mathrm{OSBL}+\mathrm{IC})$ \\
\hline Process Contingency & $0.05-0.5 \times(\mathrm{ISBL}+\mathrm{OSBL}+\mathrm{IC})$ \\
\hline Fixed Capital Investment (FCI) & Contingencies+ISBL+OSBL+IC \\
\hline Working Capital (WC) & $0.15 \times \mathrm{FCl}$ \\
\hline Total Capital Investment (TCI) & $\mathrm{FCl}+\mathrm{WC}$ \\
\hline When an interva is mentioned, the first value refers to the high TRL & \\
\hline
\end{tabular}

When an interval is mentioned, the first value refers to the high TRL technologies whereas the second one to low TRL systems 
Authors Part C: $\quad$ Ana Villa-Zaragoza, Peter W Sanderson, Katy Armstrong, Peter Styring

Reviewed by: Leonard Müller, Marvin Bachmann, André Sternberg, André Bardow

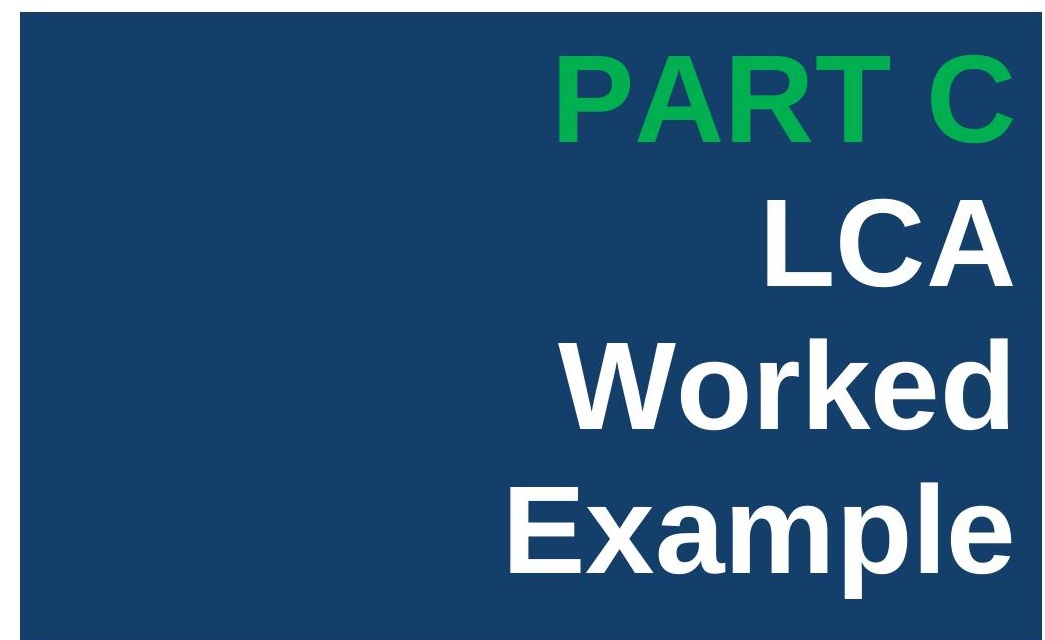


THIS LCA WORKED EXAMPLE USES A FICTIONAL MODEL PRODUCED SOLELY TO ASSIST IN THE USE AND INTERPRETATION OF THE ACCOMPANYING LCA GUIDELINES. THE FOLLOWING LCA WORKED EXAMPLE HAS THEREFORE NOT UNDERGONE AN EXTERNAL REVIEW IN ACCORDANCE WITH ISO 14040/14044 AND CONSEQUENTLY IT SHOULD NOT BE USED IN COMPARISONS OF OTHER LIFE CYCLE ASSESSMENTS OF CCU AND/OR METHANOL TECHNOLOGIES. 


\section{Contents}

Contents

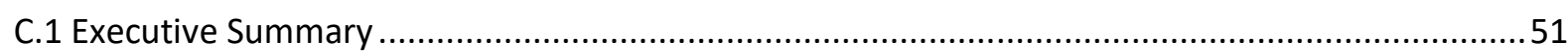

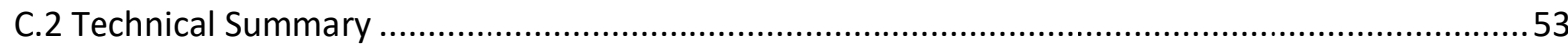

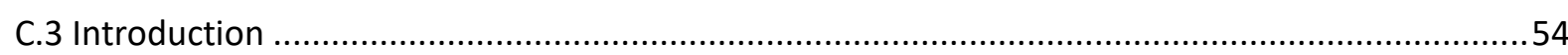

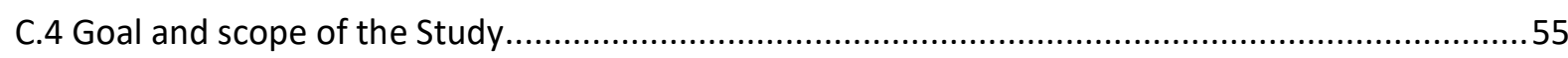

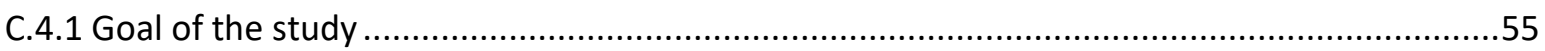

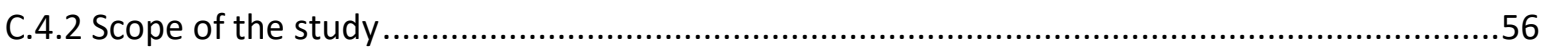

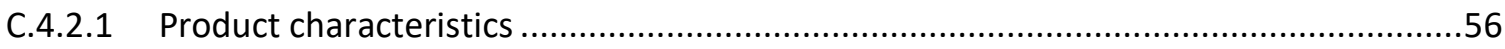

C.4.2.2 System diagrams, completeness requirements and related cut-offs.........................57

C.4.2.3 Geographical and time related representativeness............................................60

C.4.2.4 Solving multi-functionality and defining the functional unit .....................................62

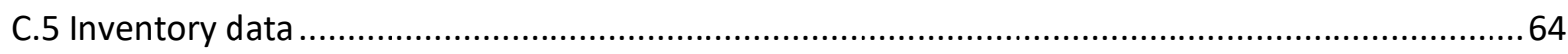

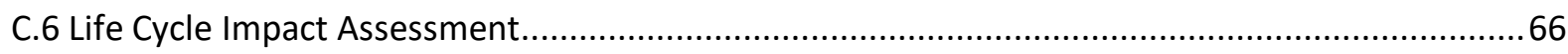

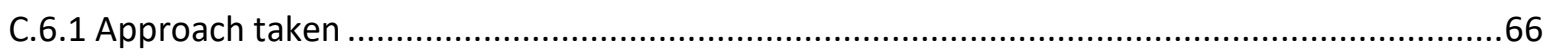

C.6.2 Results of methanol production impact assessment..............................................67

C.6.2.1 Conventional methanol vs CCU methanol production in Germany ..............................67

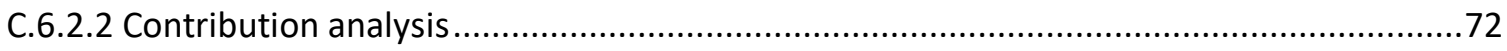

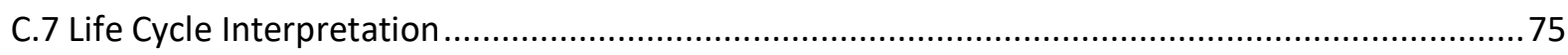

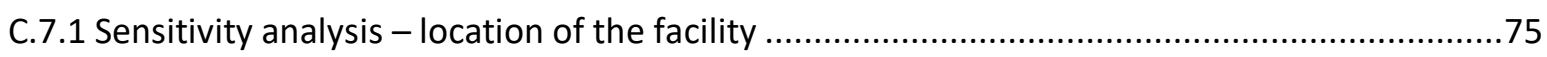

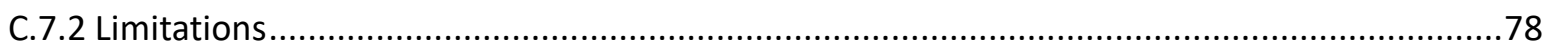

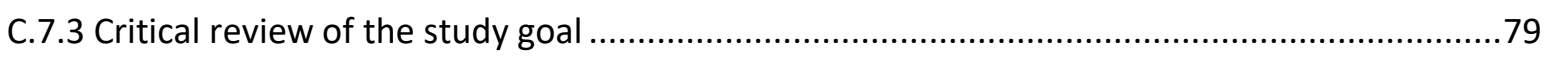

C.7.4 Interpretation and recommendations from a CCU perspective .....................................80

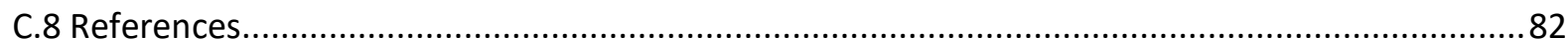

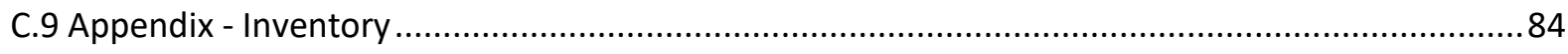

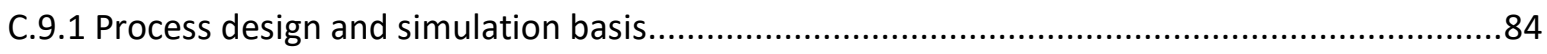

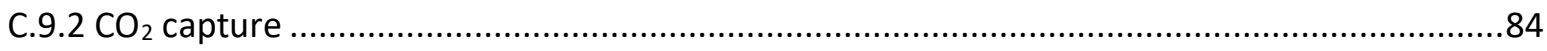

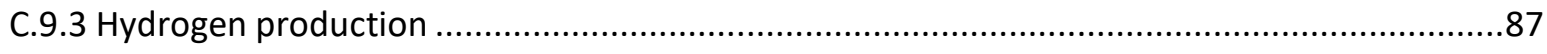

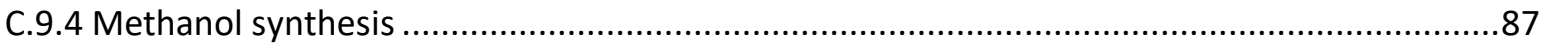

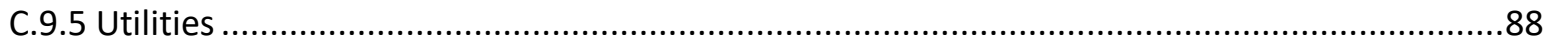

C.9.6 Inventory data sets for the main process inputs .................................................. 91 


\section{C.1 Executive Summary}

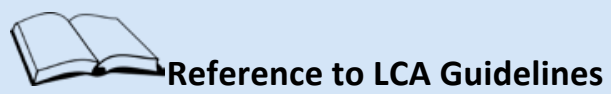

The LCA guidelines do not have a specific section covering what should be included within the executive summary, because this is not particular to CCU. However, a checklist of items to be included in the executive summary is included in Section C.8 Reporting of the guidelines, which is as follows:

\section{Checklist - Executive summary}

\section{Goal of the study}

$\square$ State the intended application of the study

State the reasons for carrying out the study

State the intended audience of the study

State whether the results are to be used in comparative assertions disclosed to public

$\square$ State unambiguously the research question(s)

- State the classification of the assessed CCU technology

\section{Scope of the study}

State functional unit clearly and unambiguously according to guideline and report changes due to solving of multi-functionality

$\square$ State system boundaries according to guideline

$\square$ State relevant issues with data quality and assumptions

State technology readiness level (TRL) of processes and sub-processes

$\square$ Report production or storage capacity

- Report geographical scope

State software system (and version) and data library (and version) used

$\square$ State type of review and provide additional information about reviewers

\section{Life cycle inventory and Life cycle impact assessment}

$\square$ State main results of life-cycle inventory and life-cycle impact assessment

I If results are reported on a relative basis, report basis

$\square$ Describe uncertainty and sensitivity analysis and report results separately

\section{Interpretation}

- State any conclusions, recommendation and limitations 
Methanol has a large global market as a commodity chemical, acting as a feedstock for many chemical processes. It can be synthesized from $\mathrm{CO}_{2}$ instead of from natural gas, which means it becomes possible to indirectly substitute the fossil carbon currently used in a multitude of plastics, polymers and carbon containing chemicals with carbon from $\mathrm{CO}_{2}$. This would release the chemicals industry from its current dependency upon fossil oil feedstock.

The goal of this study is to compare the environmental impacts (with a focus upon greenhouse gas emissions) of producing methanol as a chemical feedstock in Germany synthesised via a CCU route using $\mathrm{CO}_{2}$ captured from a cement plant, compared to the conventional route using natural gas. $\mathrm{CO}_{2}$-based methanol which is identical in chemical structure and composition to its conventional counterpart is being produced for use as a chemical feedstock. The results are intended to allow policy-makers to compare the impacts of producing methanol using CCU versus conventional technology and to review the effect of different locations. The results will not be used in comparative assertions disclosed to the public.

System expansion was used to include the additional function of the $\mathrm{CO}_{2}$ source to the functional unit - in this case a cement plant. To enable comparison, the boundary of the conventional methanol plant was expanded to include a cement plant producing the same quantity of cement. The basis for comparison between the two technologies (the functional unit) is the production of $1 \mathrm{t}$ methanol and 1.96 tonnes Portland cement. The modelled plant has a production capacity of $1 \mathrm{kt}$ methanol/day. The study is limited by the lack of infrastructure modelling for the $\mathrm{CO}_{2}$-capture and electrolysis units, the membrane $\mathrm{CO}_{2}$ capture technology used is at a low technology readiness level (TRL 4) whereas the PEM electrolyzer is at TRL 9 and the methanol plant is considered to be at TRL 7. The software used for modelling the system was Gabi version 8.6.0.20 and the database was ecoinvent v3.4.

A contribution analysis revealed that the environmental impacts of the CCU process are highly dependent upon the electricity used, much of the electricity is used for the electrolysis of water for $\mathrm{H}_{2}$ production. A scenario analysis was conducted using different electricity mixes (status-quo, low decarbonized, high decarbonized, full decarbonized) to determine the effect of decarbonizing the electricity supply.

The life cycle impact assessment revealed that the CCU methanol process only reduces greenhouse gas (GHG) emissions if low-carbon electricity is used. The high electricity demand of electrolysis means that if current grid mix electricity is used, the GHG emissions of the CCU process are several times higher than the conventional process. However, GHG emissions of the CCU process were reduced by up to $90 \%$ by switching to using decarbonized electricity. This contrasted with the conventional process where switching to wind power led to a reduction of just $2 \%$ in GHG emissions. When the low decarbonized scenario is used, GHG emissions of the CCU process are slightly lower than the conventional process. Using the high decarbonized scenario leads to GHG emissions around 50\% lower than the conventional process using the same electricity. If just wind power is used (full decarbonized scenario), then GHG emissions reductions of the order of $60 \%$ over the conventional process can be achieved. Some caution needs to be applied due to uncertainty introduced by study limitations.

The technique required to enable comparison of siting the process in different countries was discussed. An issue to be aware of is that the $\mathrm{GHG}$ emissions per main product of the $\mathrm{CO}_{2}$ source (in terms of $\mathrm{CO}_{2}$ output/t cement in this case) differs in different countries. When using system expansion of a multi-functional system, this leads to different amounts of cement/t methanol in the functional unit. When comparing siting a CCU plant in Germany versus Switzerland or USA, Switzerland comes out as being the most favourable location as the highly efficient Swiss cement plants produce more cement per quantity of $\mathrm{CO}_{2}$ required for $1 \mathrm{t}$ of methanol.

Note: the precision of results provided in the executive summary has been reduced due to caveats introduced by the study limitations discussed in Sections C.4.2.2 and C.7.2 of this worked example. 


\section{C.2 Technical Summary}

\begin{tabular}{|c|c|c|c|}
\hline & CCU Product & \multicolumn{2}{|l|}{ Methanol as a chemical feedstock } \\
\hline & Goal & \multicolumn{2}{|c|}{$\begin{array}{l}\text { What would be the environmental consequences (with a focus on global warming impacts) of using } \\
\text { methanol as a chemical feedstock synthesized via hydrogenation of carbon dioxide compared to } \\
\text { methanol synthesis from natural gas? }\end{array}$} \\
\hline द & Brief description & \multicolumn{2}{|c|}{$\begin{array}{l}\mathrm{CO}_{2} \text { is captured via membrane capture from a cement plant, } \mathrm{H}_{2} \text { is produced via } \mathrm{PEM} \text { water electrolysis, } \\
\text { subsequently methanol is produced via thermochemical synthesis. }\end{array}$} \\
\hline & Intended audience & \multicolumn{2}{|c|}{ LCA practitioner } \\
\hline & Functional Unit & \multicolumn{2}{|c|}{ The production of 1 tonne of $\mathrm{MeOH}$ as a feedstock/chemical/solvent and $1.96 \mathrm{t}$ cement. } \\
\hline & $\begin{array}{l}\text { Limitations and } \\
\text { Assumptions }\end{array}$ & \multicolumn{2}{|c|}{$\begin{array}{ll}\text { - } & \text { Based on literature data and Ecoinvent } 3.4 \\
\text { - } & \text { Cut off data - no use phase data included } \\
\text { - } & \text { No infrastructure for } \mathrm{H}_{2} \text { production or carbon capture included } \\
\text { - } & \text { Low TRL process for carbon capture }\end{array}$} \\
\hline \multirow{4}{*}{ 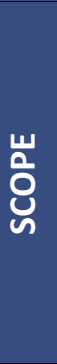 } & $\begin{array}{l}\text { Boundary } \\
\text { (i.e. cradle to gate) }\end{array}$ & \multicolumn{2}{|c|}{ Cradle to gate } \\
\hline & Location & \multicolumn{2}{|l|}{ Germany } \\
\hline & Time frames & \multicolumn{2}{|l|}{ Current, 2030, 2050} \\
\hline & $\begin{array}{l}\text { Multi-functional } \\
\text { approach }\end{array}$ & $\begin{array}{l}\square \text { Sub-division } \\
\text { 囚System expansion } \\
\square \text { System expansion via substitution } \\
\square \text { Virtual sub-division } \\
\square \text { Mass allocation }\end{array}$ & $\begin{array}{l}\square \text { Energy allocation } \\
\square \text { Economic allocation } \\
\square \text { Closed loop scenarios } \\
\square \text { Other (specify)............................................ }\end{array}$ \\
\hline \multirow{4}{*}{ 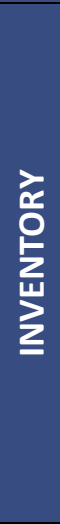 } & Data Source & $\begin{array}{l}\square \text { Primary sources } \\
\text { 囚Secondary sources } \\
\square \text { Stoichiometric data }\end{array}$ & $\begin{array}{l}\text { 囚Process modelling based data } \\
\square \text { Mixes sources } \\
\square \text { Other (specify)........................... }\end{array}$ \\
\hline & $\begin{array}{l}\text { Energy sources } \\
\text { (select all that apply) }\end{array}$ & $\begin{array}{l}\text { 囚Grid mix } \\
\square \text { Power station with Carbon Capture } \\
\text { 冈Wind } \\
\square \text { Solar }\end{array}$ & 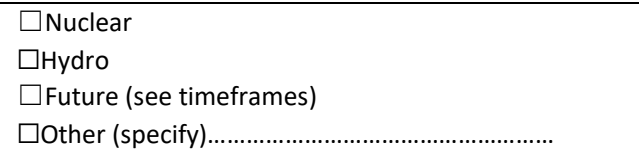 \\
\hline & $\begin{array}{l}\text { Main Sub- } \\
\text { Processes and } \\
\text { TRLS }\end{array}$ & $\begin{array}{l}\quad \text { SUB-PROCESS } \\
\text { Carbon capture via membrane } \\
\text { PEM water electrolysis } \\
\text { Methanol Synthesis }\end{array}$ & $\begin{array}{l}\text { TRL } \\
\text { TRL } 4 \\
\text { TRL } 9 \\
\text { TRL } 7 \\
\end{array}$ \\
\hline & $\begin{array}{l}\text { Database \& } \\
\text { Software }\end{array}$ & \multicolumn{2}{|l|}{ ecoinvent v3.4 and Gabi v8.6.0.20 } \\
\hline \multirow{2}{*}{ 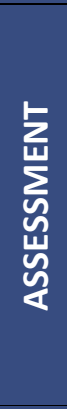 } & LCIA Method & $\begin{array}{l}\bigotimes \text { ILCD 1.09a } \\
\square \text { ReCiPe } \\
\text { OTHER IMPACT METHODS } \\
\square\end{array}$ & $\begin{array}{l}\text { SINGLE CATEGORIES: } \\
\square \text { Global warming } \\
\square \text { CED } \\
\square \text { use TOX }\end{array}$ \\
\hline & $\begin{array}{l}\text { Highlighted } \\
\text { Results } \\
\text { (graphical, text or } \\
\text { tabular format) }\end{array}$ & \multicolumn{2}{|c|}{$\begin{array}{l}\text { - GHG emissions of the modelled CCU methanol process sited in Germany are higher than } \\
\text { the conventional SMR process unless low-carbon electricity is used } \\
\text { Switching to } 100 \% \text { wind power reduces the GHG emissions of the modelled CCU process } \\
\text { by } 90 \% \text {, but the same switch only reduces the emissions of the conventional SMR methanol } \\
\text { process by } 2 \% \\
\text { - GHG emissions reductions of the order of } 60 \% \text { can be achieved by changing from the } \\
\text { conventional SMR methanol production to the modelled CCU production process }\end{array}$} \\
\hline 总 & Main Conclusions & \multicolumn{2}{|c|}{$\begin{array}{l}\text { - GHG emissions of the CCU process are highly dependent upon the source of electricity used for the } \\
\text { electrolysis which dominates the electricity use } \\
\text { - The CCU methanol process only reduces GHG emissions if low carbon energy is used } \\
\text { - If wind power is used, modelled GHG emissions can be reduced by around } 40 \% \text { over the conventional } \\
\text { process }\end{array}$} \\
\hline$\frac{a}{c}$ & Sensitivity Analysis & \multicolumn{2}{|c|}{$\begin{array}{l}\square \text { No } \quad \square \text { Yes (please specify below) } \\
\text { Sensitivity of location - Germany compared to Switzerland and USA. Switzerland would offer the } \\
\text { lowest global warming impacts per functional unit as more cement is produced per quantity of } \mathrm{CO}_{2} \\
\text { required to produce } 1 \mathrm{t} \text { methanol. }\end{array}$} \\
\hline
\end{tabular}




\section{C.3 Introduction}

Methanol can be used as a liquid fuel, either directly or after dehydration to dimethyl ether, but currently its main use is as a commodity chemical where it acts as a feedstock for many chemical processes. The market for methanol is large, with global demand reaching $70 \mathrm{Mt}$ in 2015, supplied by over 90 methanol plants worldwide [1]. Methanol can be synthesized from $\mathrm{CO}_{2}$ and is itself used as a chemical building block in the synthesis of many different compounds. By producing methanol using carbon capture and utilization (CCU) technologies from waste $\mathrm{CO}_{2}$, rather than from steam methane reformation as per the conventional route, it becomes possible to indirectly substitute fossil carbon with carbon derived from $\mathrm{CO}_{2}$ into a multitude of plastics, polymers and carbon containing chemicals. In this way, the dependency of the chemicals industry upon fossil oil feedstock is significantly reduced.

This report assesses the environmental impacts (with a focus upon global warming impacts) of a CCU methanol plant capable of producing around $1 \mathrm{Kt}$ methanol per day.

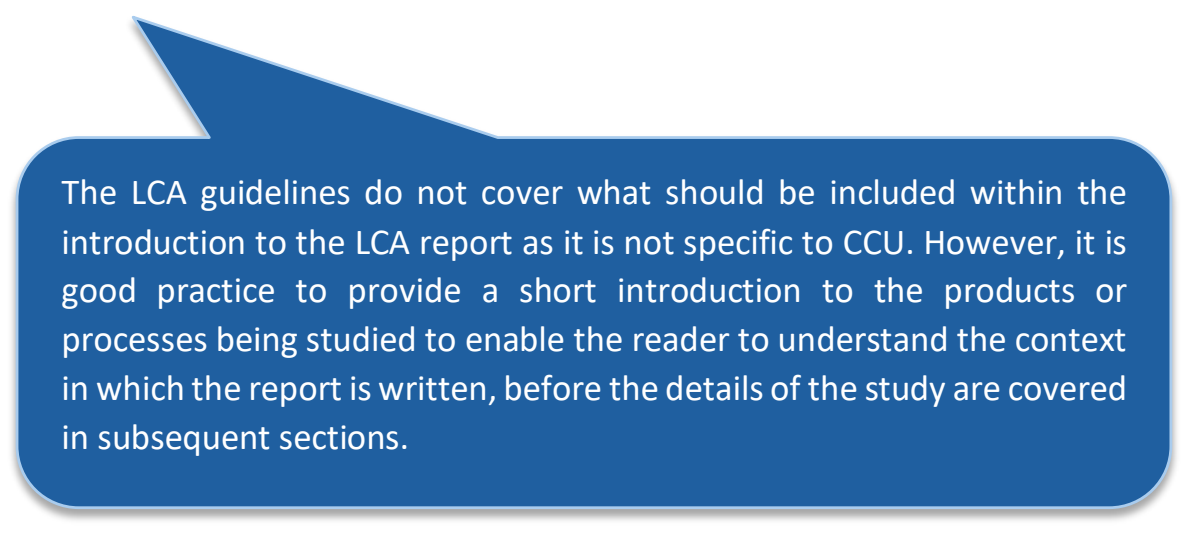




\section{C.4 Goal and scope of the Study}

\section{C.4.1 Goal of the study}

\section{Reference to LCA Guidelines}

A description of what should be included within the Goals section of an LCA report is provided in Section C.3 Goal definition of the guidelines. Specific guidelines of what shall or should be included are listed in Section C.3.2.

In addition, a checklist of items to be included in each section of the report is included in Section C.8 Reporting of the guidelines, which for the goal is as follows:

\section{Goal of the study}

$\square$ State the intended application of the study

$\square$ State the reasons for carrying out the study

- State the intended audience of the study

State whether the results are to be used in comparative assertions disclosed to public

State unambiguous research question(s)

- State the classification of the assessed CCU technology

- State limitations due to the assumptions and methods, e.g. if study is preliminary

- State the commissioner of the study and other influential actors

State technology readiness level (TRL) of processes and sub-processes

Report production or storage capacity

State review process and review experts, if any

The following study has the goal:

To compare the environmental impacts (with a focus upon global warming impacts) of producing methanol for use as a chemical feedstock in Germany, synthesised via two routes: the hydrogenation of $\mathrm{CO}_{2}$ captured from a cement plant vs methanol synthesised using the conventional steam methane reforming process from natural gas.

The results are intended to be used to compare the environmental impact of producing methanol using $\mathrm{CCU}$ technology versus conventional technology. $\mathrm{CO}_{2}$-based methanol which is identical in chemical structure and composition to its conventional counterpart and is being produced for use as a chemical feedstock rather than as a fuel. The modelled plant has a production capacity of $1 \mathrm{Kt}$ methanol/day. The study is limited by the lack of infrastructure modelling for the $\mathrm{CO}_{2}$-capture and electrolysis units, also the compression energy required to pressurise the $\mathrm{CO}_{2}$ prior to transportation was not modelled. Further limitations are imposed by the membrane $\mathrm{CO}_{2}$-capture technology utilised being at a low technology readiness level (TRL 4) whereas the PEM electrolyser is at TRL 9 and the methanol plant is considered to be at TRL 7.

The goal of the study is to provide information to assist policy-makers in comparing the environmental impacts of CCU technologies with conventional technologies. However, it is not intended that the results of this study will be used for marketing purposes or to make comparisons between products to the public. 
This study was commissioned by The Global $\mathrm{CO}_{2}$ Initiative $/ \mathrm{CO}_{2}$ Sciences and was conducted by the University of Sheffield with assistance from RWTH Aachen University. This report has undergone review by a panel of independent experts with a knowledge of CCU consisting of .... (names and affiliations).

As mentioned in the overall introduction to this set of worked examples and in the preface to this report, this document is a fictional worked example produced to help in the use and interpretation of the guidelines. Therefore, the true goal of this study is rather different than that described above and the report has not undergone external review as required by a published LCA report according to ISO 14040/14044.

\section{C.4.2 Scope of the study}

\section{Reference to LCA Guidelines}

A description of what should be included within the Scope section of an LCA report is provided in Section C.4 Scope definition of the guidelines. The specific guidelines of what shall, should or may be included are provided as Guidelines C.2 to C.6.

In addition, a checklist of items to be included in each section of the report is included in Section C.8 Reporting of the guidelines, which for the scope is as follows:

\section{Scope of the study:}

- State functional unit clearly and unambiguously according to the guideline, report changes due to solving of multi-functionality

- State performance characteristics, any omission of additional function in comparison and how performance is measured (might apply for products different in chemical structure and composition to their conventional counterparts)

- State system boundaries according to guideline and cut-off criteria including a system boundaries diagram

- State omitted life cycle stages and processes (might apply for products different in chemical structure and composition to their conventional counterparts)

- State relevant issues with data quality and assumptions

- State method(s) to solve multi-functionality

State impact assessment methods

- State data quality needs and how energy and material inputs and outputs are quantified

- State software system (and version) and data library (and version) used

- State type of review and provide additional information about reviewers

\section{C.4.2.1 Product characteristics}

The product under assessment is $\mathrm{CO}_{2}$-based methanol which is identical in chemical structure and composition to its conventional counterpart. In this study it is being assessed as a chemical rather than a fuel. The functional unit for the methanol component is 1 tonne methanol produced. Section C.4.2.4 Solving multi-functionality and defining the functional unit below further defines the functional unit in 
terms of the cement produced as this is determined by how the multi-functionality of the system is resolved.

The classification is important as it determines the nature of the functional unit. For instance, chemicals produced by CCU generally have an identical chemical structure and composition to those produced by conventional techniques. They can therefore be compared by mass with the functional unit in Kg. However, CCU fuels such as synthetic gasoline or diesel may have different energy contents than the conventional equivalents, in which case the functional unit needs to reflect the energy service such as heat that it provides. Fuels with identical chemical structure and composition would be compared using energy content in the functional unit. More information is available in the LCA Guidelines.

\section{Reference to LCA Guidelines}

As described in Section C.4.1 Product system, its function, functional unit and reference flow of the guidelines, the functional unit description provided follows the recommendation for $\mathrm{CO}_{2}$-based chemicals. In this situation, mass is used for comparison since the end-product has the same molecular structure and composition in both of the process routes assessed.

The process routes considered for this assessment are:

a. $\mathrm{MeOH}$ produced from steam methane reforming (SRM) of natural gas - the conventional route.

b. $\mathrm{MeOH}$ derived from $\mathrm{CO}_{2}$ captured from a cement plant and $\mathrm{H}_{2}$ produced from the electrolysis of water - the CCU route.

\section{C.4.2.2 System diagrams, completeness requirements and related cut-offs}

All processes in this study are assessed from cradle-to-gate as shown diagrammatically in Figures 1 and 2. System diagrams are presented for both the CCU route and the conventional (reference) route.

This example considers only the production of methanol and not its use. This is because $\mathrm{CO}_{2}$-based methanol is identical in its structure and composition to fossil-based methanol, so the usage and end-of-life treatment will be identical. It is therefore not necessary to consider a cradle-to-grave scenario, a cradle-to-gate analysis is sufficient. 


\section{Reference to LCA Guidelines}

The use of a cradle-to-gate boundary is in line with the recommendation in Section C.4.2 of the guidelines when the chemical structure and composition of the $\mathrm{CO}_{2}$-derived product is identical to the conventionally-derived product.

All processes in this case study are assessed from cradle-to-gate as shown in Figures 1 and 2.

a) Methanol from natural gas as a chemical feedstock:

The reference/benchmark process uses steam methane reforming (SMR) to produce syngas which is then converted to methanol (MeOH). The process involves inputs of energy (heat, electricity), raw materials (natural gas, water, catalyst), plant infrastructure etc., and results in emissions to air/water from the process as indicated in Figure 1 below (source: ecoinvent version 3.4).

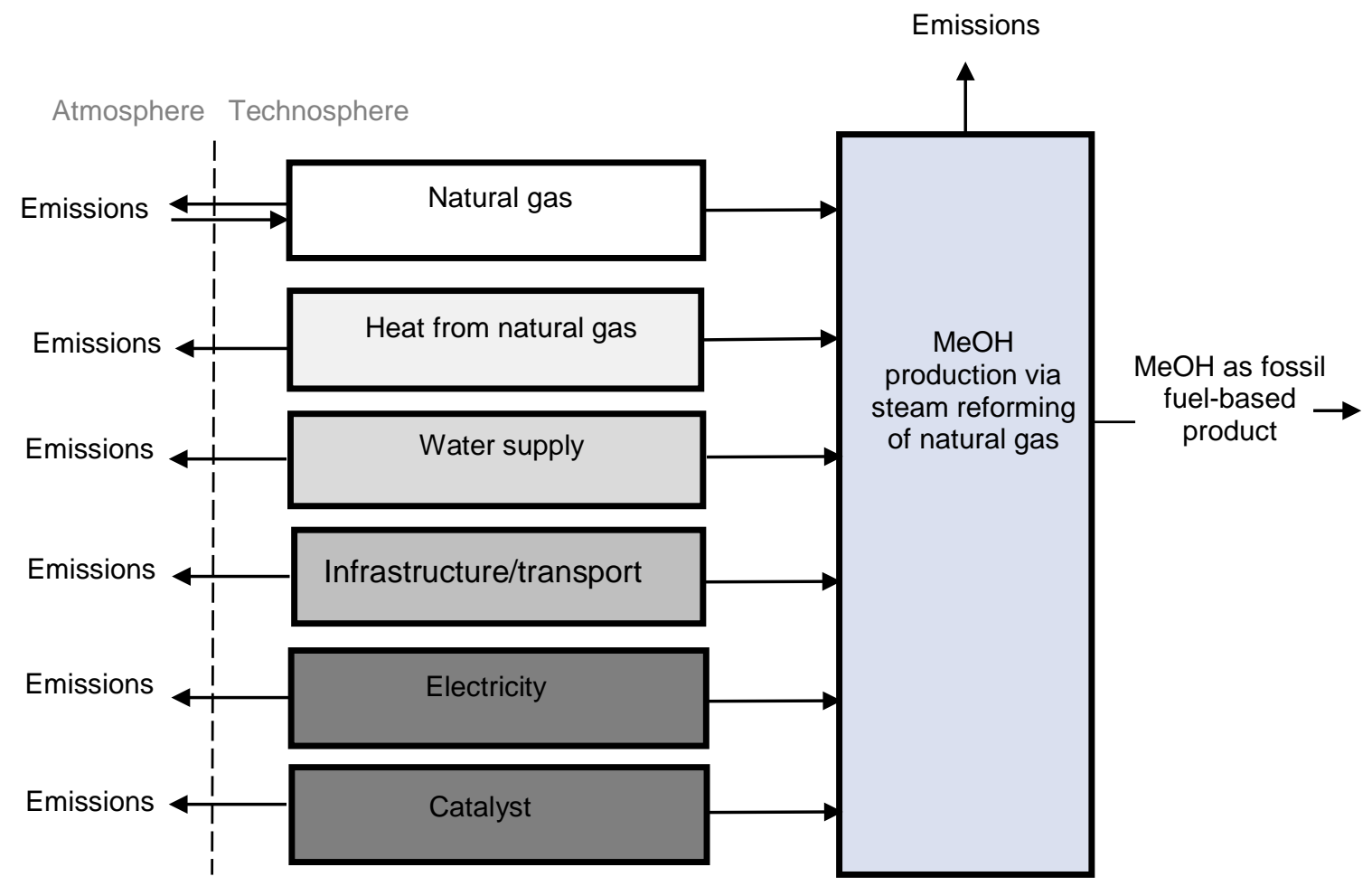

Figure 1. System diagram for methanol synthesis using natural gas as feedstock

b) Methanol derived from captured $\mathrm{CO}_{2}$ and $\mathrm{H}_{2}$ as a feedstock chemical:

A hydrogenation process is used for the synthesis of methanol using captured $\mathrm{CO}_{2}$ and $\mathrm{H}_{2}$ (Figure 2). A multistage membrane system is used to separate the $\mathrm{CO}_{2}$ from the flue gas. Hydrogen is produced via electrolysis using a proton exchange membrane (PEM) electrolyser. Inputs include energy (electricity), raw 
materials (water, catalyst), methanol plant infrastructure, and emissions to air/water result from the process. Source: the $\mathrm{LCl}$ for this process.

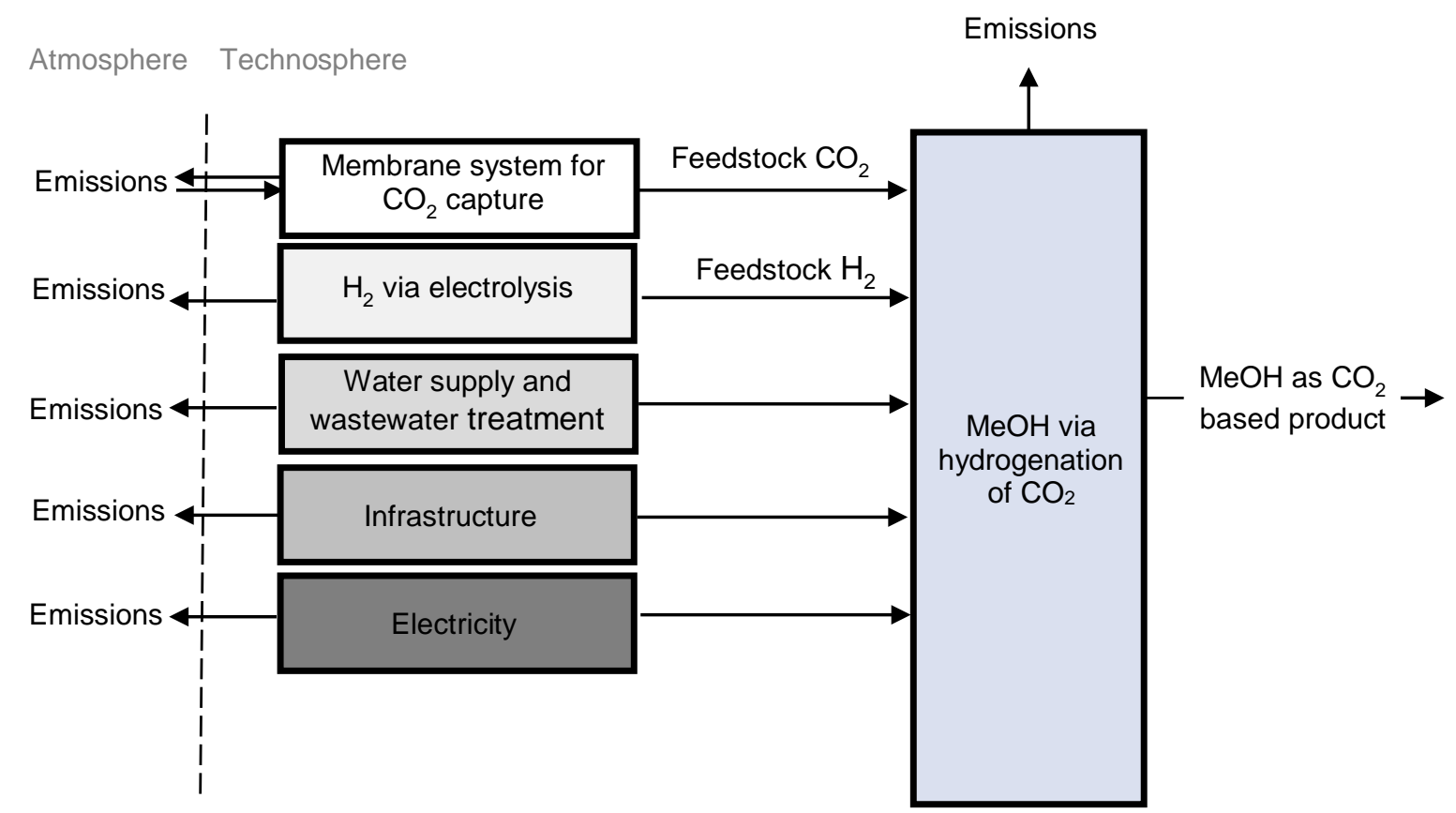

Figure 2. System diagram for methanol synthesis using $\mathrm{CO}_{2}$ and $\mathrm{H}_{2}$ as feedstock.

\section{Reference to LCA Guidelines}

The description of the reference process is included as recommended in Section C.4.2 of the guidelines. This ensures that the avoided impacts of the conventional (reference) process are transparent and measurable. The $\mathrm{CO}_{2}$ source, $\mathrm{CO}_{2}$ purification (not required in this process) and $\mathrm{CO}_{2}$ transport are included for the $\mathrm{CCU}$ process and are shown within the system boundaries of the process in Figure 2 as suggested in Section C.4.2 of the guidelines.

The limitations of the study, including data cut-offs, data availability and other uncertainties are summarized in Table 1.

\begin{tabular}{|l|l|}
\hline \multicolumn{1}{|c|}{ Limitation } & \multicolumn{1}{c|}{ Description } \\
\hline Data cut-offs & $\begin{array}{l}\text { Infrastructure for } \mathrm{CO}_{2} \text { capture and } \mathrm{H}_{2} \text { production was not included in } \\
\text { the modelling. The energy requirement for } \mathrm{CO}_{2} \text { compression prior } \\
\text { to transportation by road was not modelled. }\end{array}$ \\
\hline Data availability & $\begin{array}{l}\text { Some of the datasets used from ecoinvent version } 3.4 \text { were several } \\
\text { years out of date, as described further in Table 2 below. }\end{array}$ \\
\hline Other uncertainties & The $\mathrm{CO}_{2}$ capture unit modelled is at a low technology readiness level. \\
\hline
\end{tabular}

Table 1. Limitations of the LCA

Limitations of the study include the data cut-offs used: infrastructure was not modeled for either the $\mathrm{CO}_{2}$ capture step or $\mathrm{H}_{2}$ production and the energy required for $\mathrm{CO}_{2}$ compression prior to transport was also not modelled. The study was limited by data timeliness as some of the data sets used from the ecoinvent 
database version 3.4 are several years out of date, as presented in Table 2 below. Other uncertainties were created by the use of a carbon capture membrane separation technology which is currently at a TRL assessed to be between 3 and 4 .

\section{C.4.2.3 Geographical and time related representativeness}

\section{Region of study:}

The main location assessed in this study is Germany, but a sensitivity analysis is conducted to test the sensitivity of the environmental impacts of the process if it had been located in Switzerland or the United States. Energy and other inventories were adapted to the conditions of these locations as closely as possible, as indicated in Table 2 . When data for the specific country was not available, data for the regional average (RER for Europe) was used and if this was not available then global average (GLO) data was used. Whilst this limits the regional representativeness of the data, the technology representativeness can still be achieved through the use of such secondary data as proxy data.

A comparison of locations is included as an example sensitivity assessment

in Section C.7 Interpretation of this report, because it highlights one of the challenges of performing LCA on CCU technologies.

\section{Transportation:}

Once captured at a cement plant, the $\mathrm{CO}_{2}$ requires transportation from the point of capture to the point of use at the CCU methanol production facility. Since the necessary pipeline infrastructure does not yet exist in most locations, it has been assumed that the $\mathrm{CO}_{2}$ is transported by road freight. A distance of $50 \mathrm{Km}$ was used for all countries so that the transportation impacts could be included within the model but an individual country would not benefit from any arbitrary variations in projected/assumed transport distances. The energy requirement for $\mathrm{CO}_{2}$ compression prior to transportation by road was not modelled.

Since a cradle-to-factory-gate system boundary has been adopted, the use-phase transportation of the methanol was not modeled in this study.

\section{Reference to LCA Guidelines}

Section C.4.4 of the guidelines covers data quality. Complete data availability may be limited to full LCA studies, so clarity and transparency in explaining the sources of data used is important. Guideline C.9 in Section C.5.5 explains that the reference (conventional) process should use the current best available technology because the conventional technologies in future when CCU is implemented is likely to be unknown. In this way, the perception of bias is avoided. 


\begin{tabular}{|c|c|c|c|}
\hline \multirow{2}{*}{ Process inputs } & \multicolumn{3}{|c|}{ Location (database time period) } \\
\hline & Germany & Switzerland & USA \\
\hline Natural gas & $\begin{array}{c}\text { DE: natural gas production } \\
(1996-2000)\end{array}$ & $\begin{array}{l}\text { DE: natural gas } \\
\text { production (1996-2000) }\end{array}$ & $\begin{array}{l}\text { US: natural gas production } \\
\qquad(2010-2010)\end{array}$ \\
\hline $\begin{array}{l}\text { Methanol production: } \\
\text { Energy inputs adapted to } \\
\text { region of study }\end{array}$ & $\begin{array}{c}\text { GLO: methanol production } \\
\text { (1994 to 2001) }\end{array}$ & $\begin{array}{l}\text { GLO: methanol } \\
\text { production (1994 to } \\
\text { 2001) }\end{array}$ & $\begin{array}{c}\text { GLO: methanol production } \\
\text { (1994 to 2001) }\end{array}$ \\
\hline Tap water & $\begin{array}{l}\text { Europe without Switzerland: } \\
\text { tap water production, } \\
\text { underground water without } \\
\text { treatment (2012 to 2012) }\end{array}$ & $\begin{array}{l}\text { CH: tap water production, } \\
\text { underground water } \\
\text { without treatment ( } 2012 \\
\text { to 2012) }\end{array}$ & $\begin{array}{l}\text { GLO: tap water production, } \\
\text { underground water without } \\
\text { treatment (2012 to 2012) }\end{array}$ \\
\hline Deionised water & $\begin{array}{c}\text { Europe without Switzerland: } \\
\text { water production, deionised, } \\
\text { from tap water, at user (1992 } \\
\text { to 2002) }\end{array}$ & $\begin{array}{l}\text { CH: water production, } \\
\text { deionised, from tap } \\
\text { water, at user (1992 to } \\
\text { 2002) }\end{array}$ & $\begin{array}{c}\text { GLO: water production, } \\
\text { deionised, from tap water, at } \\
\text { user (1992 to 2002) }\end{array}$ \\
\hline Treatment of wastewater & $\begin{array}{c}\text { Europe without Switzerland: } \\
\text { treatment of wastewater, } \\
\text { average, capacity 1E9 I/year } \\
(1994-2000)\end{array}$ & $\begin{array}{c}\mathrm{CH} \text { : treatment of } \\
\text { wastewater, average, } \\
\text { capacity } 1 \mathrm{E9} \mathrm{I} / \text { year (1994- } \\
\text { 2000) }\end{array}$ & $\begin{array}{c}\text { GLO: treatment of } \\
\text { wastewater, average, } \\
\text { capacity } 1 \text { E9 I/year (1994- } \\
\text { 2000) }\end{array}$ \\
\hline Transport, lorry & $\begin{array}{l}\text { RER: transport, freight, lorry } \\
\text { 3.5-7.5 metric ton (2009-2013) }\end{array}$ & $\begin{array}{l}\text { RER: transport, freight, } \\
\text { lorry 3.5-7.5 metric ton } \\
(2009-2013)\end{array}$ & $\begin{array}{c}\text { GLO: transport, freight, lorry } \\
\text { 3.5-7.5 metric ton (2009- } \\
\text { 2013) }\end{array}$ \\
\hline Electricity grid mix & $\begin{array}{l}\text { DE: electricity high voltage, } \\
\text { production mix }\end{array}$ & $\begin{array}{c}\mathrm{CH} \text { : electricity high } \\
\text { voltage, production mix }\end{array}$ & $\begin{array}{l}\text { US: WECC, US only, electricity } \\
\text { high voltage, production mix }\end{array}$ \\
\hline Electricity, wind power & $\begin{array}{c}\text { DE: electricity production, wind } \\
>3 \mathrm{MW} \text {, turbine, onshore } \\
(2012-2012)\end{array}$ & $\begin{array}{c}\mathrm{CH} \text { : electricity } \\
\text { production, wind }>3 \mathrm{MW} \text {, } \\
\text { turbine, onshore (2016- } \\
\text { 2018) } \\
\end{array}$ & $\begin{array}{l}\text { US: WECC US only, electricity } \\
\text { production, wind }>3 \mathrm{MW}, \\
\text { turbine, onshore (2012-2012) }\end{array}$ \\
\hline Heat & $\begin{array}{l}\text { Europe without Switzerland: } \\
\text { market for heat, district or } \\
\text { industrial, natural gas (2011- } \\
\text { 2011) }\end{array}$ & $\begin{array}{l}\text { CH: market for heat, } \\
\text { district or industrial, } \\
\text { natural gas (2011-2011) }\end{array}$ & $\begin{array}{c}\text { GLO: market for heat, district } \\
\text { or industrial, natural gas } \\
(2011-2011)\end{array}$ \\
\hline Aluminium oxide & $\begin{array}{l}\text { GLO: aluminium oxide } \\
\text { production (2012-2012) }\end{array}$ & $\begin{array}{l}\text { GLO: aluminium oxide } \\
\text { production (2012-2012) }\end{array}$ & $\begin{array}{l}\text { GLO: aluminium oxide } \\
\text { production (2012-2012) }\end{array}$ \\
\hline Copper oxide & $\begin{array}{l}\text { RER: copper oxide production } \\
(2000-2020)\end{array}$ & $\begin{array}{c}\text { RER: copper oxide } \\
\text { production }(2000-2020)\end{array}$ & $\begin{array}{c}\text { GLO: copper oxide } \\
\text { production }(2000-2020)\end{array}$ \\
\hline Zinc oxide & $\begin{array}{c}\text { RER: zinc oxide production } \\
(2005-2020)\end{array}$ & $\begin{array}{c}\text { RER: zinc oxide } \\
\text { production (2005-2020) }\end{array}$ & $\begin{array}{c}\text { GLO: zinc oxide production } \\
(2005-2020)\end{array}$ \\
\hline Molybdenum & $\begin{array}{l}\text { RER: molybdenum production } \\
(2000-2003)\end{array}$ & $\begin{array}{l}\text { RER: molybdenum } \\
\text { production (2000-2003) }\end{array}$ & $\begin{array}{l}\text { GLO: molybdenum } \\
\text { production (2000-2003) }\end{array}$ \\
\hline Nickel 99.5\% & $\begin{array}{c}\text { GLO: market for nickel 99.5\% } \\
(2011-2011)\end{array}$ & $\begin{array}{l}\text { GLO: market for nickel } \\
\text { 99.5\% (2011-2011) }\end{array}$ & $\begin{array}{c}\text { GLO: market for nickel 99.5\% } \\
\text { (2011-2011) }\end{array}$ \\
\hline Zinc & $\begin{array}{l}\text { GLO: market for zinc (2011- } \\
\text { 2011) }\end{array}$ & $\begin{array}{l}\text { GLO: market for zinc } \\
(2011-2011)\end{array}$ & $\begin{array}{l}\text { GLO: market for zinc (2011- } \\
\text { 2011) }\end{array}$ \\
\hline Methanol factory & $\begin{array}{l}\text { GLO: market for methanol } \\
\text { factory (2011 to 2011) }\end{array}$ & $\begin{array}{l}\text { GLO: market for methanol } \\
\text { factory (2011 to 2011) }\end{array}$ & $\begin{array}{l}\text { GLO: market for methanol } \\
\text { factory (2011 to 2011) }\end{array}$ \\
\hline
\end{tabular}

Table 2. Databases used for process input with time representativeness. 


\section{Database time representativeness:}

The time representativeness for each process used in this case study for both production routes is shown in Table 2. All process inputs apart from the IEA electricity scenarios were obtained from ecoinvent version 3.4. The impact of this will be discussed during the interpretation of the results.

To prevent erroneous comparisons, the conventional routes have been taken in an un-aggregated form and adapted to the same conditions as the CCU process. This mainly includes energy supply, feedstocks, water supply and treatment and the same chemical facility for infrastructure assumptions.

\section{C.4.2.4 Solving multi-functionality and defining the functional unit}

In the system under investigation, $\mathrm{CO}_{2}$ is captured from a cement plant which then becomes a feedstock for methanol production as a $\mathrm{CO}_{2}$-based chemical.

To allow the environmental impacts of producing the $\mathrm{CO}_{2}$ to be included in the assessment, the cement plant is included in the analysis. This results in the overall system being multi-functional in that multiple products (cement and methanol) are produced. To enable the comparison of the conventional route and the CCU route under equal conditions, this multi-functionality needs to be solved. Depending upon where the system boundaries are drawn, solving the multifunctionality can lead to having a single product or multiple products within the functional unit.

\section{Reference to LCA Guidelines}

Section C.4.3.2 Solving multi-functionality describes a hierarchy of methods for solving multifunctionality. System expansion is the method that should be used to solve multi-functionality in this instance. For this reason, cement production is included within the system boundary of the conventional methanol production process.

Sub-division should be the first approach to solving multi-functionality, but in this instance the impacts of producing the cement cannot be separated from the impacts of producing the $\mathrm{CO}_{2}$ because cement cannot be produced without producing $\mathrm{CO}_{2}$. Since $\mathrm{CO}_{2}$ is an essential feedstock of the methanol, it is therefore impossible to separate the impacts of cement production from those of methanol production in this way.

The second approach to solving the multi-functionality of the system is to use system expansion to draw the system boundary to include both the cement plant and the methanol plant. Figure 3 below aims to present this diagrammatically. With the system expansion approach, cement is considered to be produced as a joint product along with the methanol, meaning that the functional unit contains both products. As long as a cement plant is added within the system boundary of the conventional methanol plant, then this approach allows the comparison of the conventional route and the CCU route under equal conditions. 
a)

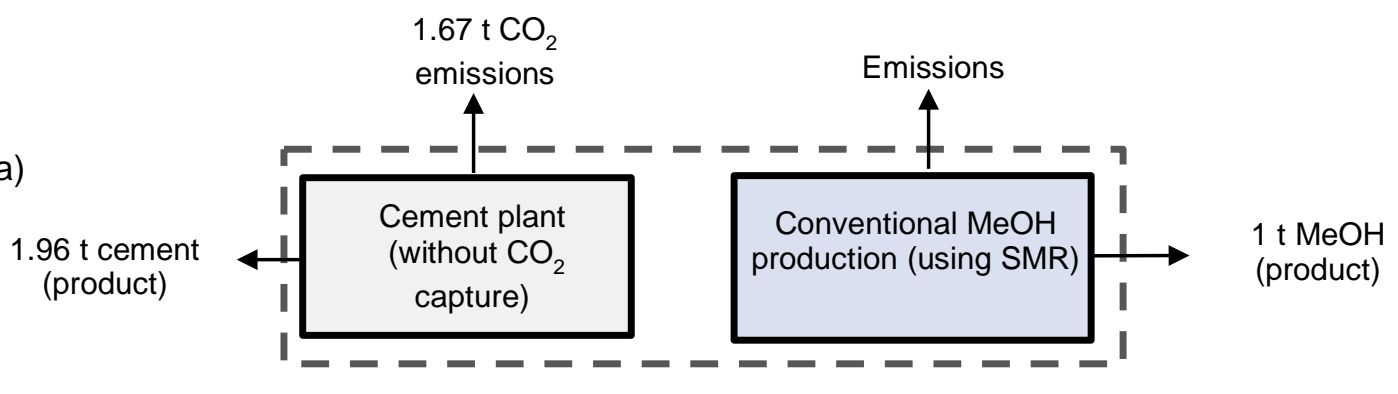

$0.22 \mathrm{t} \mathrm{CO}_{2}$ emissions

b)

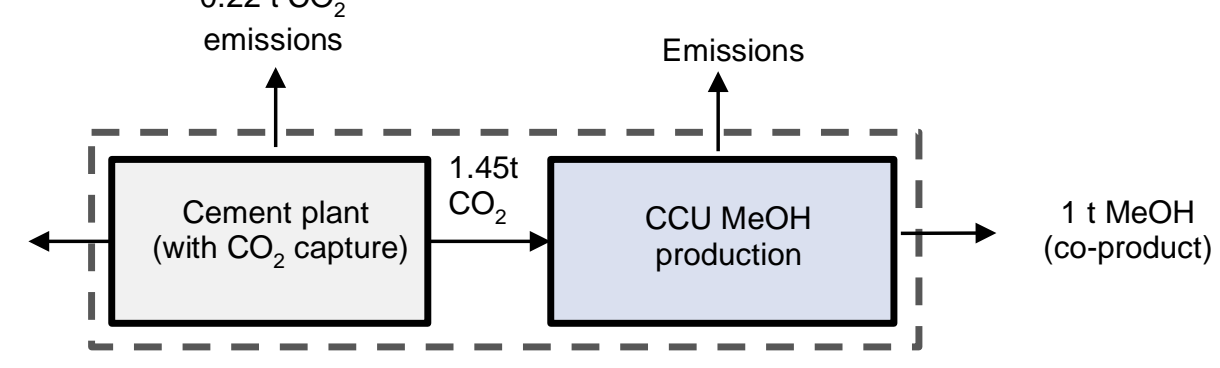

Figure 3. System expansion to enable comparison between a) the conventional production system of methanol from steam methane reforming and b) CCU based methanol. The dotted lines indicate the system boundary.

In the system described, according to ecoinvent 3.4, a Portland cement plant in Germany produces $0.852 \mathrm{Kg} \mathrm{CO} / \mathrm{Kg}$ cement, meaning that such a plant would produce $1.959 \mathrm{t}$ of cement to produce the 1.669 t CO 2 required to produce $1 \mathrm{t}$ methanol. At the modelled capture efficiency of $86.98 \%$, a feed of $1.669 \mathrm{t} \mathrm{CO}_{2}$ is required to capture the $1.451 \mathrm{t} \mathrm{CO}$ needed to produce $1 \mathrm{t}$ methanol. Therefore, in this case the functional unit required to compare CCU production with conventional production is $1 \mathrm{t}$ methanol and $1.96 \mathrm{t}$ cement.

For the product specific assessment of methanol as a chemical feedstock, the basis for comparison used is mass, therefore the functional unit used is 1 tonne of methanol and 1.96 tonnes of cement. 


\section{C.5 Inventory data}

\section{Reference to LCA Guidelines}

A description of what should be included within the inventory section of an LCA report is provided in Section C.5 Life cycle inventory ( $\mathbf{L C l}$ ) of the guidelines, with Guidelines C.7 to C.9 listing the specific items which need to be included.

In addition, a checklist of items to be included in each section of the report is included in Section C.8 Reporting of the guidelines, which for the life cycle inventory is as follows:

\section{Life cycle inventory}

Include flow diagram of assessed process system(s)

- State types and sources of required data and information

State calculation procedures

$\square$ State all assumption made

$\square$ Describe sensitivity analysis for refining system boundaries

Include calculated full LCI results (if this does not contradict with confidentiality)

$\square$ State data representativeness and appropriateness of $\mathrm{LCl}$ data

$\square$ If results are reported on a relative basis, report basis

S State results obtained from scenario analysis (including scenarios) and threshold values, if any

The main process inputs (electricity, water use, wastewater treatment etc.) into the three main stages of the $\mathrm{CCU}$ process $\left(\mathrm{CO}_{2}\right.$ capture, $\mathrm{H}_{2}$ production via electrolysis, and methanol production from hydrogenation of $\left.\mathrm{CO}_{2}\right)$ is provided in Table 3 below.

Table 3 is provided to enable the reader of this worked example to see, at-a-glance, the most relevant inputs to the CCU methanol process. The rest of the inventory data, together with the explanations of the processes and process flow diagrams are provided in the Appendix of this document. This was done in an attempt to avoid distracting the reader from working through the LCA examples by providing too much information at this stage. However, it is usual to provide all inventory data within the Inventory chapter of the report rather than in an appendix. 


\begin{tabular}{|c|c|c|c|c|}
\hline \multirow[t]{2}{*}{ Parameter } & \multicolumn{2}{|c|}{ Scaled to factory output } & \multicolumn{2}{|c|}{ Scaled to $1 \mathrm{t}$ methanol } \\
\hline & Value & Unit & Value & Unit \\
\hline \multicolumn{5}{|l|}{$\mathrm{CO}_{2}$ Capture } \\
\hline $\mathrm{CO}_{2}$ input & 71.39 & $\mathrm{t} / \mathrm{h}$ & 1.669 & $t / h$ \\
\hline $\mathrm{CO}_{2}$ capture efficiency & 86.979 & $\%$ & 86.979 & $\%$ \\
\hline $\mathrm{CO}_{2}$ output & 62.09 & $\mathrm{t} / \mathrm{h}$ & 1.451 & $\mathrm{t} / \mathrm{h}$ \\
\hline Net electricity demand & 8.97 & MW & 0.209 & MW \\
\hline Cooling water (make up) & 71.05 & $\mathrm{t} / \mathrm{h}$ & 1.661 & $\mathrm{t} / \mathrm{h}$ \\
\hline Waste water & 9 & $\mathrm{t} / \mathrm{h}$ & 0.210 & $t / h$ \\
\hline \multicolumn{5}{|l|}{ Electrolysis } \\
\hline Deionised water & 80.85 & $\mathrm{t} / \mathrm{h}$ & 1.89 & $t / h$ \\
\hline $\mathrm{H}_{2}$ output & 8.594 & $\mathrm{t} / \mathrm{h}$ & 0.2 & $\mathrm{t} / \mathrm{h}$ \\
\hline Electricity for electrolysis & 450.12 & MW & 10.522 & MW \\
\hline Waste water & 4 & $\mathrm{t} / \mathrm{h}$ & 0.1 & $\mathrm{t} / \mathrm{h}$ \\
\hline \multicolumn{5}{|l|}{ Methanol synthesis } \\
\hline $\mathrm{CO}_{2}$ input & 62.09 & $\mathrm{t} / \mathrm{h}$ & 1.451 & $t / h$ \\
\hline $\mathrm{CO}_{2}$ output & 3.32 & $t / h$ & 0.077 & $t / h$ \\
\hline MeOH output & 42.78 & $\mathrm{t} / \mathrm{h}$ & 1 & $\mathrm{t} / \mathrm{h}$ \\
\hline Net electricity demand & 4.73 & MW & 0.111 & MWh \\
\hline Cooling water (make up) & 190.3 & $\mathrm{t} / \mathrm{h}$ & 4.448 & $\mathrm{t} / \mathrm{h}$ \\
\hline Boiler water (make up) & 1.6 & $\mathrm{t} / \mathrm{h}$ & 0.037 & $\mathrm{t} / \mathrm{h}$ \\
\hline Catalyst & 4.375 & $\mathrm{Kg} / \mathrm{h}$ & 0.102 & $\mathrm{Kg} / \mathrm{h}$ \\
\hline Waste water & 24 & $\mathrm{t} / \mathrm{h}$ & 0.56 & $\mathrm{t} / \mathrm{h}$ \\
\hline
\end{tabular}

Table 3. The main process inputs and outputs from the three main stages of production of methanol by the hydrogenation of $\mathrm{CO}_{2}$. 


\section{C.6 Life Cycle Impact Assessment}

\section{Reference to LCA Guidelines}

A description of what should be included within this section of an LCA report is provided in Section C.6 Life cycle impact assessment of the guidelines, with Guidelines C.10 and C.11 specifying the items which need to be included.

In addition, a checklist of items to be included in each section of the report is included in Section C.8 Reporting of the guidelines, which for the life cycle inventory is as follows:

\section{Life cycle impact assessment}

Include results of life cycle impact assessment

$\square$ State if impact categories coverage is reduced, e.g. in case of carbon footprinting

- If results are reported on a relative basis, report basis

- State if delayed emissions occur and include emission time profile if needed

$\square$ If applied, state discounting method and discounted results

\section{C.6.1 Approach taken}

Gabi ts software (version 8.6.0.20) from thinkstep, utilizing the ecoinvent 3.4 database, was used in this study. A model of methanol production utilizing $\mathrm{CO}_{2}$ as the carbon source was compared to methanol production using the conventional technique of steam methane reforming (SMR).

Note: when constructing the model in Gabi using ecoinvent 3.4, the input flow of $\mathrm{CO}_{2}$ into the methanol plant was treated as an elementary flow (using Carbon dioxide [inorganic emission to air]) so that the environmental impact of capturing the $\mathrm{CO}_{2}$ emissions were included in the assessment. Treating the $\mathrm{CO}_{2}$ flow as a technical flow (using Carbon dioxide [inorganic intermediate product]) enables determination of the environmental impact of the process without distortion caused by the captured $\mathrm{CO}_{2}$ but does not include the beneficial impact of avoiding the $\mathrm{CO}_{2}$ emissions that were captured.

The results arising from the life cycle impact assessment were obtained using the ILCD/PEF recommendation method v1.09 due to this method being recommended by the European Commission's Joint Research Centre as appropriate for a study based in Germany. Although impacts upon global warming are the main category of interest in this report, for transparency, all of the ILCD impact categories at midpoint level are presented in tabular form.

\section{Reference to LCA Guidelines}

The method used to analyze the results of the LCIA are described in Section C.6.1 of the guidelines and specific guidelines of what shall, should or may be included as Guideline C.10. 
A contribution analysis was conducted to determine the contribution that the different processes which make up the $\mathrm{CCU}$ process ( $\mathrm{CO}_{2}$ capture, $\mathrm{CO}_{2}$ transport, electrolysis, methanol production) make towards the overall environmental impacts. The contribution that electricity usage makes to the impacts of each of these individual processes is calculated.

\section{Reference to LCA Guidelines}

As described in Section C.7.3 of the guidelines, environmental impacts in CCU can be very sensitive as they are often closely linked to energy requirements. Showing only a dependency on clean feedstocks limits interpretation and can leave to ambiguity. Presenting alternative energy scenarios facilitates comparison between similar assessments and prevents overstating the environmental benefits of $\mathrm{CO}_{2}$ based products. The standard inventory data-sets for electricity scenarios, as introduced in Section C.7.3 (and described in greater detail in Appendix C.9.1) of the guidelines, have therefore been used.

Electricity usage was found to be the major cause of the environmental impacts caused by the CCU process, so a scenario analysis of the effect of using different electricity scenarios was conducted as part of the impact assessment. For both the conventional methanol production process and the CCU production process, the status-quo is compared to a low decarbonized (IEA 2030 electricity mix scenario), a high decarbonized (IEA 2050 electricity mix scenario) and a fully decarbonized scenario where all electricity used is provided by onshore wind power. The low and high decarbonized scenarios were created based upon data published in the IEA Energy Technology Perspectives 2017 report [18]. They are not specific to any country, but simply reflect a lower carbon intensity and other environmental impacts as specified by the IEA per KWh of electricity produced. The wind power used for the decarbonized scenario was created using current wind power data for $>3 \mathrm{MW}$ onshore wind turbines in Germany and therefore reflects the efficiencies of wind power today, rather than projected efficiencies in 2030, 2050 or beyond.

It is recognized that LCA practitioners may wish to evaluate the environmental impact of changing the country in which processes are modelled in order to identify the best location for a new development. A CCU-specific challenge to having a consistent functional unit which arises due to differences in the carbon efficiency of the $\mathrm{CO}_{2}$ source is highlighted and methods to avoid it are discussed in Section C.7 Life Cycle Interpretation.

Additional sensitivity analyses to assess the sensitivity of the system to changes to the electrolyser efficiency, the $\mathrm{CO}_{2}$ capture efficiency and methanol reactor pressure were also conducted. As it is recognized that many LCA practitioners wish to integrate the results of an LCA together with a TEA, these sensitivity analyses have been included in the section of this document specifically dealing with the integration of LCA and TEA data, as an example of how the environmental and economic impacts of such analyses can be presented.

\section{C.6.2 Results of methanol production impact assessment}

\section{C.6.2.1 Conventional methanol vs CCU methanol production in Germany}

Life cycle impact assessment was conducted, involving the utilisation of the four different electricity scenarios discussed in Section C.6.1 (status-quo, low decarbonized, high decarbonized and fully 
decarbonized). The data is presented following system expansion to enable the direct comparison of conventional methanol production (Table 4) with CCU methanol production (Table 5) where the $\mathrm{CO}_{2}$ used for the $\mathrm{CO}_{2}$-derived methanol is provided by a cement plant.

The first observation which can be made from Table 4 is that the greenhouse gas emissions of the conventional steam methane reforming (SMR) process of methanol production is only modestly dependent upon the source of the electricity. Attempting to decarbonize the conventional process by switching from using electricity from the current German grid to electricity sourced from $100 \%$ onshore wind turbines leads to a reduction in the greenhouse gas emissions (as determined by the impact category: climate change midpoint, excluding biogenic carbon) of just $2 \%$. Clearly the greenhouse gas emissions arising from this process arise from the SMR process itself rather than through electricity use.

In contrast, Table 5 reveals that the impacts of the CCU process are highly dependent upon the source of the electricity, reflecting that the CCU process has a much higher reliance upon electricity. A reduction of $90 \%$ in greenhouse gas emissions is obtained if the status-quo electricity (current grid mix) is switched to fully decarbonized electricity (onshore wind turbines). The low and high decarbonized scenarios reflect the impacts part-way through the transition between the current and the fully decarbonized scenarios. 


\begin{tabular}{|c|c|c|c|c|}
\hline \multirow{2}{*}{$\begin{array}{l}\text { Impact categories } \\
\text { (ILCD/PEF recommendation v1.09) }\end{array}$} & \multicolumn{4}{|c|}{ Conventional Methanol Plant } \\
\hline & Status-quo & $\begin{array}{c}\text { Low } \\
\text { decarbonised }\end{array}$ & $\begin{array}{c}\text { High } \\
\text { decarbonised }\end{array}$ & $\begin{array}{c}\text { Fully } \\
\text { decarbonised }\end{array}$ \\
\hline Acidification midpoint (v1.09) [Mole of $\mathrm{H}+$ eq.] & 7.3 & 7.1 & 7.1 & 7.1 \\
\hline Climate change midpoint, excl biogenic carbon (v1.09) [kg CO2 eq.] & 2260 & 2223 & 2217 & 2214 \\
\hline Climate change midpoint, incl biogenic carbon (v1.09) [kg CO2 eq.] & 2290 & 2250 & 2242 & 2242 \\
\hline Ecotoxicity freshwater midpoint (v1.09) [CTUe] & 3354 & 2901 & 2901 & 4279 \\
\hline Eutrophication freshwater midpoint (v1.09) [kg P eq.] & 0.25 & 0.18 & 0.18 & 0.18 \\
\hline Eutrophication marine midpoint (v1.09) [kg N eq.] & 1.26 & 1.23 & 1.23 & 1.23 \\
\hline Eutrophication terrestrial midpoint (v1.09) [Mole of $\mathrm{N}$ eq.] & 15.0 & 14.3 & 14.3 & 14.3 \\
\hline Human toxicity midpoint, cancer effects (v1.09) [CTUh] & 0.00003 & 0.00003 & 0.00003 & 0.00003 \\
\hline Human toxicity midpoint, non-cancer effects (v1.09) [CTUh] & 0.0002 & 0.0002 & 0.0002 & 0.0002 \\
\hline Ionizing radiation midpoint, human health (v1.09) [kBq U235 eq.] & 72.3 & 69.6 & 69.5 & 63.7 \\
\hline Land use midpoint (v1.09) [kg C deficit eq.] & 1801 & 1803 & 1806 & 1795 \\
\hline Ozone depletion midpoint (v1.09) [kg CFC-11 eq.] & 0.0001 & 0.0001 & 0.0001 & 0.0001 \\
\hline Particulate matter/Respiratory inorganics midpoint (v1.09) [kg PM2.5 eq.] & 0.45 & 0.44 & 0.44 & 0.45 \\
\hline Photochemical ozone formation midpoint, human health (v1.09) [kg NMVOC eq.] & 5.3 & 5.3 & 5.3 & 5.2 \\
\hline Resource depletion water, midpoint (v1.09) [m³ eq.] & 7.8 & 10.0 & 9.8 & 7.1 \\
\hline Resource depletion, mineral, fossils and renewables, midpoint (v1.09) [kg Sb eq.] & 0.03 & 0.03 & 0.03 & 0.03 \\
\hline
\end{tabular}

Table 4. Impact assessment per 1 tonne of methanol and 1.96 tonnes of cement produced in Germany in a conventional methanol plant (using system expansion to include the impacts associated with a cement plant). 


\begin{tabular}{|c|c|c|c|c|}
\hline \multirow{2}{*}{$\begin{array}{l}\text { Impact categories } \\
\text { (ILCD/PEF recommendation v1.09) }\end{array}$} & \multicolumn{4}{|c|}{ CCU Methanol Plant } \\
\hline & Status-quo & $\begin{array}{c}\text { Low } \\
\text { decarbonised }\end{array}$ & $\begin{array}{c}\text { High } \\
\text { decarbonised }\end{array}$ & $\begin{array}{c}\text { Fully } \\
\text { decarbonised }\end{array}$ \\
\hline Acidification midpoint (v1.09) [Mole of $\mathrm{H}+$ eq.] & 36.5 & 7.7 & 6.8 & 7.9 \\
\hline Climate change midpoint, excl biogenic carbon (v1.09) [kg CO2 eq.] & 7376 & 2009 & 1042 & 700 \\
\hline Climate change midpoint, incl biogenic carbon (v1.09) [kg CO2 eq.] & 7849 & 2018 & 859 & 725 \\
\hline Ecotoxicity freshwater midpoint (v1.09) [CTUe] & 70067 & 3732 & 3736 & 205606 \\
\hline Eutrophication freshwater midpoint (v1.09) [kg P eq.] & 9.7 & 0.19 & 0.19 & 0.76 \\
\hline Eutrophication terrestrial midpoint (v1.09) [Mole of N eq.] & 128.9 & 23.9 & 20.9 & 17.1 \\
\hline Human toxicity midpoint, cancer effects (v1.09) [CTUh] & 0.001 & 0.00003 & 0.00003 & 0.0002 \\
\hline Human toxicity midpoint, non-cancer effects (v1.09) [CTUh] & 0.002 & 0.0003 & 0.0003 & 0.001 \\
\hline Ionizing radiation midpoint, human health (v1.09) [kBq U235 eq.] & 1342 & 943 & 934 & 81.9 \\
\hline Land use midpoint (v1.09) [kg C deficit eq.] & 3123 & 3474 & 3920 & 2293 \\
\hline Ozone depletion midpoint (v1.09) [kg CFC-11 eq.] & 0.0003 & 0.0001 & 0.0001 & 0.00008 \\
\hline Particulate matter/Respiratory inorganics midpoint (v1.09) [kg PM2.5 eq.] & 1.64 & 0.49 & 0.47 & 0.83 \\
\hline Photochemical ozone formation midpoint, human health (v1.09) [kg NMVOC eq.] & 9.4 & 5.9 & 5.1 & 4.7 \\
\hline Resource depletion, mineral, fossils and renewables, midpoint (v1.09) [kg Sb eq.] & 0.05 & 0.05 & 0.06 & 0.09 \\
\hline
\end{tabular}

Table 5. Impact assessment per 1 tonne of methanol and 1.96 tonnes produced in Germany in a CCU methanol plant (using system expansion to include the impacts associated with the cement plant which provided the $\mathrm{CO}_{2}$ ). 
Figure 4 below presents the greenhouse gas emissions graphically, making clear the limited impact that the electricity scenarios have upon the conventional process but the significant role that the carbon intensity of electricity plays in the greenhouse gas emissions from the CCU process.

The same figure allows direct comparison of the greenhouse gas emissions from the CCU process compared to the conventional SMR process. If current grid mix electricity (status-quo) is used for both processes, the greenhouse gas emissions of the CCU process are several-fold higher than the emissions from the conventional process. However, if low-carbon electricity is used, then the CCU process has the potential to reduce greenhouse gas emissions significantly.

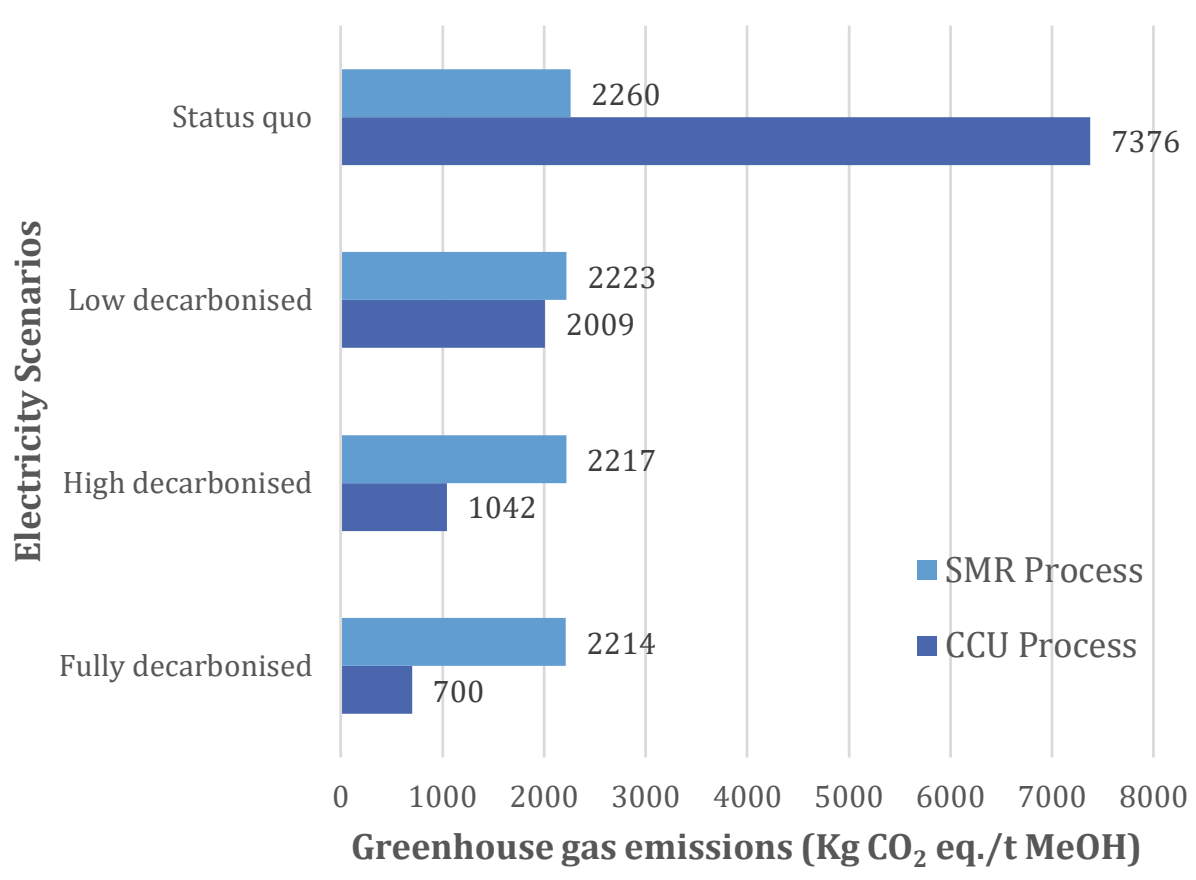

Figure 4. Greenhouse gas emissions of the conventional SMR process compared to the CCU methanol process using different electricity grid scenarios.

Comparing the impacts of the two processes reveals that the greenhouse gas emissions arising from the CCU process are $9.6 \%$ lower than the conventional process when the low decarbonized scenario is used for both processes. If the high decarbonized scenario is used for both, then the CCU process shows $53 \%$ lower greenhouse gas emissions than the conventional process. If fully decarbonized electricity (modeled as onshore wind turbines) is used for both processes, then greenhouse gas emissions from the CCU process are $68 \%$ lower than if the conventional process is used. 
This worked example does not aim to provide a template for how to write an LCA report, it attempts to focus upon problems and issues specific to CCU. Since the most common reason for implementing CCU technologies is to reduce the greenhouse gas emissions of the underlying process, the emphasis of the impact assessment presented is upon the climate change impact category. The other environmental impacts have been mentioned here only briefly as examples of what would need to be highlighted and discussed in an LCA report. However, as with any LCA, an assessment needs to be made of which impact categories need to be discussed and analysed and the reasons given.

Comparison between the conventional SMR and the CCU processes when utilising the status-quo grid mix electricity reveals that the CCU process results in higher impacts across most of the environmental impact categories.

The effect upon the environmental impacts of both processes of changing the electricity scenarios is varied. When using status-quo scenario electricity, the acidification midpoint was $7.3 \mathrm{~mol} \mathrm{H}^{+}$eq. for the SMR process but $36.5 \mathrm{~mol} \mathrm{H}^{+}$eq. for the CCU. However, fully decarbonising the electricity brought the figure obtained for the CCU process down to a similar level as for the SMR process. The same pattern of response can be seen for terrestrial eutrophication.

Water usage (resource depletion water impact category) shows a similar dependency, with the SMR process having an impact of $7.8 \mathrm{~m}^{3}$ eq. compared to $106.3 \mathrm{~m}^{3}$ eq. for the CCU process. After switching to electricity sourced from onshore wind turbines the water use of the SMR process reduced slightly to 7.1 whereas that for the CCU process fell dramatically to a more similar $8.4 \mathrm{~m}^{3}$ eq. However, the interpretation is complicated by the fact that water usage of the CCU process rises to 432.7 and $390.8 \mathrm{~m} 3 \mathrm{eq}$. when the low and high decarbonized scenarios are used. This likely reflects the lower water use efficiency of some of the renewable technologies included within these scenarios.

Freshwater ecotoxicity for the SMR process was 3,354 CTUe (comparative toxic units, ecosystems) when using the status-quo electricity scenario, this reduced to 2,901 when the low and high decarbonized scenarios were applied but increased to 4,279 when the system was modelled using electricity from onshore wind. The CCU process resulted in higher freshwater ecotoxicity values of 70,067 CTUe when using grid mix electricity, which reduced to more comparable values of 3,732 and 3,736 when the 2030 and 2050 scenarios were applied. However, when the electricity source was switched to $100 \%$ onshore wind the value increased significantly to 205,606 CTUe.

\section{C.6.2.2 Contribution analysis}

An analysis was conducted in order to reveal the contribution of each of the four main processes that form the $\mathrm{CCU}$ methanol process $\left(\mathrm{CO}_{2}\right.$ capture, $\mathrm{CO}_{2}$ transport, $\mathrm{H}_{2}$ production by electrolysis and methanol production) made towards the overall environmental impact. The proportion of these impacts that was due to electricity usage as opposed to the other main operational inputs into the processes such as water use, wastewater treatment and catalysts was also evaluated. 
The electricity modelled for the analysis was $100 \%$ wind power, because, as will be shown, the use of current (2018) grid mix electricity to run the processes involved with a CCU methanol plant would be unlikely.

This contribution analysis includes only the indirect emissions. The direct $\mathrm{CO}_{2}$ inputs and emissions are not included in the following charts, for example the $1669 \mathrm{Kg} \mathrm{CO}_{2} / \mathrm{t}$ methanol input into the $\mathrm{CO}_{2}$ capture unit (which would otherwise have to be treated as a negative emission) or the emission of $217 \mathrm{Kg} \mathrm{CO} / \mathrm{t}$ methanol of $\mathrm{CO}_{2}$ which was not captured (reflecting the $87 \%$ capture efficiency modelled) are not included. Similarly, the emission of $77.7 \mathrm{Kg} \mathrm{CO}_{2} / \mathrm{t}$ methanol arising from the methanol plant which reflects the $94.5 \%$ conversion efficiency of $\mathrm{CO}_{2}$ to methanol within the plant was not included. The contribution analysis was done in this way to enable the climate impacts of the electricity and other inputs to be determined alone, rather than allowing the input and emission of captured $\mathrm{CO}_{2}$ through the system to distort the analysis. Figure 5 overleaf presents a pie chart reflecting the contribution of the four main steps involved in the modelled CCU process.

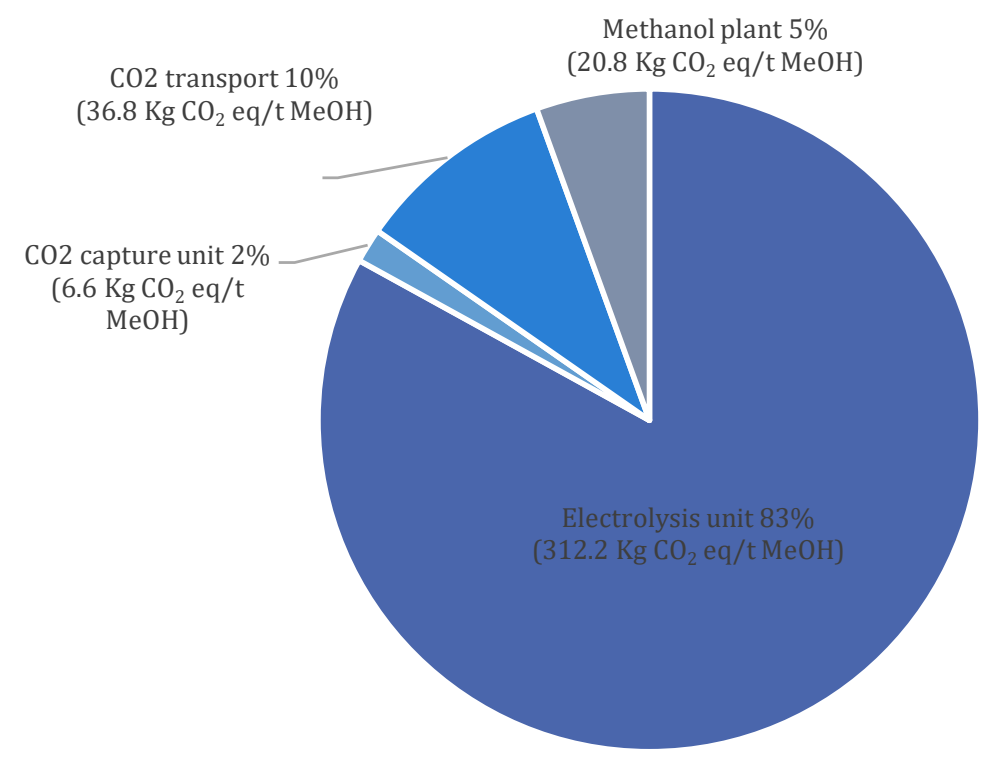

Figure 5. The indirect global warming impacts of the four main processes identified as components of the CCU methanol production process.

Despite the fact that renewable electricity was used, the contribution made by electricity usage compared to the other inputs was dominant, as presented in Figure 6 below. 

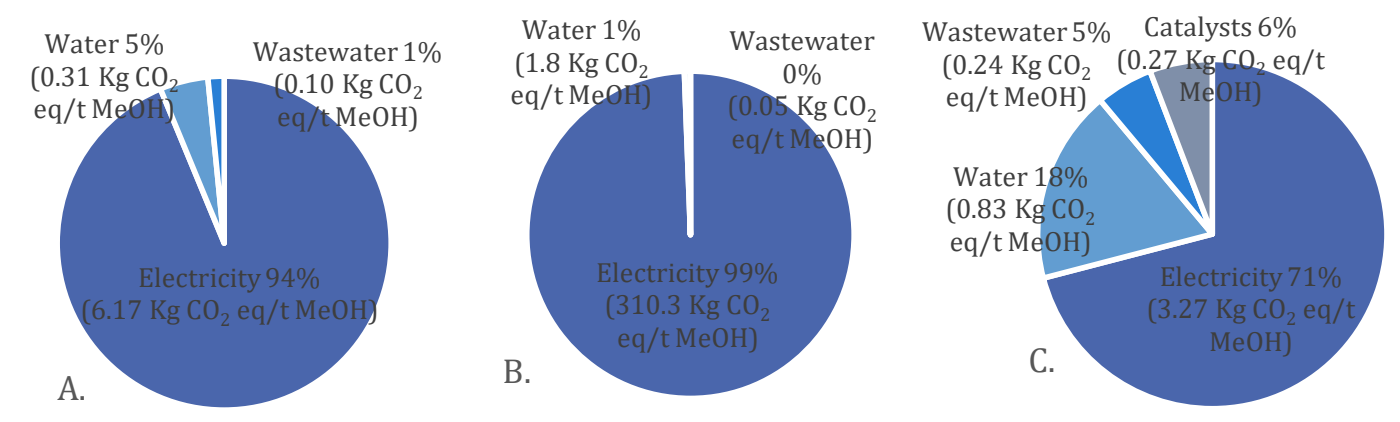

Figure 6. The contribution that the main process inputs make to the indirect global warming impacts of the component processes of the $\mathrm{CCU}$ methanol production. A. $\mathrm{CO}_{2}$ capture unit, B. electrolysis unit and C. methanol plant. 


\section{C.7 Life Cycle Interpretation}

\section{Reference to LCA Guidelines}

A description of what should be included within this section of an LCA report is provided in Section C.7 Life cycle interpretation of the guidelines, with Guidelines $\mathbf{C . 1 2}$ and C.13 specifying what is required.

In addition, a checklist of items to be included in each section of the report is included in Section C.8 Reporting of the guidelines, which for the life cycle interpretation is as follows:

\section{Life cycle interpretation}

Include and describe the results

Negative emission in cradle-to gate studies shall not be interpreted as $\mathrm{CO}_{2}$ sinks if life does not end with permanent carbon fixation

- Emission reductions due to substitution effects shall be interpreted as environmental benefits but not as negative emissions

Describe uncertainty and sensitivity analysis and report results separately

Include completeness check

Include consistency check

- State assumptions and limitation associated with the interpretation of results

Include conclusions

Include recommendations, if any

It is clear from the data presented in Figure 4 that switching methanol production from the conventional SMR process to the CCU process reduces the global warming impacts only if low carbon electricity is used. If that is the case, then significant savings can be made.

No attempt is made here to explain the variations in results of the impact categories obtained when the electricity scenarios were changed, since as mentioned previously, the focus is on issues specific to CCU. Such explanations are readily available in other LCA comparisons of electricity sources.

\subsection{Sensitivity analysis - location of the facility}

It is common practice when performing LCA of industrial processes to determine the sensitivity of the environmental impacts of the process to the country where the facilities are located. In this case, the baseline process was evaluated in Germany, so it would make sense to compare the same process in other countries. However, when utilizing $\mathrm{CO}_{2}$ derived from another industry (such as a cement or power plant) the LCA practitioner needs to be aware that the efficiency of the $\mathrm{CO}_{2}$ source may differ in different countries. This has implications, since it means that the amount of co-product produced per unit $\mathrm{CO}_{2}$ varies. The following section provides a worked example of how this impacts LCA. 
The CCU methanol plant modeled requires $1.45 \mathrm{t} \mathrm{CO}_{2}$ to produce $1 \mathrm{t}$ methanol. At a capture efficiency of $86.98 \%$, this means that $1.669 \mathrm{t} \mathrm{CO}_{2}$ per hour is required from the cement plant. Cement plants in the ecoinvent 3.4 database differ in efficiency between countries. For instance, Portland cement produced in Switzerland results in $0.729 \mathrm{Kg} \mathrm{CO}_{2} / \mathrm{Kg}$ cement, but in Germany this is 0.852 and in USA it is $0.883 \mathrm{Kg} \mathrm{CO}_{2} / \mathrm{Kg}$ cement. This means that a cement plant in Germany will manufacture $1.959 \mathrm{t}$ cement while producing the required $1.669 \mathrm{t} \mathrm{CO}_{2}$ (as was used in the functional unit of this report) but a similar plant in Switzerland would manufacture $2.289 \mathrm{t}$ cement while producing the same quantity of $\mathrm{CO}_{2}$ whereas a plant in the USA would produce only $1.890 \mathrm{t}$ cement when producing the same quantity of $\mathrm{CO}_{2}$.

The differing productivity of co-products per tonne $\mathrm{CO}_{2}$ produced in different countries means that there needs to be some consideration of how a consistent functional unit can be obtained if doing such a comparison. If the same $1.959 \mathrm{t}$ cement that was produced in Germany is manufactured in Switzerland and USA, then the highly efficient Swiss cement plant would not produce enough $\mathrm{CO}_{2}$ to produce the 1 tonne methanol required by the functional unit, whereas enough $\mathrm{CO}_{2}$ would be produced in USA to produce more than 1 tonne methanol.

Since a consistent functional unit is required to enable comparison of the impacts of the CCU processes in different countries, the suggested approach is to model the production of the mass of cement in the most efficient country which produces the required $1.669 \mathrm{t} \mathrm{CO}_{2}$. In this example Switzerland has the most efficient cement plants, where $2.289 \mathrm{t}$ cement needs to be produced to generate the $1.669 \mathrm{t} \mathrm{CO}_{2}$. Therefore, a functional unit of $1 \mathrm{t}$ methanol and $2.289 \mathrm{t}$ cement is used, which allows all countries to produce enough $\mathrm{CO}_{2}$ for the methanol production.

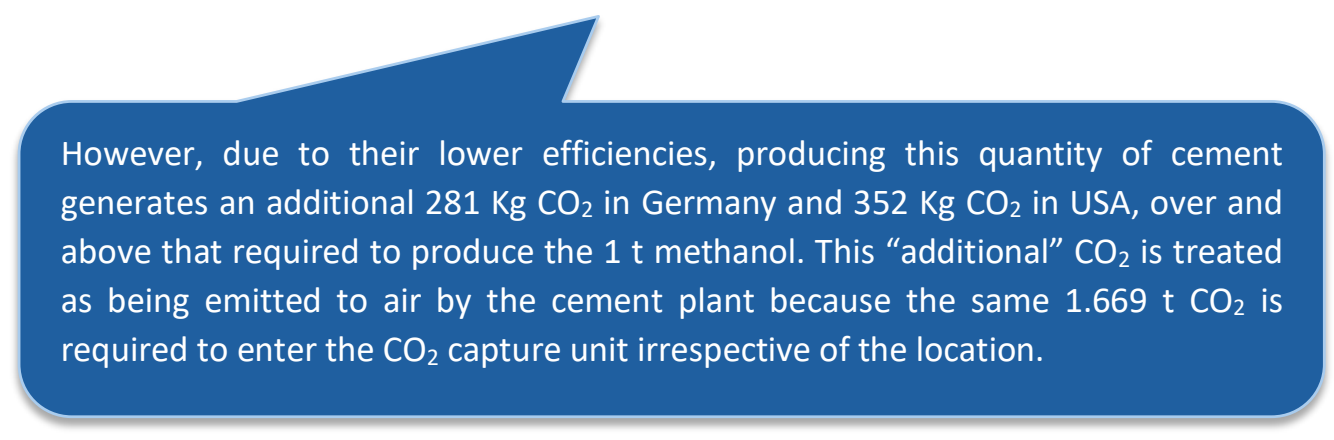

Table 6 presents the LCIA results of this analysis, which assumes that the electricity used for all processes is decarbonized as used previously. The same system expansion approach was used to include the impacts of the cement plant as used previously. Figure 7 presents the climate change impact category (excluding biogenic carbon) resulting from this analysis as a graph to enable comparison of the conventional (SMR) versus CCU process in the three countries studied. This shows that the climate impact of the SMR process was $21 \%$ lower if the process was modelled in Switzerland rather than in USA. Similarly, the climate change impact of the CCU process was almost 25\% lower if sited in Switzerland than in Germany (due to German onshore wind having a higher carbon intensity than US onshore wind, according to ecoinvent 3.4). Therefore, the production of methanol does not only change over time but is also depended on the regional setting.

The reduction in climate impacts achieved by switching from conventional steam methane reforming to the CCU methanol process was $63 \%$ when located in USA or Switzerland and $61 \%$ when located in Germany. 


\begin{tabular}{|c|c|c|c|c|c|c|}
\hline \multirow{2}{*}{$\begin{array}{l}\text { Impact categories } \\
\text { (ILCD/PEF recommendation v1.09) }\end{array}$} & \multicolumn{2}{|c|}{ Germany } & \multicolumn{2}{|c|}{ Switzerland } & \multicolumn{2}{|c|}{ USA } \\
\hline & SMR & CCU & SMR & CCU & SMR & CCU \\
\hline Acidification midpoint (v1.09) [Mole of $\mathrm{H}+$ eq.] & 7.8 & 8.5 & 6.5 & 7.8 & 5.5 & 7.4 \\
\hline Climate change midpoint, excl biogenic carbon (v1.09) [kg CO2 eq.] & 2501 & 986 & 2029 & 741 & 2582 & 948 \\
\hline Climate change midpoint, incl biogenic carbon (v1.09) [kg CO2 eq.] & 2532 & 1016 & 2133 & 842 & 2613 & 977 \\
\hline Ecotoxicity freshwater midpoint (v1.09) [CTUe] & 4646 & 205972 & 4292 & 229369 & 6438 & 141612 \\
\hline Eutrophication freshwater midpoint (v1.09) [kg P eq.] & 0.21 & 0.78 & 0.21 & 0.85 & 0.37 & 0.74 \\
\hline Eutrophication marine midpoint (v1.09) [kg N eq.] & 1.40 & 1.76 & 1.11 & 1.54 & 1.47 & 1.66 \\
\hline Eutrophication terrestrial midpoint (v1.09) [Mole of $\mathrm{N}$ eq.] & 16.3 & 19.1 & 13.6 & 17.0 & 16.2 & 17.7 \\
\hline Human toxicity midpoint, cancer effects (v1.09) [CTUh] & 0.00003 & 0.0002 & 0.00002 & 0.0002 & 0.00004 & 0.0001 \\
\hline Human toxicity midpoint, non-cancer effects (v1.09) [CTUh] & 0.0002 & 0.001 & 0.0001 & 0.001 & 0.0002 & 0.001 \\
\hline Ionizing radiation midpoint, human health (v1.09) [kBq U235 eq.] & 73.5 & 91.7 & 125.2 & 148.6 & 74.7 & 84.3 \\
\hline Land use midpoint (v1.09) [kg C deficit eq.] & 1916 & 2413 & 1269 & 1975 & 2110 & 2013 \\
\hline Ozone depletion midpoint (v1.09) [kg CFC-11 eq.] & 0.0001 & 0.00008 & 0.0001 & 0.00005 & 0.0001 & 0.0001 \\
\hline Particulate matter/Respiratory inorganics midpoint (v1.09) [kg PM2.5 eq.] & 0.49 & 0.88 & 0.33 & 0.78 & 0.88 & 1.16 \\
\hline Photochemical ozone formation midpoint, human health (v1.09) [kg NMVOC eq.] & 5.7 & 5.1 & 5.0 & 4.6 & 4.9 & 4.7 \\
\hline Resource depletion water, midpoint (v1.09) [ $\mathrm{m}^{3}$ eq.] & 7.9 & 9.1 & 5.2 & 8.0 & 9.5 & 7.5 \\
\hline Resource depletion, mineral, fossils and renewables, midpoint (v1.09) [kg Sb eq.] & 0.03 & 0.10 & 0.02 & 0.10 & 0.03 & 0.07 \\
\hline
\end{tabular}

Table 6. Impact assessment per tonne methanol produced in a conventional (SMR) methanol plant compared to a CCU methanol plant using electricity generated by wind

turbines. System expansion was used to include the impacts associated with the cement plant which provided the feedstock-CO ${ }_{2}$. 


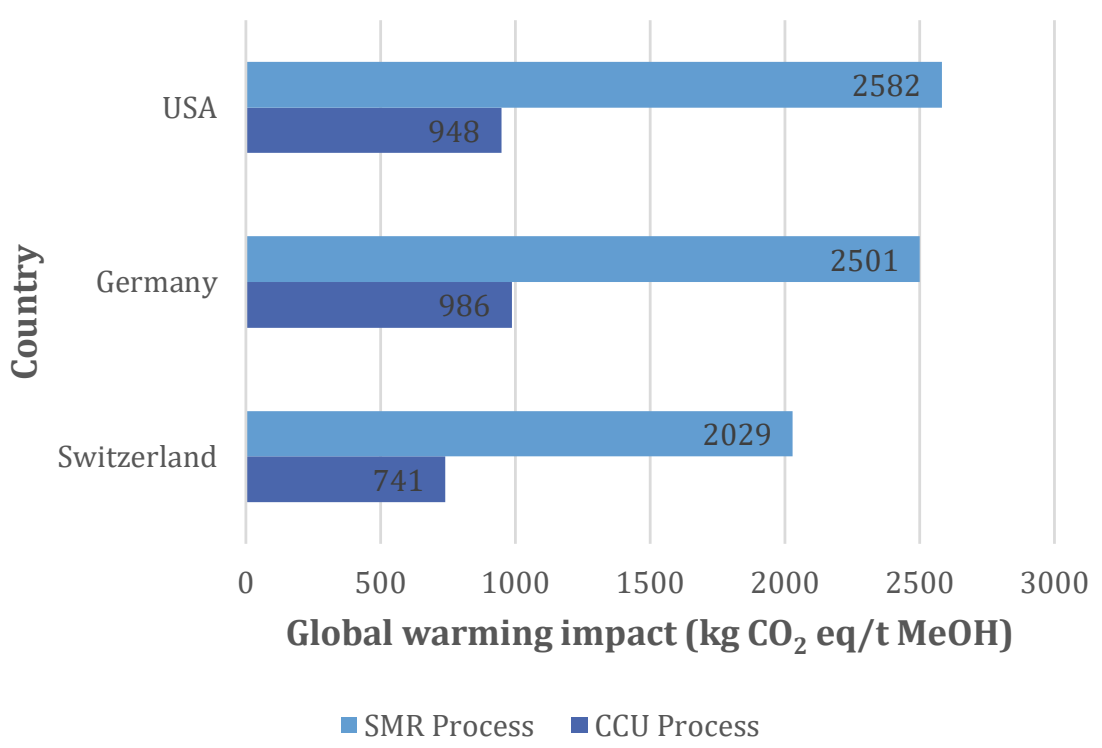

Figure 7. Comparison of the global warming impacts of the conventional SMR process vs the CCU process in USA, Germany and Switzerland. Wind power was used for all processes.

It should be noted that the global warming impact results for both the SMR and CCU processes in Germany presented in Figure $\mathbf{7}$ are higher than those presented previously in Figure $\mathbf{4}$ in Section C. 6 of this document. This is due to $2.289 \mathrm{t}$ cement used in the functional unit in this part of the study, as opposed to $1.959 \mathrm{t}$ used previously. This additional mass of cement was previously calculated to account for an extra $281 \mathrm{Kg} \mathrm{CO}_{2}$, reflected by the climate impact increase of $286 \mathrm{Kg}$ $\mathrm{CO}_{2}$ eq. This discrepancy has been retained to enable the reader to see the impact of using a different functional unit within different parts of the same study.

For the reasons highlighted above, only one functional unit should be used in an LCA study. If an analysis involving comparisons between different countries is to be used, then all sections of the analysis need to be conducted using the same functional unit, i.e. in this report the functional unit involving $2.289 \mathrm{t}$ cement would need to be used from the start. However, to justify the additional $\mathrm{CO}_{2}$ production apparent at the start of the assessment, the country comparison would need to be made one of the goals of the study, rather than just an example as provided here.

Additionally, the use of the countries from different regions as comparator country has impacts upon the impact assessment methodology used for the study. ILCD is appropriate for studies within Europe, but if the USA is to be included as a comparator country then the CML assessment methodology should be used.

\section{C.7.2 Limitations}

The accuracy of this study was limited by the lack of modelling of the infrastructure for either the $\mathrm{CO}_{2}$ capture unit or the electrolysis unit (as recorded in Section C.4.2.2 and Table 1). An infrastructure 
component was added to the model for the CCU methanol plant itself. The database values for the conventional (SMR) methanol plant that the CCU plant is being compared to will be included within the ecoinvent 3.4 data used. This will result in a slightly unequal comparison, with a lower infrastructure contribution to the CCU process than the SMR process. The results should therefore be considered to be limited in their accuracy.

All weaknesses in modelling or data availability should be identified to enable the reader to determine their significance upon the interpretation of the results.

In Section C.4.2.3 and Table 2 of this report it was highlighted that some of the reference process data from ecoinvent v3.4 utilized in modeling is several years old. This adds a level of uncertainty since the reference processes used in reality today may be slightly more efficient than those used in the models. If this is the case, then the observed reduction in global warming impacts gained by switching from conventional production to the CCU process may be smaller than the results suggest. However, the scale of the reductions in global warming impacts (in Germany, CCU production caused climate impacts up to $68 \%$ lower than conventional SMR if both processes use electricity from wind power) are so great that a small increase in efficiency of the conventional process would only slightly reduce the large $\mathrm{CO}_{2}$ eq. reductions obtained by switching to the CCU process.

Another area of uncertainty was that caused the use of low TRL membrane capture system. However, a sensitivity analysis (described in the Integration worked example provided as Part D of this document) revealed the relatively small effect upon global warming impacts that changes to the efficiency of the capture system cause.

In addition, the focus of this worked example analysis has been the effect of the CCU process upon the global warming impacts. The results of the other impact categories have been presented as tabulated data but not presented graphically and analyzed in any detail. If a full life-cycle assessment was to take a similar approach and only present global warming impacts, this could potentially mislead decision-making since trade-offs between environmental impact categories cannot be identified by such a study.

\section{C.7.3 Critical review of the study goal}

The goal for this study was:

To compare the environmental impacts (with a focus upon global warming impacts) of producing methanol for use as a chemical feedstock in Germany, synthesised via two routes: the hydrogenation of $\mathrm{CO}_{2}$ captured from a cement plant vs methanol synthesised using the conventional steam methane reforming process from natural gas.

The goal of this study was achieved. The environmental impacts of the two processes located in Germany were compared. Contribution analysis revealed that the most significant contribution to the impacts was 
found to be electricity use, so different electricity scenarios were tested - comparing the status-quo with a low decarbonized, high decarbonized and a decarbonized scenario using $100 \%$ wind power.

As explained previously, if a comparison between countries is going to be conducted (either as part of the main study or just as part of a sensitivity analysis) then this should be captured within the goal of the study.

\section{.7.4 Interpretation and recommendations from a CCU perspective}

The production of methanol from $\mathrm{CO}_{2}$ does not provide a long-term net $\mathrm{CO}_{2}$ sink as the chemical feedstock being produced has a limited lifetime before it is oxidized back to $\mathrm{CO}_{2}$ and re-emitted to atmosphere. However, if low-carbon electricity is used, a significant reduction in global warming impacts is achieved if conventional (SMR) production is switched to CCU production. There are also no environmental impact reduction benefits from the CCU processes when comparing between the conventional SMR and the CCU processes if the current grid mix electricity is used. This may be expected from a technology with a very high electricity demand where most of the environmental impacts are related to the supply of electricity to the electrolyzer.

There are approximately 90 large-scale methanol plants globally [1]. Switching them from SMR-based processes to CCU-based processes to achieve the aims described above would lead to a significant increase in demand for low carbon/renewable hydrogen. Currently, producing low-carbon hydrogen requires large amounts of low-carbon electricity. If the efficiency of this process is increased, the impact reductions of switching to CCU processes would be even greater. However, assessing the impacts of a large-scale switch to CCU methanol was beyond the scope of this study.

In conclusion, life cycle assessment using system expansion was used to compare the environmental impacts of producing methanol from $\mathrm{CO}_{2}$ captured from a cement plant with producing methanol from SMR. Modelling indicates that the global warming impact of $\mathrm{CO}_{2}$-derived methanol is of the order of $60 \%$ lower than SMR-derived methanol if both processes use wind power. Comparison between countries reveals that the impacts are lowest if the plant is sited in a country where less $\mathrm{CO}_{2}$ is emitted at the $\mathrm{CO}_{2}$ source per main product, as more co-product is produced per quantity of $\mathrm{CO}_{2}$ required to produce $1 \mathrm{t}$ of methanol.

The results revealed that the global warming impacts were $68 \%$ lower than the impacts of conventional SMR production if electricity sourced from wind turbines was used for both processes. However, the limitations of the study discussed in Section C.7.2 mean that it may not be wise to be too exact with the numerical results when reporting the final conclusions, as there is a degree of uncertainty imposed by the study limitations. A similar level of caution, reflecting the uncertainty in the results, was also applied in the executive summary. An uncertainty analysis would need to be conducted to enable the scale of this uncertainty to be determined. 
Following from the above conclusions it is recommended that further analysis is done to reduce the recognized limitations of this study. Modelling of the impacts due to the infrastructure requirements of both the electrolysis unit and the $\mathrm{CO}_{2}$ capture unit would be a useful step towards this goal. Low TRL membrane capture technology was modelled in the current study. It is therefore recommended that modelling is done using different (higher TRL) capture techniques to determine the sensitivity of the observed environmental impacts of the $\mathrm{CCU}$ methanol process to the $\mathrm{CO}_{2}$ capture technology used. 


\section{C.8 References}

1. Methanol Institute (2018). The Methanol Industry. Available at: http://www.methanol.org/themethanol-industry/ Accessed March 2018.

2. CArbon-free Electricity by SEWGS: Advanced materials, Reactor and process design. European best practice guidelines for assessment of $\mathrm{CO} 2$ capture technologies, 2011.

3. Walas SM. Chemical Process Equipment: Selection and Design: Butterworth-Heinemann; 1988.

4. Brian B. Guidelines for Estimating Unmetered Industrial Water Use. Pacific Northwest National Laboratory, 2011.

5. Vatopoulos K, Tzimas E. Assessment of $\mathrm{CO} 2$ capture technologies in cement manufacturing process. Journal of Cleaner Production. 2012;32:251-61.

6. Hassan SMN, Douglas PL, Croiset E. Techno-Economic Study of CO2 Capture from an Existing Cement Plant Using MEA Scrubbing. International Journal of Green Energy. 2007;4(2):197-220.

7. Scholes CA, Ho MT, Aguiar AA, Wiley DE, Stevens GW, Kentish SE. Membrane gas separation processes for $\mathrm{CO} 2$ capture from cement kiln flue gas. International Journal of Greenhouse Gas Control. 2014;24:78-86.

8. He X, Hägg M-B. Energy Efficient Process for $\mathrm{CO} 2$ Capture from Flue gas with Novel Fixed-sitecarrier Membranes. Energy Procedia. 2014;63:174-85.

9. Zhang X, He X, Gundersen T. Post-combustion Carbon Capture with a Gas Separation Membrane: Parametric Study, Capture Cost, and Exergy Analysis. Energy \& Fuels. 2013;27(8):4137

10. He X, Fu C, Hägg M-B. Membrane system design and process feasibility analysis for $\mathrm{CO} 2$ capture from flue gas with a fixed-site-carrier membrane. Chemical Engineering Journal. 2015;268:1

11. Pascu A, Badea A, Dinca C, Stoica L. Simulation of polymeric membrane in Aspen Plus for $\mathrm{CO} 2$ post-combustion capture. 4th International Conference on Engineering Optimization Volume: Engineering Optmization, 2014.

12. Belaissaoui $B$, Le Moullec $Y$, Willson D, Favre E. Hybrid membrane cryogenic process for postcombustion CO2 capture. Journal of Membrane Science. 2012;415-416:424-34.

13. Carmo M, Fritz DL, Mergel J, Stolten D. A comprehensive review on PEM water electrolysis. International Journal of Hydrogen Energy. 2013;38(12):4901-34.

14. Hank C, Gelpke S, Schnabl A, White RJ, Full J, Wiebe N, et al. Economics \& Carbon Dioxide Avoidance Cost of Methanol Production based on Renewable Hydrogen and recycled Carbon Dioxide - Power-to-Methanol. Sustainable Energy \& Fuels. 2018.

15. Teichmann D, Stark K, Muller K, Zottl G, Wasserscheid P, Arlt W. Energy storage in residential and commercial buildings via Liquid Organic Hydrogen Carriers (LOHC). Energy \& Environmental Science. 2012;5(10):9044-54.

16. Atsonios K, Panopoulos KD, Kakaras E. Investigation of technical and economic aspects for methanol production through $\mathrm{CO}_{2}$ hydrogenation. International Journal of Hydrogen Energy. 2016;41(4):2202-14.

17. SILYZER 200 High-pressure efficiency in the megawatt range. Retrieved from: https://www.industry.siemens.com/topics/global/en/pem-electrolyzer/silyzer/Documents/201704-Silyzer200-boschure-en.pdf.

18. Van-Dal ÉS, Bouallou C. Design and simulation of a methanol production plant from $\mathrm{CO}_{2}$ hydrogenation. Journal of Cleaner Production. 2013;57:38-45. 
19. Pérez-Fortes M, Schöneberger JC, Boulamanti A, Tzimas E. Methanol synthesis using captured CO2 as raw material: Techno-economic and environmental assessment. Applied Energy. 2016;161:71832.

20. Kiss AA, Pragt JJ, Vos HJ, Bargeman G, de Groot MT. Novel efficient process for methanol synthesis by $\mathrm{CO} 2$ hydrogenation. Chemical Engineering Journal. 2016;284:260-9.

21. Nag PK. Engineering Thermodynamics, 5e: McGraw Hill Education.

22. Vanden Bussche KM, Froment GF. A steady-state kinetic model for methanol synthesis and the water gas shift reaction on a commercial $\mathrm{Cu} / \mathrm{ZnO} / \mathrm{Al} 2 \mathrm{O} 3$ catalyst. Journal of Catalysis. 1996;161(1):1-10.

23. Mignard D, Sahibzada M, Duthie JM, Whittington HW. Methanol synthesis from flue-gas CO2 and renewable electricity: a feasibility study. International Journal of Hydrogen Energy. 2003;28(4):455-64.

24. Sun JT., Metcalfe I.S. and Sahibzada M. Deactivation of $\mathrm{Cu} / \mathrm{ZnO} / \mathrm{Al}_{2} \mathrm{O}_{3}$ methanol synthesis catalyst by sintering. Industrial and Engineering Chemistry Research 1999; 38: 3868-3872.

25. International Energy Agency. Energy Technology Perspectives 2017: Catalysing Energy Technology Transformations. Available at: http://www.iea.org/etp/. 


\section{C.9 Appendix - Inventory}

\section{.9.1 Process design and simulation basis}

This section presents the process design and simulation of the showcase methanol plant. For this purpose, Aspen Plus simulator was employed to execute the necessary mass and energy balances. A sequentialmodular approach was adapted in which the equations describing each process unit (module) were solved module-by-module in a stepwise manner. Iterative techniques were then used to solve the problems arising from the recycle of information. Four models were employed to determine the thermodynamic properties: Redlich-Kwong-Soave with Huron-Vidal mixing rules for streams at high pressure ( $>10 \mathrm{bar}$ ), and NRTL-RK for streams at low pressure ( $<10$ bar), electrolyte-NRTL for electrolysis reactions and typical steam tables for the CHP units.

For compressors and gas turbines, mechanical and isentropic efficiencies are $95 \%$ and $90 \%$ respectively, while for pumps overall efficiency is set equal to $70 \%$. For high pressure, intermediate pressure and low pressure steam turbines, isentropic efficiencies are $92 \%, 94 \%$ and $88 \%$ respectively [2]. Pressure drop in heat exchangers is typically dependent on phase. Usually liquid phase pressure drop is absolute and does not depend on relative pressure of the liquid. Liquid phase pressure drop for cold and hot side was set equal to 0.3 bar and gas phase pressure drop for cold and hot side 3\% [3]. In addition, a minimum temperature difference of $7^{\circ} \mathrm{C}$ was applied for heat transfer. When, during heating exchanging, phase change occurs then at least three heat exchangers were used; two to count for the sensible heat above and below the temperature at which the phase change occurs and one for the latent heat. Openrecirculating cooling systems, that utilise the evaporation process to provide process or comfort cooling, were considered in the present study. A $5 \%$ loss was assumed to count for drift, evaporation and blow down losses. The temperature range of cooling water is typically $15-25^{\circ} \mathrm{C}$. Furthermore, for a condensate return of $80 \%$ (of generated steam), the make-up rate of feed boiler water should be expected to be around $25 \%$ of the recirculated rate [4].

The system to produce methanol is divided into three main areas:

1. $\mathrm{CO}_{2}$ capture

2. Hydrogen production

3. Methanol synthesis

\section{$.9 .2 \mathrm{CO}_{2}$ capture}

Among the different carbon capture processes, membrane separation generates growing interest. Membrane separation can handle low to moderate dilute $\mathrm{CO}_{2}$ streams and achieve high purity of $\mathrm{CO}_{2}$ capture streams. However, based on the existing materials performances, the target purity $(>99.5 \%)$ cannot be attained by a single or multiple stages [5]. $\mathrm{CO}_{2}$ can be also separated from other gases by cooling and condensation. Cryogenic separation is widely used commercially for streams that already have high $\mathrm{CO}_{2}$ concentrations (typically $>90 \%$ ) but it is not used for more dilute $\mathrm{CO}_{2}$ streams. This suggests that a synergy between the two separations processes is possible and their combination could lead to a possible optimum with a minimal overall requirement. The study focuses on decarbonising heavy industries rather than power generation units as the latter are projected to shut down in the next few years while the market for the former is expected to grow over the foreseeable future.

There are two distinct sources of $\mathrm{CO}_{2}$ associated with a cement kiln. The first is the result of the direct combustion of fossil fuels for heat energy which produces a flue gas of $4-15$ vol $\% \mathrm{CO}_{2}$ depending upon the 
source of fuel. The second is the by-product of calcining of limestone to produce the clinker material [6], where stoichiometric quantities of carbon dioxide are produced according to the reaction.

$\mathrm{CaCO}_{3} \rightarrow \mathrm{CaO}+\mathrm{CO}_{2}$

Both of these sources emit roughly equal amounts of $\mathrm{CO}_{2}$ per tonne of cement produced and therefore when combined generate a flue gas that is more concentrated in $\mathrm{CO}_{2}$ than is generally found in the power generation industry [7]. Typical total flue gas concentrations range from 22 to $28 \mathrm{~mol} \%$, with $900 \mathrm{~kg}$ of $\mathrm{CO}_{2}$ emitted during production of $1000 \mathrm{~kg}$ of cement [5].

A single-stage membrane unit cannot achieve a high $\mathrm{CO}_{2}$ capture ratio $(>80 \%)$ and $\mathrm{CO}_{2}$ purity $(>95 \%)$ simultaneously, as reported by $\mathrm{He}$ et al. [8], and energy efficiency could be improved using multiple-stage membrane systems to reduce the irreversibility of the whole process, as documented by Zhang et al. [9]. Based on the design of $\mathrm{He}$ et al. [10], a two-stage cascade membrane system was considered in the present study. The first stage membrane unit is used for pre-concentration of $\mathrm{CO}_{2}$ up to $50-70 \%$. The concentrated $\mathrm{CO}_{2}$ stream is then compressed to a certain pressure (e.g., 2-3 bar) and fed into the second stage membrane unit for ultimate $\mathrm{CO}_{2}$ purification to achieve high $\mathrm{CO}_{2}$ purity (>95\%). In order to document the process and economic feasibility of membrane systems the following assumptions were made: 1) A membrane gas separation processes based on MTR (Membrane Research and Technology) Polaris ${ }^{\mathrm{TM}}$ membrane at a feed and permeate pressure of $2.5 \mathrm{bar}$ and $250 \mathrm{mbar}$ (optimal pressure reported in [8]) was employed, 2) a $\mathrm{CO}_{2} / \mathrm{N}_{2}$ and $\mathrm{CO}_{2} / \mathrm{O}_{2}$ selectivity of 50 and 20 were [11]. Selectivity of $\mathrm{CO}_{2} / \mathrm{H}_{2} \mathrm{O}$ is assumed as unity and 3) pressure drop between retentate and feed streams in conjunction with temperature difference between feed and permeate sides due to the Joule-Thompson effect are assumed to be negligible.

Flue gas is assumed to be delivered free of $\mathrm{NO}_{x}$ and $\mathrm{SO}_{x}$ components. Initially, flue gas is cooled below dew point, water is then removed and subsequently compressed to 2.5 bars. Before each membrane flue gas is conditioned so as to meet the pressure conditions (via vacuum pumps and compressors), monitor temperature at $35^{\circ} \mathrm{C}$ and where necessary remove condensed water. The permeate stream exiting the second membrane has a $95 \% \mathrm{CO}_{2}$ purity. Vent streams are collected and due to the high pressure of the mixed stream, electricity can be generated in an expander. Prior to this step, heat integration is realised with the aim of increasing the temperature (and consequently the enthalpy content) of the vent stream. For this purpose, three heat exchangers are added as depicted in Figure 4 (red circles) to recover heat from the gas streams exiting, Compr1, Compr2 and Compr3 as well as VPump2. The integrated design reduces the cooling duties by $27.2 \%$ and the electricity demand by $32.9 \%$. The next step of the carbon capture system configuration involves the cryogenic treatment of the $\mathrm{CO}_{2}$ rich stream. According to Belaissaoui et al. [12], highly concentrated $\mathrm{CO}_{2}$ streams $(>90 \%)$, should be pressurised up to 11 bar before entering the economiser unit; a two-stage compressor with intermediate cooling is utilised. Afterwards, the gas is cooled down by water and cooled down further in the economiser to $-73^{\circ} \mathrm{C}$. The gas goes through a valve in order to reach the minimal necessary liquefaction pressure. The inlet pressure flash is set in order to have a $\mathrm{CO}_{2}$ partial pressure of 5.4 bar ensuring a proper liquefaction of $\mathrm{CO}_{2}$ and non-frosting conditions. After being heated in the economizer, the incondensable gases are mixed with the retentate streams and sent to an expander to generate electricity while the $\mathrm{CO}_{2}$ enters a flash unit to remove water and is sent to the methanol synthesis plant. Overall, a $\mathrm{CO}_{2}$ purity of $99.6 \%$ is achieved along with a capture ratio of approximately $87 \%$. 


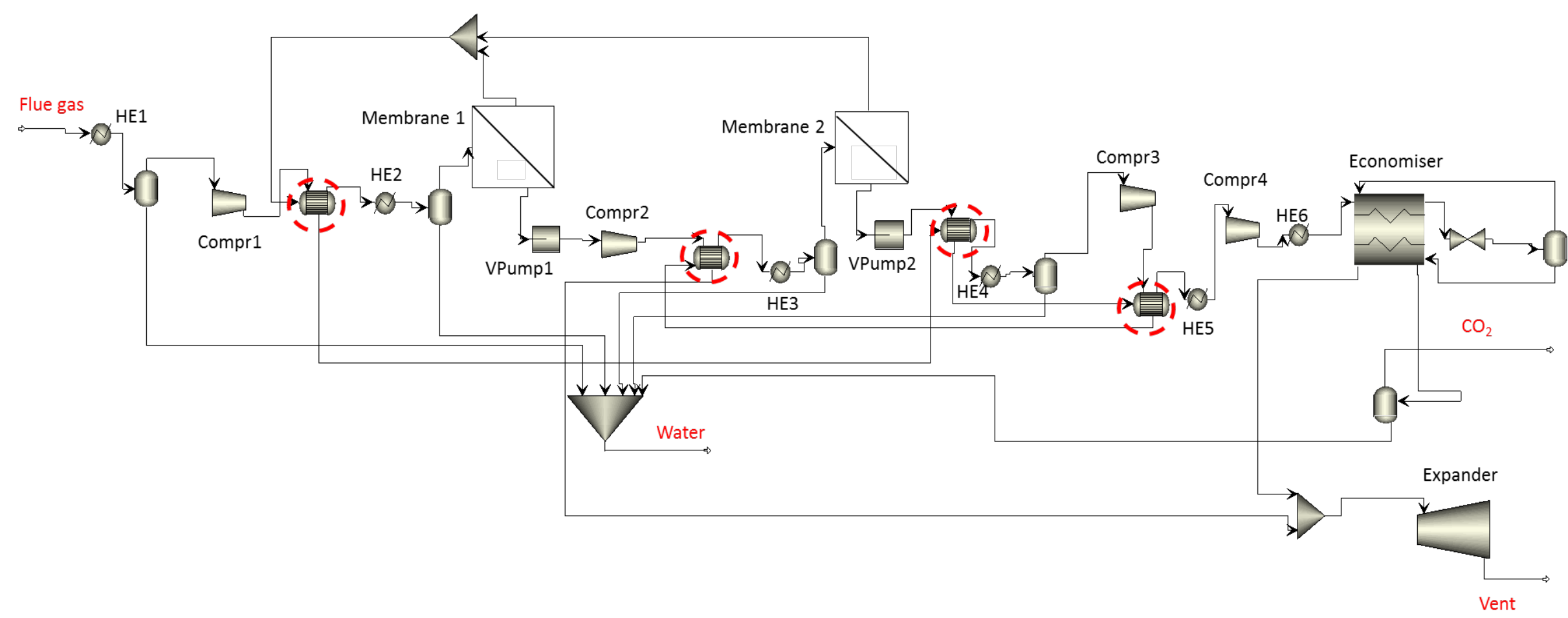

Figure 4. Process flow diagram for $\mathrm{CO}_{2}$ capture though a multistage membrane system. 


\section{C.9.3 Hydrogen production}

Hydrogen is produced via electrolysis by passing electricity through two electrodes in water. The water molecule is split and produces oxygen at the anode and hydrogen at the cathode. A proton exchange membrane (PEM) electrolyser was selected over an alkaline process as it provides higher efficiencies and also serves to separate the hydrogen and oxygen gases, as oxygen is produced at the anode on one side of the membrane and hydrogen is produced on the opposite side of the membrane [13]. Additionally, PEM electrolysers operate very well under variable loads further efficiency enhancements are anticipated in the coming decade [14]. The membrane allows the $\mathrm{H}^{+}$ion to transfer from the anode side of the membrane to the cathode side, where it forms hydrogen. An efficiency of $70 \%$ based on $\mathrm{H}_{2}$ LHV [15] was considered and the required electricity is derived for the base study from the grid. An additional $10 \%$ is supplied to cover the demand of the balance of the electrolysis (BOE) section [16]; the overall electrical consumption is 52.4 $\mathrm{kWh} / \mathrm{kgH}_{2}$. The lifetime of the electrolyser is $80,000 \mathrm{~h} \mathrm{[17].} \mathrm{In} \mathrm{order} \mathrm{for} \mathrm{the} \mathrm{process} \mathrm{to} \mathrm{be} \mathrm{sustainable,} \mathrm{it}$ should be noted that green electricity is a prerequisite and therefore either renewable energy certificates and/or substantial penetration of renewable energy in the grid are required.

The PEM unit was modelled by employing two RSTOICH reactors both operating at temperature and pressure of $80^{\circ} \mathrm{C}$ and 35 bar respectively. The first represents the anode $\left(\mathrm{H}_{2} \mathrm{O} \rightarrow 1 / 2 \mathrm{O}_{2}+2 \mathrm{H}^{+}+2 \mathrm{e}^{-}\right)$and the second the cathode $\left(2 \mathrm{H}^{+}+2 \mathrm{e}^{-} \rightarrow \mathrm{H}_{2}\right)$. A $95 \%$ water conversion is realized while the electricity demand was calculated by FORTRAN statements based on the necessary amount of hydrogen. Additionally, it should be noted deionized water is utilized. Oxygen is separated via a common separator ( $100 \%$ efficiency was assumed), then cooling to $30^{\circ} \mathrm{C}$ is applied and subsequently condensed water is removed. Purified hydrogen is recovered and is sent to methanol production plant. It was assumed that electrolysis occurs on site and no transport is required. Additionally, for a constant electricity load a constant $\mathrm{H}_{2}$ production can be assumed and as so no buffering is included for the base case study.

\section{-9.4 Methanol synthesis}

The process design for the methanol plant is based on previous works conducted by Van-Dal and Bouallou [18], Perez-Fortes et al. [19] and Kiss et al. [20]. The plant produces $\mathrm{MeOH}$ at a rate of $42.78 \mathrm{t} / \mathrm{h}(1.02$ $\mathrm{kt} /$ day). $\mathrm{CO}_{2}$ is delivered to the plant at a flowrate of $62.08 \mathrm{t} / \mathrm{h}$, pressure of 5.4 bar and temperature of $25^{\circ} \mathrm{C}$. The required $\mathrm{H}_{2}\left(3: 1 \mathrm{H}_{2}: \mathrm{CO}_{2}\right.$ molar ratio) produced from the PEM unit is supplied at a pressure of 35 bar and temperature of $25^{\circ} \mathrm{C}$. The first step of the process incorporates the conditioning of the reactant gases to the operating conditions of the synthesis reactor, i.e. 78 bar and $210^{\circ} \mathrm{C} . \mathrm{CO}_{2}$ is compressed via a multistage compressor consisting of two compressors with intermediate cooling. If the gas is cooled to the inlet or slightly higher $\left(\sim 35^{\circ} \mathrm{C}\right)$ temperature of the previous lower pressure compressor it can be shown that minimum specific work is consumed when the pressure ratios (3.8:1 in our case) of the compressors are equal [21]. A single stage compressor was utilised to raise $\mathrm{H}_{2}$ pressure up to $78 \mathrm{bar}$. The two gases are mixed and then re-mixed (for convergence purpose) with the recycle stream. The stream is then heated to $210^{\circ} \mathrm{C}$ and injected into the fixed bed adiabatic reactor. The adiabatic reactor is packed with a fixed bed of 44.5 tonnes of $\mathrm{Cu} / \mathrm{ZnO} / \mathrm{Al}_{2} \mathrm{O}_{3}$ commercial catalyst. For this catalyst, the model proposed by Vanden Bussche and Froment [22] with readjusted parameters of Mignard and Pritchard [23] is able to describe with good precision the reactions of methanol production, Eq. (1) and the RWGS reaction, Eq. (2).

$$
\begin{aligned}
& \mathrm{CO}_{2}+3 \mathrm{H}_{2} \rightarrow \mathrm{CH}_{3} \mathrm{OH}+\mathrm{H}_{2} \mathrm{O} \\
& \mathrm{CO}_{2}+\mathrm{H}_{2} \rightarrow \mathrm{CO}+\mathrm{H}_{2} \mathrm{O}
\end{aligned}
$$

The kinetic model is described with Langmuir-Hinshelwood kinetics and it can be found in [18]. The model was directly implemented in Aspen Plus and pressure drop was calculated $d$ by the Ergun equation, already nested in the simulator. For a pellet density of $1,775 \mathrm{~kg} / \mathrm{m}^{3}$ and a void fraction of 0.5 the volume of the 
reactor is approximately $50 \mathrm{~m}^{3}$. It was observed that steady state can be reached at lower volumes meaning that less amount of catalyst can result in same methanol productivities, i.e. 35 tonnes. The gases leave the reactor at a temperature of $288^{\circ} \mathrm{C}$ and subsequently is divided into two streams: the first $(60 \%$ of initial stream) is used to heat the fresh feed, while the second is used in the reboiler and also to heat the feed of the distillation column. The two streams are re-mixed and cooled to $35^{\circ} \mathrm{C}$. Water and methanol, after being condensed, are separated from the non-reacted gases in a knock-out drum. Some of the non-reacted gases (1.3\%) are purged to minimise the accumulation of inerts and by-products in the reaction loop. The crude methanol that leaves the reactor is a mixture of methanol, water and residual gases (i.e., $\mathrm{H}_{2}$ and $\mathrm{CO}$ and $\mathrm{CO}_{2}$ ). To remove the non-reacted gases, the stream is expanded to 1 bar using valves, and then separated in a flash tank. The remaining liquid is heated to $75^{\circ} \mathrm{C}$ and fed into the distillation column. The bottom product of the distillation column corresponds to water while the top product is mostly methanol with some unreacted gases. The column was simulated with the rigorous model RadFrac. A rate-based calculation of the column is carried out, using the mass and heat transfer model from Billet and Schultes. The column has 50 stages and the reflux ratio is equal to 1.2. However, the column can be intensified by reducing the reflux ratio to 1; reboiler's heating duty is reduced to $16.5 \mathrm{MW}$ from $19.5 \mathrm{MW}$ while methanol recovery and purity remain unchanged. Methanol is then compressed to 1.2 bar and cooled to $40^{\circ} \mathrm{C}$ proceeding to another flash that separates the gases (top outlet) from the methanol product with $99 \% \mathrm{w} / \mathrm{w}$ in the bottom stream.

Table 5 provides the simulated requirements of the $\mathrm{CO}_{2}$ capture, electrolysis and methanol production units and Figure 6 provides a process flow diagram of the methanol plant including the electrolysis unit.

\section{-9.5 Utilities}

The streams containing unreacted gases were collected and sent to a gas turbine unit to generate electricity. The gas stream is then compressed up to 6 bar and enters a gas turbine where it is burned with excess of pressurised air (15\%) to produce electricity at a temperature of $1200^{\circ} \mathrm{C}$. The required air is specified by a FORTRAN calculator according to the flows of carbon monoxide and hydrogen. The exhaust gas from the gas turbine is recovered from a heat recovery steam generation (HRSG) system, composed of three heat exchangers (namely economizer, evaporator and superheater) where superheated steam $\left(550^{\circ} \mathrm{C}, 100 \mathrm{bar}\right)$ is produced. According to the present design, the economiser is placed before HE1 to extract heat from the pressurised $\mathrm{CO}_{2}$. This way more steam can be produced as the exhaust gas provides heat only to the evaporator and the superheater. A series of high, intermediate and low-pressure steam turbines are employed to generate electricity. Part of high pressure steam is utilised to provide heat to the deaerator. The combined Rankine-Brayton cycle generates $4 \mathrm{MW}$ of electricity. Furthermore, based on the design of Van-Dal and Bouallou [18], hot water at a temperature of $85^{\circ} \mathrm{C}$ that is raised from HE1, HE2, HE3, HE4 and HE6 is mixed with the bottom stream of the distillation column and enters an Organic Rankine Cycle (ORC) unit. The working fluid is the R245fa and electricity of $1 \mathrm{MW}$ is generated. Finally, it should be noted that the wastewater unit and the cooling system were not simulated but considered in the economic evaluation. 


\begin{tabular}{|c|c|c|}
\hline Parameter & Value & Unit \\
\hline \multicolumn{3}{|l|}{$\mathrm{CO}_{2}$ Capture } \\
\hline Flue gas & 224.27 & $t / h$ \\
\hline $\mathrm{CO}_{2}$ input & 71.39 & $\mathrm{t} / \mathrm{h}$ \\
\hline $\mathrm{CO}_{2}$ capture & 86.979 & $\%$ \\
\hline $\mathrm{CO}_{2}$ output & 62.09 & $t / h$ \\
\hline Electricity consumption & 16.86 & MW \\
\hline Electricity generation & 7.89 & MW \\
\hline Net electricity demand & 8.97 & MW \\
\hline Cooling duty & 16.1 & MW \\
\hline Cooling water (circulated) & 1421 & $t / h$ \\
\hline Cooling water (make up) & 71.05 & $t / h$ \\
\hline Waste water & 9 & $t / h$ \\
\hline \multicolumn{3}{|l|}{ Electrolysis } \\
\hline Deionised water & 80.85 & $t / h$ \\
\hline Oxygen & 68.2 & $t / h$ \\
\hline $\mathrm{H}_{2}$ & 8.594 & $t / h$ \\
\hline Electricity for electrolysis & 450.12 & MW \\
\hline Cooling duties & 2.81 & MW \\
\hline Cooling water (circulated) & 248 & $t / h$ \\
\hline Cooling water (make up) & 12 & $t / h$ \\
\hline Waste water & 4 & $\mathrm{t} / \mathrm{h}$ \\
\hline \multicolumn{3}{|l|}{ Methanol synthesis } \\
\hline $\mathrm{CO}_{2}$ input & 62.09 & $\mathrm{t} / \mathrm{h}$ \\
\hline $\mathrm{CO}_{2}$ output & 3.32 & $t / h$ \\
\hline MeOH output & 42.78 & $t / h$ \\
\hline Cooling duties & 43.13 & MW \\
\hline Heating duties (fully integrated) & 31.3 & MW \\
\hline Electricity consumption & 9.73 & MW \\
\hline Electricity generation & 5 & MW \\
\hline Net electricity demand & 4.73 & MW \\
\hline Cooling water (circulated) & 3806 & $t / h$ \\
\hline Cooling water (make up) & 190.3 & $\mathrm{t} / \mathrm{h}$ \\
\hline Boiler water (circulated) & 6.4 & $t / h$ \\
\hline Boiler water (make up) & 1.6 & $t / h$ \\
\hline Air & 20 & $t / h$ \\
\hline Catalyst & 35 & $t / y$ \\
\hline Waste water & 24 & $\mathrm{t} / \mathrm{h}$ \\
\hline
\end{tabular}

Table 5. Simulation results for the $\mathrm{CO}_{2}$ capture, PEM and methanol units. 


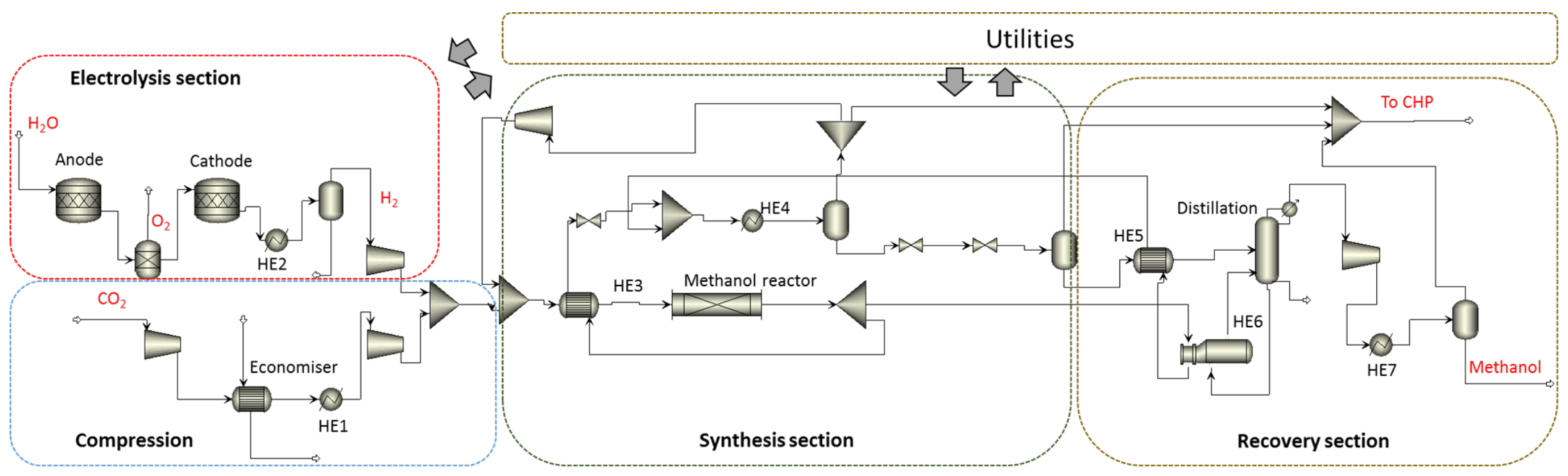

Figure 6. Methanol plant process flow diagram, showing the PEM electrolysis unit, conditioning of the resultant $\mathrm{H}_{2}$ and captured $\mathrm{CO}_{2}$ to the required temperature and pressure $\left(78\right.$ bar, $\left.210^{\circ} \mathrm{C}\right)$ prior to entry into the synthesis reactor. The $\mathrm{CO}_{2}$ is compressed by two compressors with intermediate cooling prior to injection into the fixed bed adiabatic reactor containing $\mathrm{Cu} / \mathrm{ZnO} / \mathrm{Al}_{2} \mathrm{O}_{3}$ catalyst. The methanol containing gas leaving the reactor is used to heat the fresh feed and the feed to the distillation column. Methanol and unreacted gases are condensed and separated in a knock-out drum. Unreacted gases are separated by expanded to 1 bar using valves then separated in a flash tank before the liquid methanol is fed into the distillation column. The top product is mostly methanol while the bottom product is mostly water. The methanol is compressed and cooled to $40^{\circ} \mathrm{C}$ before proceeding to another flash tank to separate gases from methanol. 


\section{-9.6 Inventory data sets for the main process inputs}

In accordance with the functional unit, all inputs/outputs have been scaled to a final production of $1 \mathrm{t}$ methanol and $1.96 \mathrm{t}$ cement as final products. Table 6 provides the input/output data for the CCU methanol production route whilst Table 7 provides data for the conventional SMR from natural gas. Additionally, Figure 7 presents the input/output data for the CCU methanol process in the form of a block diagram. The catalyst composition is taken to be $\mathrm{CuO} 60.1 \%, \mathrm{ZnO} 28.3 \%$ and $\mathrm{Al}_{2} \mathrm{O}_{3} 11.3 \%$ [24].

It was assumed that the $\mathrm{CO}_{2}$ was transported by road freight a distance of $50 \mathrm{Km}$, giving the figure of 72.5 tKm per tonne methanol produced (i.e. $1.45 \mathrm{t} \mathrm{CO}_{2} \times 50 \mathrm{Km}=72.5 \mathrm{tKm}$ ).

\begin{tabular}{|c|c|}
\hline Input flows & Amount \\
\hline \multicolumn{2}{|l|}{$\mathrm{CO}_{2}$ capture } \\
\hline Electricity (MWh) & 0.209 \\
\hline Tap water $(\mathrm{t})$ & 1.66 \\
\hline Wastewater treatment $(\mathrm{t})$ & 0.21 \\
\hline \multicolumn{2}{|l|}{ Hydrogen production } \\
\hline Deionised water $(\mathrm{t})$ & 1.89 \\
\hline Electricity (MWh) & 10.52 \\
\hline Wastewater treatment $\left(\mathrm{m}^{3}\right)$ & 0.1 \\
\hline \multicolumn{2}{|l|}{ Transport of $\mathrm{CO}_{2}$ to industrial plant } \\
\hline $\mathrm{CO}_{2}$ feedstock $(\mathrm{t})$ & 1.45 \\
\hline Assumed $\mathrm{CO}_{2}$ feedstock transport (tkm) & 72.5 \\
\hline \multicolumn{2}{|l|}{ MeOH synthesis } \\
\hline Tap water $(\mathrm{t})$ & 4.49 \\
\hline Electricity from grid mix/renewables (MWh) & 0.111 \\
\hline Chemical plant (pcs) & $9.8 \times 10^{-8}$ \\
\hline Wastewater treatment $\left(\mathrm{m}^{3}\right)$ & 0.56 \\
\hline Aluminum oxide $(\mathrm{kg})$ & 0.012 \\
\hline Copper oxide (kg) & 0.062 \\
\hline Zinc oxide $(\mathrm{kg})$ & 0.029 \\
\hline Output flows & Amount \\
\hline \multicolumn{2}{|l|}{$\mathrm{CO}_{2}$ capture } \\
\hline $\mathrm{CO}_{2}$ feedstock $(\mathrm{t})$ & 1.45 \\
\hline $\mathrm{CO}_{2}$ direct emissions $(\mathrm{t})$ & 0.22 \\
\hline \multicolumn{2}{|l|}{$\mathrm{H}_{2}$ production } \\
\hline $\mathrm{H}_{2}$ feedstock $(\mathrm{t})$ & 0.20 \\
\hline \multicolumn{2}{|l|}{ Methanol synthesis } \\
\hline Methanol (t) & 1 \\
\hline $\mathrm{CO}_{2}$ direct emissions $(\mathrm{t})$ & 0.078 \\
\hline
\end{tabular}

Table 6. Inputs/output data for $\mathrm{CO}_{2}$-based methanol production system, based on $1 \mathrm{t}$ methanol. 
$0.22 \mathrm{t} \mathrm{CO}_{2}$ not

captured

Emissions

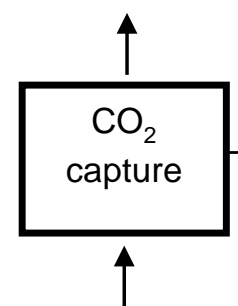

$\mathrm{CO}_{2}$ capture $\mathrm{LCl}$

$0.209 \mathrm{MWh}$ electricity

$1.66 \mathrm{t}$ water

$0.468 \mathrm{t}$ wastewater treatment

$0.210 \mathrm{t} \mathrm{CO}_{2}$

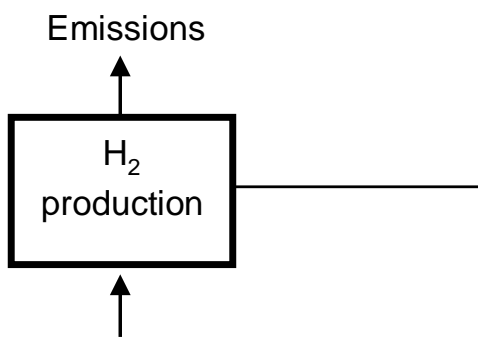

\section{Hydrogen production $\mathrm{LCl}$}

1. $1.89 \mathrm{t}$ deionised water

2. $\quad 10.52 \mathrm{MWh}$ electricity

3. $0.1 \mathrm{~m}^{3}$ wastewater treatment

$0.2 \mathrm{t} \mathrm{H}_{2}$

feedstock

Emissions

Road freight $\mathrm{LCl}$

$72.5 \mathrm{tkm}$

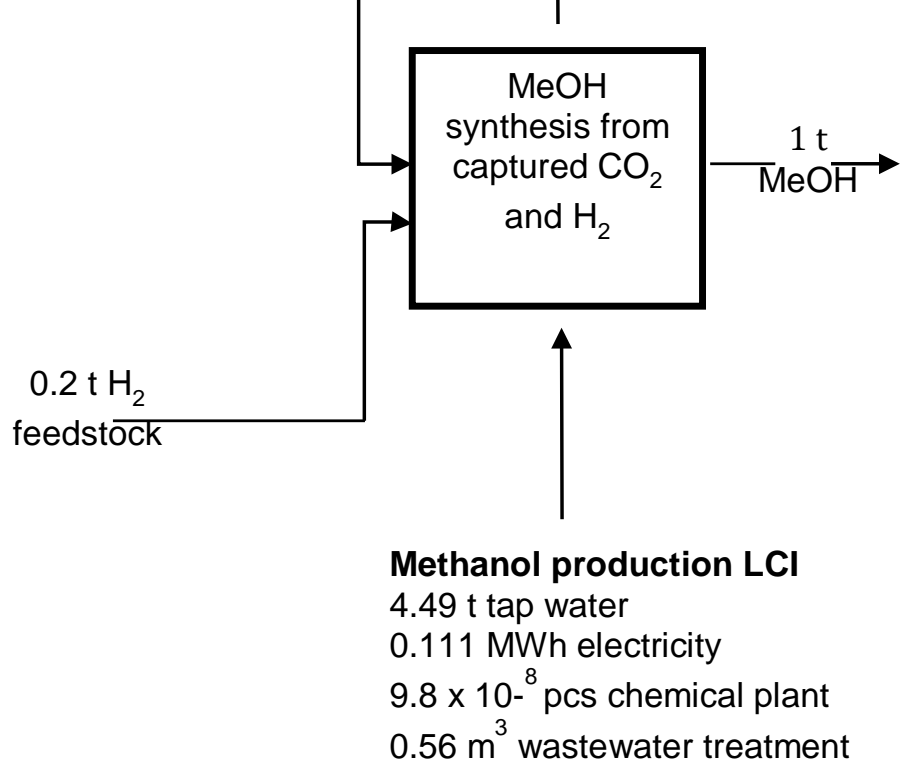

Figure 7. Block diagram of inputs and outputs for the $\mathrm{CO}_{2}$-based methanol production system. 


\begin{tabular}{|c|c|}
\hline Input flows & Amount \\
\hline Zinc $(\mathrm{kg})$ & 0.03 \\
\hline Natural gas $\left(\mathrm{m}^{3}\right)$ & 0.652 \\
\hline Electricity from grid mix/renewables (MWh) & 0.07 \\
\hline Methanol factory (pcs) & $3.7 \times 10^{-8}$ \\
\hline Copper oxide $(\mathrm{kg})$ & 0.1 \\
\hline Aluminium oxide $(\mathrm{kg})$ & 0.2 \\
\hline Heat, district or industrial natural gas (MJ) & 6930 \\
\hline Molybdenum (kg) & 0.01 \\
\hline Nickel (kg) & 0.02 \\
\hline Deionised water (kg) & 850 \\
\hline Output flows & Amount \\
\hline Methanol (t) & 1 \\
\hline
\end{tabular}

Table 7. The input and output flows used by ecoinvent $v 3.4$ for conventional methanol production from natural gas. 
Authors Part D:

Peter W Sanderson, Stavros

Michailos, Ana Villa_Zaragoza, Katy Armstrong, Peter Styring

Reviewed by:
Leonard Müller, Marvin Bachmann, André Sternberg, André Bardow, Arno Zimmermann, Johannes Wunderlich

\section{Integration Worked Example}




\section{Content}

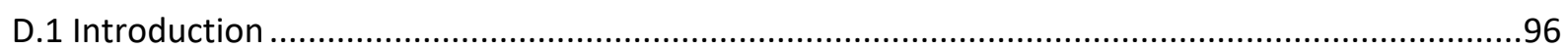

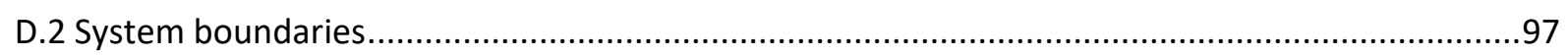

D.2.1 Options for dealing with the multi-functionality of the system ..........................................97

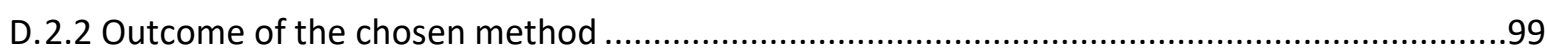

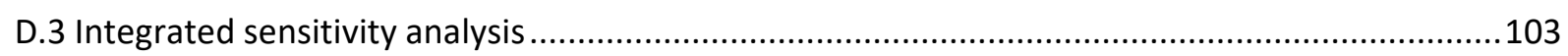

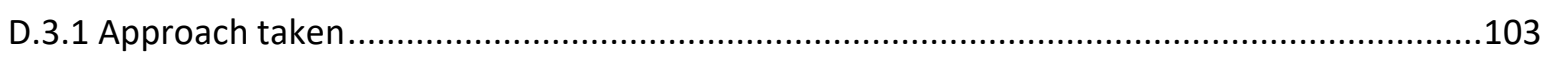

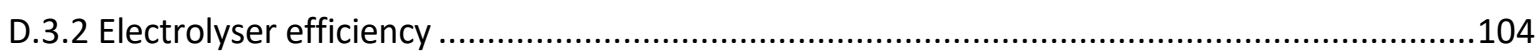

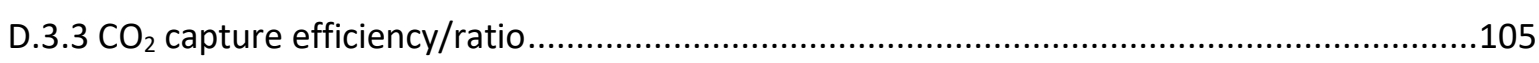

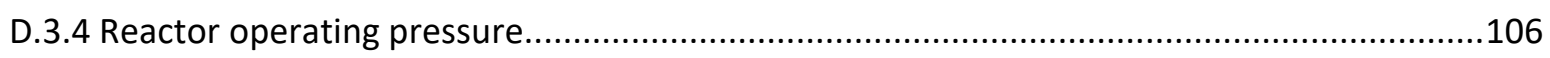

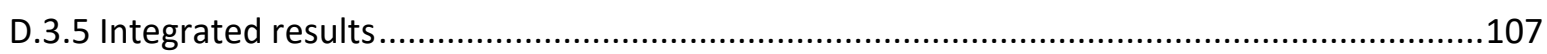

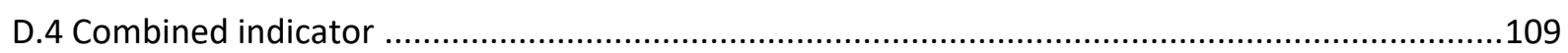

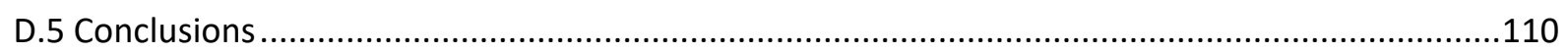




\section{D.1 Introduction}

This section provides the combined results of the techno-economic assessment (TEA) and life cycle assessment (LCA) for the investigated sensitivity analysis of the CCU methanol process. The selected indicators are the minimal methanol selling price (MMSP) $(€ / \mathrm{t} \mathrm{MeOH})$ and the climate change impact ( $\mathrm{kg} \mathrm{CO}_{2} / \mathrm{t} \mathrm{MeOH)} \mathrm{for} \mathrm{the} \mathrm{TEA} \mathrm{and} \mathrm{LCA} \mathrm{respectively.} \mathrm{The} \mathrm{goal} \mathrm{is} \mathrm{to} \mathrm{provide} \mathrm{a} \mathrm{holistic} \mathrm{approach} \mathrm{and} \mathrm{deliver}$ combined economic and environmental results. The presented methodology demonstrates the technical variables with the highest overall impact from both an economic and environmental perspective. 


\section{D.2 System boundaries}

\section{D.2.1 Options for dealing with the multi-functionality of the system}

In the LCA worked example provided in Part $\mathbf{C}$ of this document, the multi-functionality of the system was solved by using system expansion. One feature of using system expansion with a multi-functional system is that it results in the functional unit with multiple functions (i.e. products). In the life cycle impact assessment described in Part B of this document, the functional unit was $1 \mathrm{t}$ methanol and $1.96 \mathrm{t}$ cement.

For a stand-alone LCA report, such a functional unit does not present a problem as LCA is commonly used in systems with multiple products. However, if the LCA study is to be integrated with a techno-economic assessment (TEA), problems can arise. TEA does not commonly use system expansion to include upstream processes, because the focus of TEA is the cost or market prices of the raw materials and products at the factory gates. If system expansion was used for TEA, it would necessitate the modelling of the processes which produce the $\mathrm{CO}_{2}$ supply, requiring a significant increase in time and effort and access to data from another industrial plant which may not be available. To ease the integration of LCA and TEA, a method of achieving a functional unit with a single product is required. The following section describes the two options available for achieving this in accordance with the LCA Guidelines.

In the LCA worked example provided as Part C of this document, system expansion was used solve the multi-functionality of the system. However, whilst this approach is preferable for an LCA analysis, it results in a functional unit with two functions or products: $1 \mathrm{t}$ methanol plus $1.96 \mathrm{t}$ cement. Having cement in addition to methanol within the functional unit potentially makes the TEA challenging, so to enable a more straightforward integration of aspects of the LCA and TEA to be conducted, a second LCA analysis needed to be performed with cement excluded from the functional unit. This then allows the same functional unit to be used for the techno-economic analysis as for the environmental impact analysis. Two approaches to solving multi-functionality are discussed.

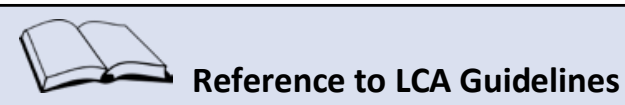

Section C.4.3.2 Solving multi-functionality describes a hierarchy of approaches. According to this hierarchy, after system expansion, the next option is to try system expansion with substitution.

System expansion via substitution follows the same process for system expansion as described in Part B of this report, however when using this approach credit is given for the substitution of cement production without carbon capture as this enables the avoidance of the burdens caused by those $\mathrm{CO}_{2}$ emissions. In practice, this means subtracting (or substituting) the impacts caused by the conventional cement 
production from the system expansion model. The diagram in Figure 1 below shows a conceptual plan of how the impacts of a conventional cement plant are subtracted from the system expansion model. The system boundary of the resulting model includes only the methanol plant, meaning that the only product within the functional unit is methanol.

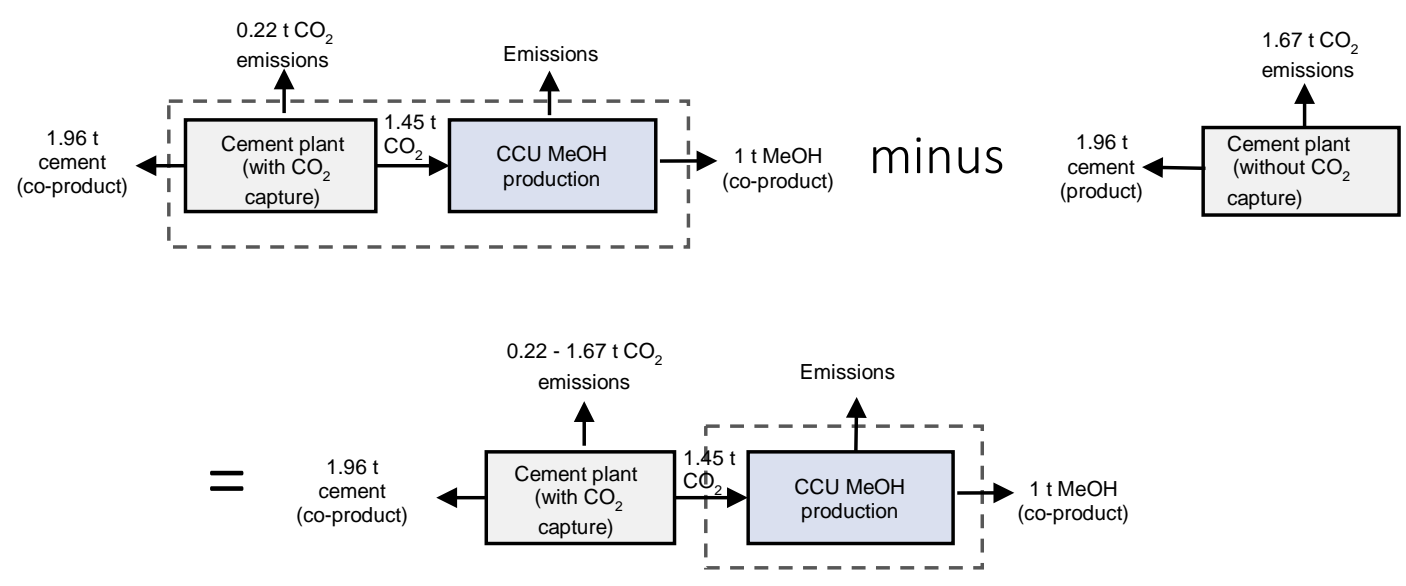

Figure 1. Representation of system expansion with substitution, whereby the impacts of a conventional cement plant are subtracted from the impacts of the system expansion model of a CCU methanol plant (including a cement plant with $\mathrm{CO}_{2}$ capture), to give the impacts arising from the $\mathrm{CCU}$ methanol plant alone. The dotted lines indicate the system boundary.

By performing this subtraction, the impacts of cement production are effectively removed from the system boundary and therefore cement is removed from the functional unit. However, one outcome of the substitution of conventional cement production without carbon capture, with cement production with carbon capture is that once the life-cycle impact assessment (LCIA) is run the methanol process may appear to have a negative $\mathrm{CO}_{2}$ emission. This occurs when the $\mathrm{CO}_{2}$ emissions avoided by using carbon capture are greater than the $\mathrm{CO}_{2}$ emitted by the methanol production process. We know from the LCA worked example in Part $\mathbf{C}$ of this document that such an outcome is highly likely. Such a "negative emission" requires clear interpretation to avoid misleading the reader.

\section{Reference to LCA Guidelines}

According to the hierarchy of approaches provided in Section C.4.3.2 Solving multi-functionality, the next approach to solving the multi-functionality following system expansion via substitution is allocation. Here the impacts of the $\mathrm{CO}_{2}$ source (cement production in this case) are distributed between the $\mathrm{CCU}$ product (methanol) and the $\mathrm{CO}_{2}$ production according to an underlying physical relationship or simply the mass, energy content or economic value of the products produced. In this way, the system can be viewed as being mono-functional, producing just one product. 
An alternative approach to system expansion with substitution is allocation whereby the environmental impacts of the system are distributed amongst the functions. In practice, in this case this means allocating the impacts associated with the $\mathrm{CO}_{2}$ production to the cement plant rather than to the methanol plant. By creating a model containing the $\mathrm{CO}_{2}$ capture unit, the electrolysis unit and the methanol plant within the system boundary, but the cement plant is outside the boundary, we have essentially done just that. The results obtained by this technique are the same as those achieved by system expansion via substitution, but the conceptual process of how to get there is different, as representation by the diagram of the model as shown in Figure 2 below.

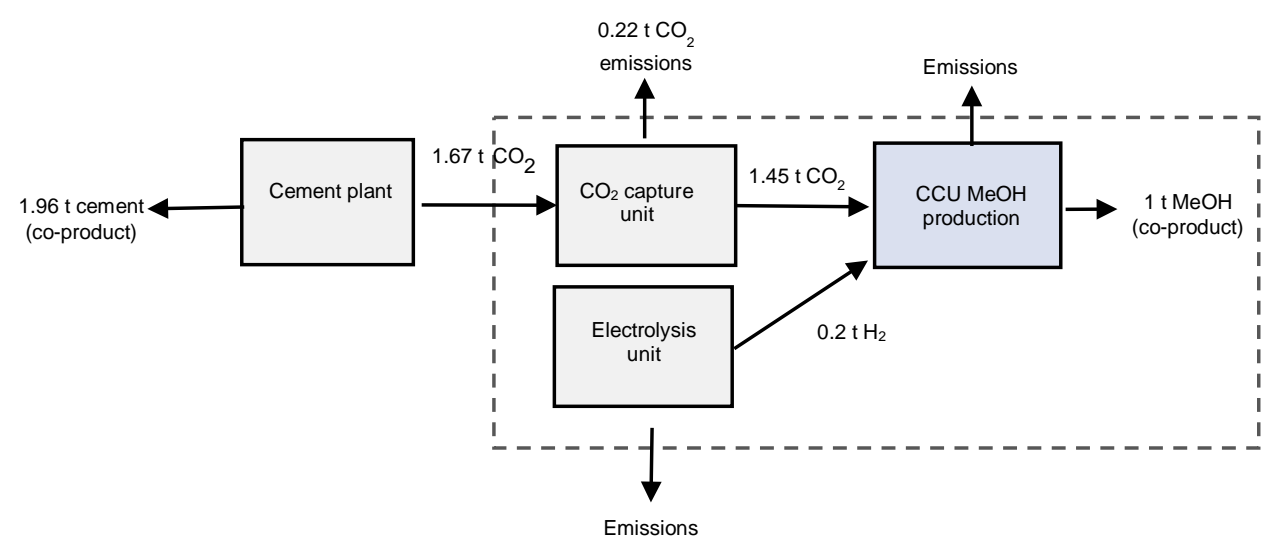

Figure 2. Representation of the system boundary (dotted line) when the impacts of producing the $\mathrm{CO}_{2}$ from a cement plant are excluded from the system consisting of the $\mathrm{CO}_{2}$ capture unit, the electrolysis unit and the $\mathrm{CO}_{2}$ derived methanol plant.

By changing the system boundary in this way to include the $\mathrm{CO}_{2}$ capture unit but not the source of the $\mathrm{CO}_{2}$, this approach effectively allocates all the burdens of the $\mathrm{CO}_{2}$ production to the cement plant and none to the methanol plant. It simply assumes that the $\mathrm{CO}_{2}$ produced by the cement plant is a waste product which is an environmental burden "belonging" to the cement plant.

\section{D.2.2 Outcome of the chosen method}

System expansion via substitution was conducted using the data obtained by modelling the CCU methanol plant in Germany used in the LCA worked example (Part $C$ of this document). The results of this approach are presented below in Table 1 overleaf.

The table allows comparison of the results obtained from system expansion (the preferred method of determining the life cycle impacts of CCU processes), with those results obtained from system expansion with substitution (which may be used to ease LCA integration with TEA). It can be seen that all impact categories show a reduction in impacts when the substitution method is used, but the climate change impacts show the most significant reduction and the substitution method gives a negative value.

When interpreting the results, it is important to remember that when using system expansion, the impact values reflect the impacts of both the methanol plant and the cement plant whilst only those from the 
methanol plant are reflected when using system expansion with substitution. In addition, the latter technique assumes that the $\mathrm{CO}_{2}$ emissions avoided at the cement plant by utilizing $\mathrm{CO}_{2}$ capture are allocated solely to the methanol plant. In such a scenario, the cement plant cannot also claim to be producing low-carbon cement without "double-counting" any emissions reductions.

The negative climate impact value for the CCU methanol plant obtained by using the substitution approach is due to the technique effectively comparing between the process with and without carbon capture. The negative value obtained shows that the CCU process has a lower impact than the conventional process, but it does not mean that the CCU process is carbon negative (or even carbonneutral). Rather, the value obtained is negative due to subtracting the avoided $\mathrm{CO}_{2}$ emissions from the lower emissions resulting from the CCU plant itself. This needs to be made clear to avoid misunderstandings by policy-makers or other readers of the LCA report.

\begin{tabular}{|c|c|c|c|}
\hline \multirow[b]{2}{*}{$\begin{array}{l}\text { Impact categories } \\
\text { (ILCD/PEF recommendation v1.09) }\end{array}$} & \multicolumn{3}{|c|}{ Impact value } \\
\hline & $\begin{array}{l}\text { System } \\
\text { expansion } \\
\text { (SE) }\end{array}$ & $\begin{array}{c}\text { Cement } \\
\text { plant } \\
\text { (without } \\
\text { capture) }\end{array}$ & $\begin{array}{l}\text { SE with } \\
\text { substitution }\end{array}$ \\
\hline Acidification midpoint (v1.09) [Mole of $\mathrm{H}+$ eq.] & 7.9 & 3.9 & 4.0 \\
\hline Climate change midpoint, excl biogenic carbon (v1.09) [kg CO2 eq.] & 700 & 1698 & -998 \\
\hline Climate change midpoint, incl biogenic carbon (v1.09) [kg CO2 eq.] & 725 & 1724 & -999 \\
\hline Ecotoxicity freshwater midpoint (v1.09) [CTUe] & 205606 & 2178 & 203428 \\
\hline Eutrophication freshwater midpoint (v1.09) [kg P eq.] & 0.76 & 0.15 & 0.61 \\
\hline Eutrophication marine midpoint (v1.09) [kg N eq.] & 1.59 & 1.01 & 0.58 \\
\hline Eutrophication terrestrial midpoint (v1.09) [Mole of $\mathrm{N}$ eq.] & 17.1 & 11.8 & 5.3 \\
\hline Human toxicity midpoint, cancer effects (v1.09) [CTUh] & 0.0002 & 0.00002 & $1.8 \mathrm{E}-04$ \\
\hline Human toxicity midpoint, non-cancer effects (v1.09) [CTUh] & 0.001 & 0.00013 & $8.7 \mathrm{E}-04$ \\
\hline Ionizing radiation midpoint, human health (v1.09) [kBq U235 eq.] & 81.9 & 58.1 & 23.8 \\
\hline Land use midpoint (v1.09) [kg C deficit eq.] & 2293 & 717 & 1576 \\
\hline Ozone depletion midpoint (v1.09) [kg CFC-11 eq.] & 0.00008 & $4.76 \mathrm{E}-05$ & $3.24 \mathrm{E}-05$ \\
\hline Particulate matter/Respiratory inorganics midpoint (v1.09) [kg PM2.5 eq.] & 0.83 & 0.28 & 0.55 \\
\hline $\begin{array}{l}\text { Photochemical ozone formation midpoint, human health (v1.09) [kg NMVOC } \\
\text { eq.] }\end{array}$ & 4.7 & 2.89 & 1.81 \\
\hline Resource depletion water, midpoint (v1.09) [ $\mathrm{m}^{3}$ eq.] & 8.4 & 4.2 & 4.2 \\
\hline $\begin{array}{l}\text { Resource depletion, mineral, fossils and renewables, midpoint (v1.09) [kg Sb } \\
\text { eq.] }\end{array}$ & 0.09 & 0.010 & 0.08 \\
\hline
\end{tabular}


Table 1. Results of the LCIA of the CCU methanol plant sited in Germany, presented following system expansion with substitution. Impacts are presented per t methanol.

The LCIA conducted using Gabi and ecoinvent as part of the LCA worked example presented in Part C determined the climate change impact category, excluding biogenic carbon (which is measured in $\mathrm{CO}_{2}$ equivalent and includes $\mathrm{CO}_{2}$ plus other greenhouse gases such as methane and nitrous oxide) to be $700 \mathrm{Kg} \mathrm{CO}_{2}$ eq. for the system expansion model. The data for all impact categories is presented again in Table 1 above so that it can be used for the system expansion via substitution calculation.

The same table also provides the LCIA results for a conventional cement plant sited in Germany. It can be seen that it emits $1698 \mathrm{Kg} \mathrm{CO}_{2}$ eq. per $1959 \mathrm{Kg}$ cement produced (i.e. the amount of cement manufactured, which produces the quantity of $\mathrm{CO}_{2}$ required to produce $1 \mathrm{t}$ methanol via CCU).

To obtain the results for system expansion via substitution, the LCIA results obtained from the conventional cement plant are subtracted from the LCIA results obtained when using system expansion. If we focus upon the climate change (excl. biogenic carbon) impact category as an example: $700-1698=-998 \mathrm{Kg} \mathrm{CO} 2 \mathrm{eq} . / \mathrm{t} \mathrm{MeOH}$.

An advantage of removing cement from the functional unit (in addition to enabling a more straightforward integration with TEA) is that the problem encountered with comparing $\mathrm{CO}_{2}-$ generating processes located in different countries as described in Section C.7.1 Sensitivity analysis of the LCA worked example is also avoided. Any additional $\mathrm{CO}_{2}$ emitted by the cement plant (or whatever $\mathrm{CO}_{2}$ source is used) due to differences in efficiency in different countries does not alter the results of the methanol plant results.

The drawback of this approach is that it effectively allocates all of the $\mathrm{CO}_{2}$ emission savings obtained due to using carbon capture to the methanol plant and none to the cement plant. In this way, a negative greenhouse gas emission value is obtained for the methanol plant, but the cement plant in such a scenario has to be considered to emit the same emissions as a conventional cement plant, despite the fact that a $\mathrm{CO}_{2}$ capture is being used. The negative value attributed to the methanol plant actually reflects the difference compared to the conventional system rather than reflecting a truly carbon negative methanol process. This needs to be made very clear in the conclusions drawn from the analysis to avoid misinterpretation by both the report author and the reader.

In summary, to allow an integrated analysis, the same functional unit needs to be used for the environmental analysis and the economic analysis. When conducting LCA of CCU processes, the widely accepted approach is to use system expansion to solve the multi-functionality associated with utilising $\mathrm{CO}_{2}$ arising from one process to supply a separate CCU process. However, TEA does not commonly use system 
expansion to include upstream processes as TEA tends to focus upon the cost or market prices of the raw materials and product at the factory gates. If system expansion was used for TEA, it would require modelling the processes which produce the $\mathrm{CO}_{2}$. To avoid this, a method of achieving a functional unit with a single product was used - namely system expansion with substitution. 


\section{D.3 Integrated sensitivity analysis}

Contribution and sensitivity analyses conducted as part of the separate LCA and TEA studies provided in Parts $B$ and $C$ of this document revealed that electrolyser efficiency is of crucial importance and a key contributor to both the economic and environmental performance of the CCU methanol process. Additionally, it is recognized that both the $\mathrm{CO}_{2}$ capture ratio and the reactor operating pressure during methanol synthesis play a role in determining the methanol production efficiency. An integrated environmental and economic assessment of changes to the efficiency of these three processes has therefore been conducted.

The approach taken is the "alignment and combined indicators integration" as described in the Integration Chapter which is included within Part A of the associated Guidelines document.

\section{D.3.1 Approach taken}

To enable such an assessment to take place, the inventory data used for the economic and environmental analyses must be aligned and consistent and the functional units used must be the same to allow direct comparison of the two sets of results.

\section{Reference to General Assessment Principles}

Section A.5.2 Types of Study describes the different levels of TEA and LCA integration.

Section A.5.3 Alignment describes the data equivalency requirements to enable integration of TEA and LCA data and Section A.5.4 Multi-functionality and system boundaries suggests how to best align the system boundaries of the economic and environmental assessments.

In the original model, the efficiency of the PEM electrolysis unit was taken to be $70 \%$, so the effect of this dropping to $60 \%$ or rising to $85 \%$ is modelled. Likewise, the $\mathrm{CO}_{2}$ capture efficiency was taken to be $87 \%$, so the effect of this reducing slightly to $85 \%$ or rising to $92 \%$ is evaluated. An additional analysis was conducted on the impact of changing the operating pressure of the methanol synthesis reactor. The baseline pressure was 78 bar, so this was varied from 50 to 100 bar to determine the effect of this upon the climate change impacts and the MMSP. Data obtained from Aspen modelling of these scenarios is provided in Table $\mathbf{2}$. 


\begin{tabular}{|c|c|c|c|}
\hline Electrolysis Efficiency & $60 \%$ & $70 \%$ & $85 \%$ \\
\hline Electrolyser electricity use (MW) & 477.4 & 409.2 & 337.0 \\
\hline Balance of electrolysis plant (MW) & 47.7 & 40.9 & 33.7 \\
\hline Overall electricity use (MW) & 525.2 & 450.2 & 370.7 \\
\hline $\mathrm{CO}_{2}$ Capture Efficiency & $85 \%$ & $87 \%$ & $92 \%$ \\
\hline Net electricity use (MW) & 8.6 & 8.97 & 9.87 \\
\hline Cooling water (make-up) (t/h) & 66.64 & 71.05 & 76.79 \\
\hline Membrane operating pressure (bar) & 2 & 2.5 & 3 \\
\hline MeOH Synthesis Operating Pressure & 50 bar & 78 bar & 100 bar \\
\hline Electricity (MW) & 3.76 & 4.73 & 5.4 \\
\hline $\mathrm{MeOH}$ Flowrate $(\mathrm{t} / \mathrm{h})$ & 42.08 & 42.78 & 43.1 \\
\hline $\mathrm{CO}_{2}$ emissions $(\mathrm{t} / \mathrm{h})$ & 4.1 & 3.32 & 3.02 \\
\hline
\end{tabular}

Table 2. Changes in inputs resulting from changes to the modelled efficiency of the PEM electrolysis and membrane $\mathrm{CO}_{2}$ capture systems, and changes to the operating pressure of the methanol synthesis reactor.

In the following section the results of the sensitivity analyses will be presented initially with the analysis of the greenhouse gas (GHG) emissions and the cost impact upon the methanol selling price separately. The integrated results will then be presented as an example of how such data could be presented in a single graphical representation.

\section{D.3.2 Electrolyser efficiency}

The contribution analysis in Section C.6.2.2 of the LCA Worked Example revealed that even when utilizing low-carbon electricity derived from wind turbines, $\mathrm{H}_{2}$ production by electrolysis contributes $83 \%$ of the GHG emissions of the entire process due to its high electricity demand. It is therefore to be expected that modelled changes to the efficiency of the PEM electrolysis unit would have a significantly greater impact than the modelled changes to the efficiency of the $\mathrm{CO}_{2}$ capture unit.

This is indeed what is found, with Figure 3 showing that GHG emissions decrease by $5.5 \%$ (or $55 \mathrm{Kg} \mathrm{CO} 2 \mathrm{eq} / \mathrm{t}$ $\mathrm{MeOH}$ ) when the electrolyser efficiency is increased from $70 \%$ to $85 \%$. When the electrolyser efficiency is decreased from the baseline $70 \%$ to $60 \%$, the GHG emissions increase by an almost identical $5.2 \%$ (corresponding to $52 \mathrm{Kg} \mathrm{CO}_{2} \mathrm{eq} / \mathrm{t} \mathrm{MeOH}$ ). Overall, the increase in electrolyser efficiency from 60 to $85 \%$ results in a decrease in $\mathrm{GHG}$ emissions of $11.3 \%$ (or $107 \mathrm{Kg} \mathrm{CO} 2 \mathrm{eq} / \mathrm{t} \mathrm{MeOH}$ ).

Similar to the assessment of GHG emissions, the assessment of minimal methanol selling price (MMSP) for the same sensitivity analysis was carried out. Figure 4 reveals that increasing the electrolyser efficiency from $60 \%$ to $85 \%$ results in an even more significant reduction in the MMSP of $21.4 \%$. 


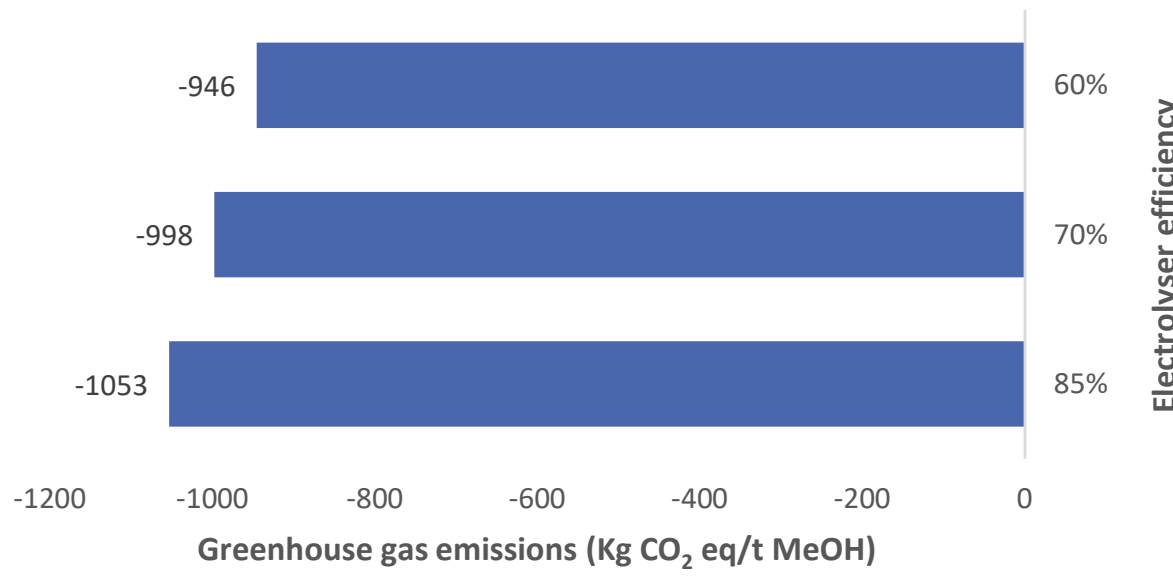

Figure 3. Effect upon the greenhouse gas emissions of the CCU methanol plant as the efficiency of the PEM electrolysis unit increases. Using system expansion with substitution.

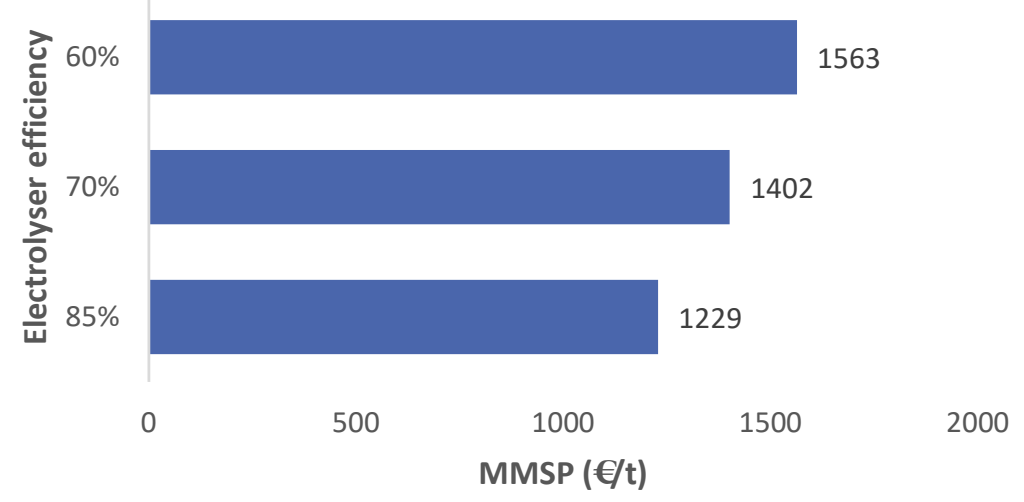

Figure 4. Effect on the MMSP of the CCU methanol plant as the efficiency of the PEM electrolysis unit is increased.

\section{D.3.3 $\mathrm{CO}_{2}$ capture efficiency/ratio}

The small changes in capture efficiency of the membrane capture technology which were modelled resulted in very small changes in the climate change impact of less than $0.5 \mathrm{Kg} \mathrm{CO} 2 \mathrm{eq} / \mathrm{t} \mathrm{MeOH}$. However, the increase in efficiency caused a small increase in GHG emissions (rather than the expected decrease) whereas a decrease in efficiency resulted in a small decrease in emissions, as shown in Figure 5 overleaf. This can be explained by the fact that when using membrane capture technology, increases in capture efficiency (or the capture ratio) are achieved by using more energy. However, it should be noted that the increases modelled are very small, reflecting the fact that only around $2 \%$ of the overall GHG emissions of the entire $\mathrm{CCU}$ methanol process are due to the $\mathrm{CO}_{2}$ capture unit.

As depicted in Figure 6, enhancing the $\mathrm{CO}_{2}$ capture efficiency by elevating the operating pressures of the membranes does not translate into economic improvements and the MMSP is increased slightly (by $0.6 \%$ ) as the efficiency increases from $85 \%$ to $92 \%$. 


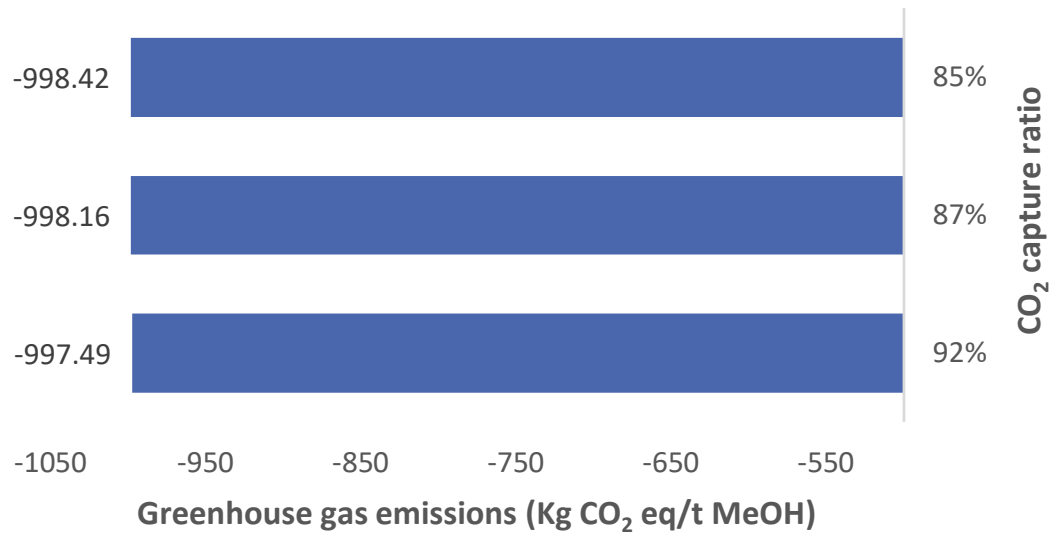

Figure 5. Effect upon the greenhouse gas emissions of a CCU methanol plant as the efficiency of the $\mathrm{CO}_{2} \mathrm{Capture}$ unit increases. Using system expansion with substitution.

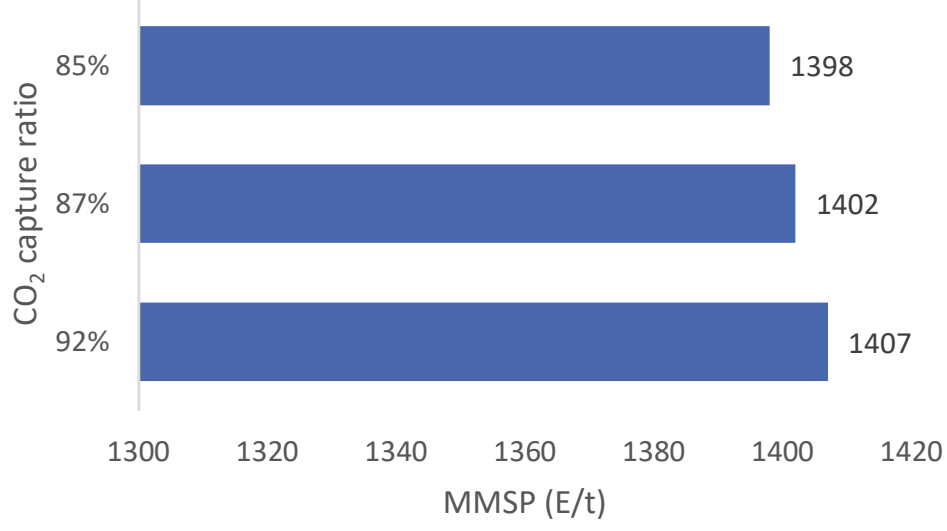

Figure 6. Effect on the MMSP of the CCU methanol plant as the efficiency of the $\mathrm{CO}_{2}$ capture unit is increased.

As with the GHG emissions, we see that the MMSP increases with increased efficiency of the electrolyser, but decreases with increased efficiency of the membrane capture unit. This reflects the decreased electricity use in the electrolyser but increased electricity use in the capture unit to achieve the higher capture efficiency. Note that only the electricity costs are changing the MMSP, potential changes to the equipment required by the changing efficiencies were not modelled.

\section{D.3.4 Reactor operating pressure}

In the third and final sensitivity analysis, the baseline operating pressure of the methanol reactor was 78 bar, so this was varied from 50 to 100 bar to determine the effect of this upon the GHG emissions and the MMSP. Whilst the increased pressure leads to higher methanol yield and so productivity, it also increases the electricity consumption of the synthesis plant. The opposite effect is observed when lower pressures are modelled. 


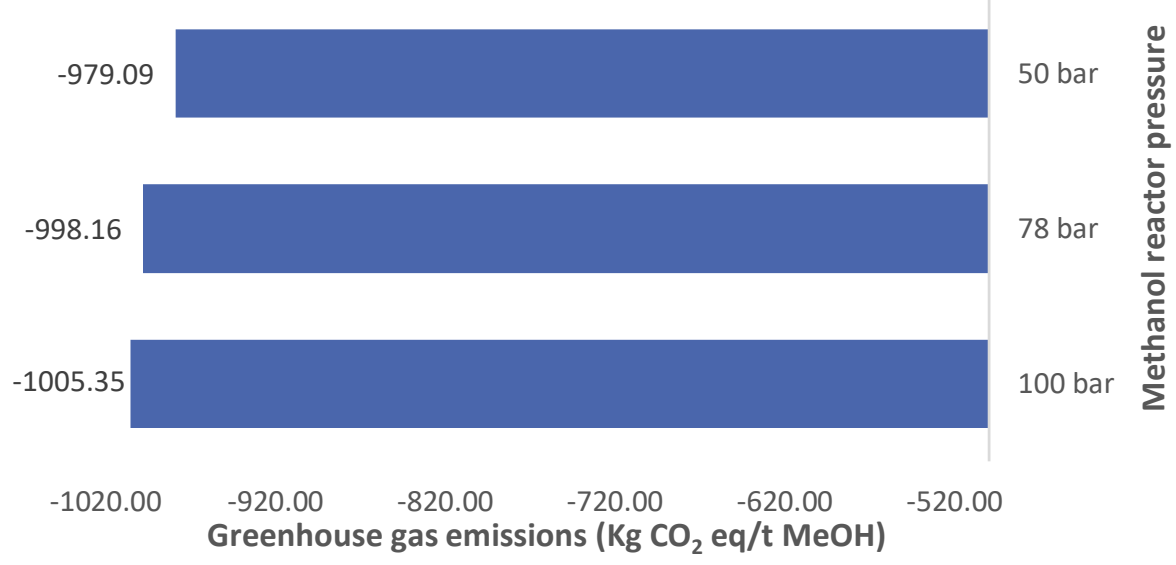

Figure 7. Effect upon the greenhouse gas emissions of a CCU methanol plant as a function of the operating pressure of the methanol reactor. Using system expansion with substitution.

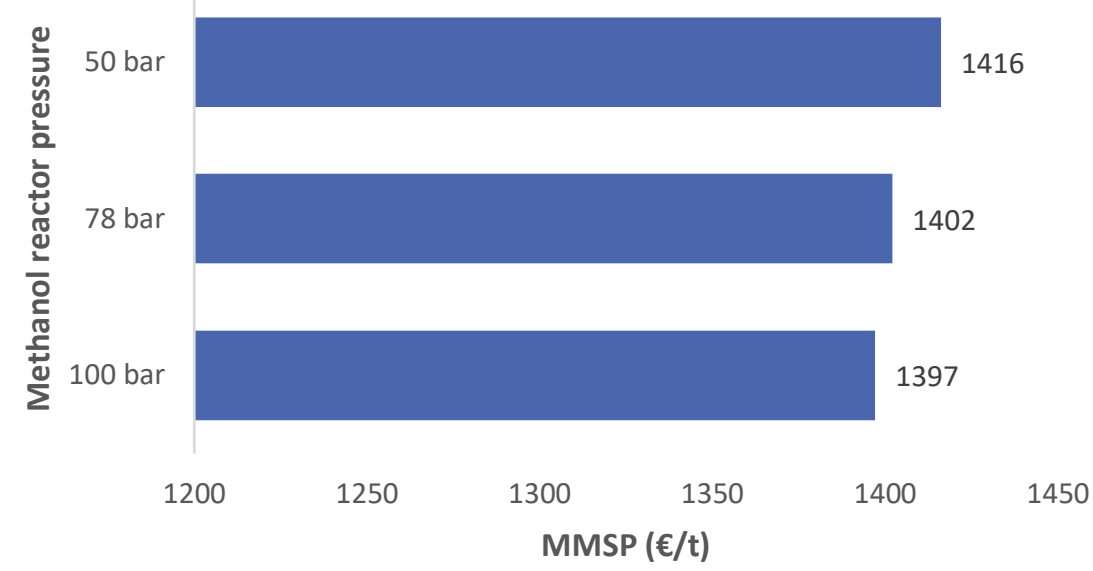

Figure 8. Effect upon the MMSP of a CCU methanol plant as a function of the operating pressure of the methanol reactor.

The data in Figures 7 and 8 reveals that the increased productivity overrides the higher electricity demand, so increasing pressures from 50 to 100 bar decreases GHG emissions by $2.6 \%$ and decreases MMSP by $1.3 \%$.

\section{D.3.5 Integrated results}

The modelled effects upon GHG emissions and economic data provided above were displayed on separate graphs, but the same data can be shown on a single graph, in the form of a nested box chart. The results combined in this way are presented in Figure 9. The benefit of this form of presentation is that it enables the scale of the sensitivity of both MMSP and GHG emissions to changes in the three variables (electrolyser efficiency, $\mathrm{CO} 2$ capture ratio and methanol reactor pressure) to be compared relative to each other. 


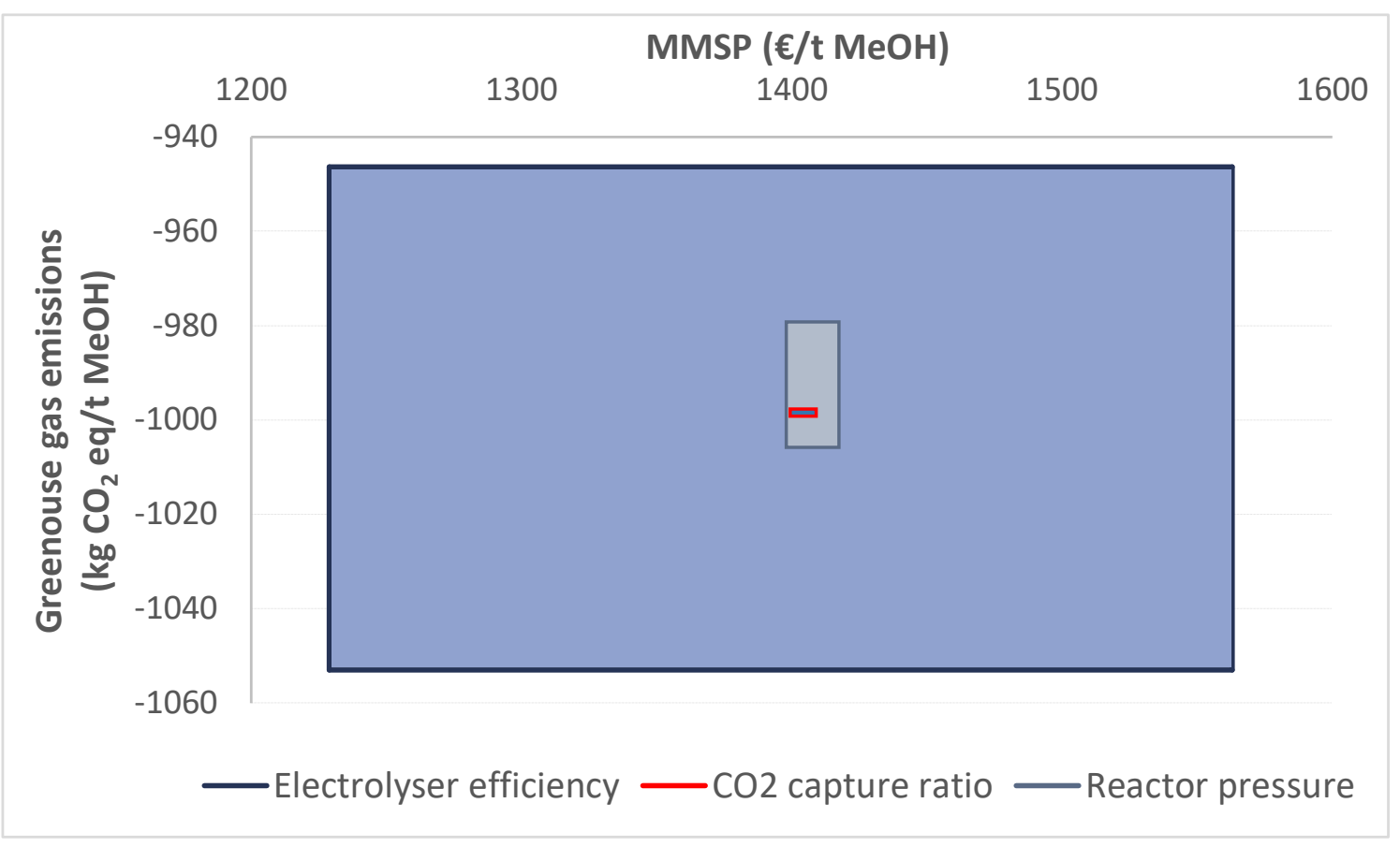

Figure 9. Combined LCA and TEA results considering the effect of the electrolyser efficiency, MeOH reactor pressure and the $\mathrm{CO}_{2}$ capture ratio

The blue box indicates the sensitivity of the CCU methanol system to the electrolyser efficiency. The range (or scale) in both axes shows that the system is far more sensitive to changes to this variable than to the other two variables - both in terms of impacts upon the economics and GHG emissions.

The yellow box indicates the more limited sensitivity of the system to changes in the methanol reactor operating pressure of the scale modelled, both in terms of MMSP and GHG emissions. In this type of presentation, the shape of the boxes (along with the scales of the axis) is significant as it allows the comparison of the relative importance of a variable to the two indicators. In this case, the results suggest that the MMSP is relatively more sensitive to changes in the electrolyser efficiency than are the GHG emissions. However, the MMSP is relatively less sensitive to changes in reactor pressure than the GHG emissions which show a larger change (as the yellow box is tall and narrow compared to the blue box). The sensitivity of the system to changes in the $\mathrm{CO}_{2}$ capture ratio (red box) can be considered negligible.

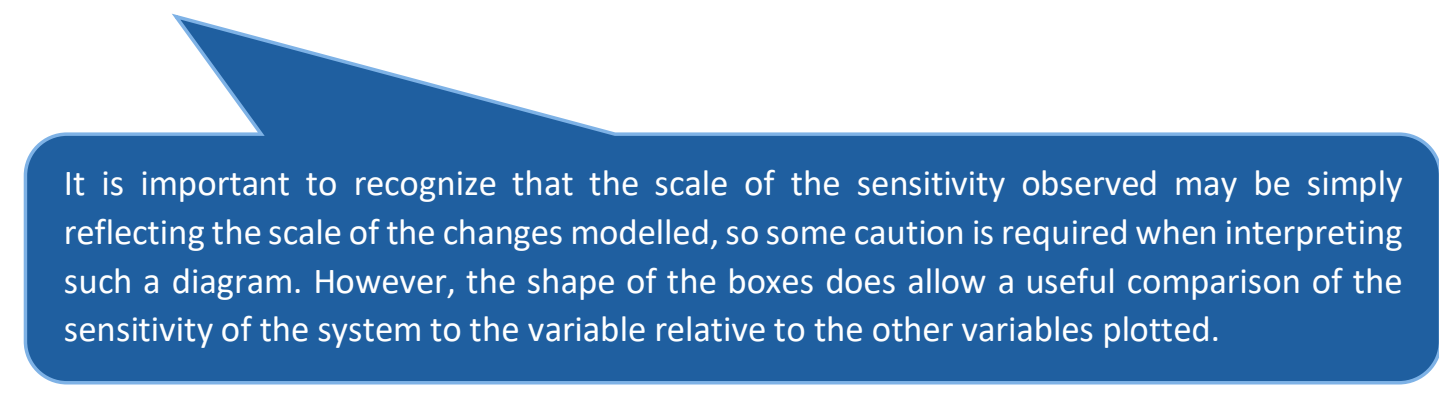




\section{D.4 Combined indicator}

\section{Reference to General Assessment Principles}

Section A.5.6 Calculating combined economic and environmental indicators provides an example of the calculation of $\mathrm{CO}_{2}$ abatement costs, as an example of a combined indicator of relevance to $\mathrm{CCU}$ processes.

A combined indicator that is used widely is the abatement cost of $\mathrm{CO}_{2}, \mathrm{C}_{\text {abated }}\left(€ / \mathrm{t} \mathrm{CO}_{2}\right.$ abated). Equation 1 shows that different technologies should be compared with each other against a reference system.

$$
c_{\text {abated }}=\frac{C_{C C U}-C_{\text {ref }}}{\text { GHG emissions } \text { ref }- \text { GHG emissions }_{C C U}}
$$

As was used in the separate LCA and TEA assessments, the reference or benchmark technology is conventional methanol production from steam methane reforming. The GHG emissions of SMR is $516.4 \mathrm{~kg}$ $\mathrm{CO}_{2}$ eq./ $\mathrm{t} \mathrm{MeOH}$ (taken from the LCA worked example Part $C$ ) and the average market price of methanol in 2016 was $248 € / \mathrm{t}$.

Usually, the abatement cost is calculated to compare different conversion systems. In our case, however, since only one technology was examined, abatement costs were calculated for different electrolyser efficiencies as previously described. As expected, the abatement cost reduces as the efficiency of the electrolyser increases, as displayed in Figure 10. An electrolyser efficiency of $85 \%$ therefore corresponds to a higher economic efficiency in respect to emission savings. For all cases, positive costs are observed, due to the difference between the prices of the conventional methanol and the $\mathrm{CO}_{2}$-derived methanol.

In this case, selling prices instead of production costs were used due to data availability. Nevertheless, the prices include the costs of producing the methanol.

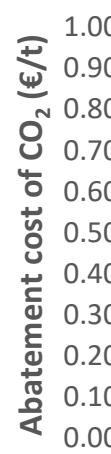

0.90

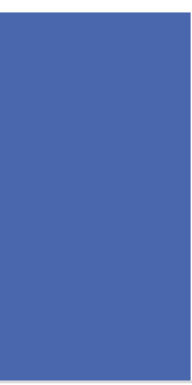

$60 \%$

0.76

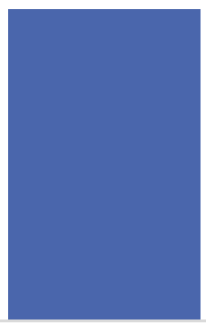

$70 \%$
0.63

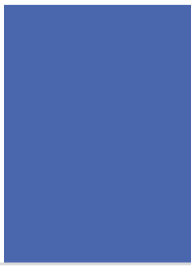

$85 \%$

Electrolyser efficiency

Figure 10. Abatement costs of $\mathrm{CO}_{2}$ for different electrolyser efficiencies 


\section{D.5 Conclusions}

In conclusion, the sensitivity analyses described here determined that increasing the efficiency of the electrolysis process and the methanol reactor operating pressure yields positive outcomes from both an environmental and an economic standpoint. However, increasing the $\mathrm{CO}_{2}$ capture ratio by increasing the operating pressure of the membranes was found to have slightly negative environmental and cost outcomes which can be attributed to the increased pressures that have to be applied in order to enhance the membrane separation efficiency. The consequent increased electricity consumption cannot be offset by the reduced CapEx and reduced emissions of $\mathrm{CO}_{2}$ due to the reduced volume of flue gas treated.

The depiction of the system sensitivity to the three variables tested using a box chart enabled the relative scale of the resulting impacts to be appreciated. Clearly, changes to the electrolyser efficiency would likely dwarf any changes to the reactor operating pressure or $\mathrm{CO}_{2}$ capture ratio, both in terms of financial impact (MMSP) and environmental impacts (GHG emissions).

This chapter does not aim to provide a template or a definitive guide to performing an integrated TEA/LCA assessment of a CCU process. Rather, it hopes to give some initial direction and signpost practitioners towards possible routes towards integration of these two forms of assessment.

The approach taken enables the comparison of the $\mathrm{CO}_{2}$ abatement costs achieved by producing $\mathrm{CO}_{2}$-derived methanol with other $\mathrm{CO}_{2}$ abatement technologies. However, the benefits of $\mathrm{CCU}$ are not solely $\mathrm{CO}_{2}$ abatement, but also the ability to move the chemicals and wider process industries away from their current reliance upon fossil-derived carbon feedstock.

As explained in the LCA worked example presented in Part $\mathbf{C}$, the examples of environmental impact provided have focused upon the climate change impact category which provides a calculation of the GHG emissions. This was done because this impact category is of direct interest (and is often a driver) to those conducting CCU processes. However, a focus upon the GHG emissions alone risks masking other environmental impacts resulting from a CCU process which would have been identified by analysis of the other environmental impact categories. For this reason, it must be emphasised that when conducting an LCA of CCU process, whether integrated with TEA or not, all impact categories need to be assessed. 
PUBLISHED BY CO2CHEM MEDIA AND PUBLISHING LTD

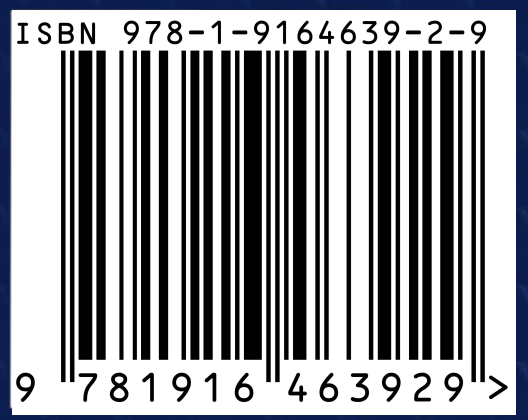

DOI: $10.3998 / 2027.42 / 145723$

http://hdl.handle.net/ 2027.42/145723

SUPPORTED BY

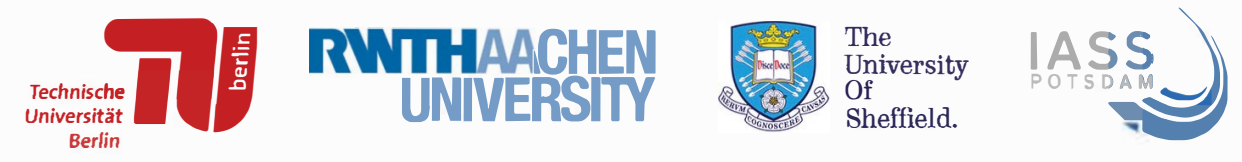

